LIAMES, Campinas, SP, v. 19, 1-71, e019012, 2019

\title{
Línguas Arawak da Bolívia
}

\author{
Henri Ramirez \\ Universidade Federal de Rondônia, Brasil \\ http://orcid.org/0000-0003-0784-3812 \\ Maria Cristina Victorino de França \\ Universidade Federal de Rondônia, Brasil \\ http://orcid.org/0000-0003-1907-1098
}

\begin{abstract}
This summary of the Bolivian subgroup (Mojeño, Baure, Pauna, Tereno) of the Arawak family is extracted from our Encyclopedia of Arawak Languages - with six new languages and two databases (in press). No branch of this family is as cohesive as the Bolivian subgroup: its lexicon, its grammar, with an unusual suprafix $A$ "non-factual", and two complex vocalic chain shifts ( $\left.*_{\mathbf{i}}>*_{\mathbf{i}}>*_{\mathbf{e}}>*_{\mathbf{a}} ; *^{*} \mathbf{a}>*_{\boldsymbol{\sigma}} / *_{\mathbf{0}}>\mathbf{i} / \mathbf{i} / \mathbf{u}\right)$ show a diagnostic unity among its languages. After detailing the historical and dialectical destruction of each of these four languages $\left(16^{\text {th }}-18^{\text {th }}\right.$ centuries), as well as their phonological and grammatical structures, we suggest a reconstruction of Proto-Bolivian and a Bolivian-Purus-Kampa-Amuesha supergroup (BPKA) among Arawak languages. This contribution ends by listing more than 500 cognate sets for the whole Bolivian subgroup.

Since Payne (1991), comparative Arawak studies in the Bolivian subgroup have been extremely chaotic and, in some ways, have regressed rather than advanced. Besides, a thorough analysis of Paikone, Magiana and Apolista leads us to some spurious word lists that force us to revise the status of these languages.
\end{abstract}

KEYWORDS: Arawak classification; Bolivian subgroup; Vocalic chain shifts; Spurious data.

RESUMO: Este artigo é um capítulo resumido e extraído de nossa Enciclopédia das Línguas Arawak - acrescida de seis novas línguas e dois bancos de dados (no prelo). Trata do subgrupo Bolívia (mojeño, baure, pauna, tereno) da família arawak. Nenhum ramo da família arawak apresenta tanta coesão como o subgrupo Bolívia: seu léxico, sua gramática, com um inusitado suprafixo $A$ "não-factual", e duas complexas cadeias de mudanças vocálicas $\left(* \dot{\mathbf{i}}>*_{\mathbf{i}}>*_{\mathbf{e}}>*_{\mathbf{a}} ; *_{\mathbf{a}}>*_{\boldsymbol{\sigma}} / *_{\mathbf{0}}>\mathbf{i} / \mathbf{i} / \mathbf{u}\right)$ evidenciam uma unidade diagnóstica entre suas línguas. Fornecemos dados detalhados sobre a história e a destruição dialetal dessas quatro línguas (séculos XVI-XVIII), assim como um resumo de suas estruturas fonológicas e gramaticais, antes de propor uma reconstrução do proto-Bolívia e um supergrupo Bolivia-Purus-Kampa-Amuesha (BPKA) dentro das línguas arawak. Este estudo termina com uma lista de mais de 500 jogos de cognatos para o subgrupo Bolívia.

Desde Payne (1991), os estudos comparativos arawak do subgrupo Bolívia são extremamente caóticos e, de uma certa forma, regrediram. Além disso, uma análise abrangente do paikone, magíana e apolista nos leva a alguns materiais lexicais falsificados que obrigam a rever o estatuto dessas línguas.

PALAVRaS-CHAVES: Classificação arawak; Subgrupo Bolívia; Cadeias de mudanças vocálicas; Dados falsificados. 
Este trabalho é um capítulo resumido extraído de nossa Enciclopédia das Línguas Arawak - acrescida de seis novas línguas e dois bancos de dados, que está prestes a ser publicada. Nessa enciclopédia, todas as 56 línguas arawak são estudadas. Certas línguas (†mepuri, †aroaqui, †parawana, †mainatari, †cararí, etc.) são provavelmente desconhecidas do leitor por terem sido desenterradas há muito pouco tempo de manuscritos do século XIX. A incorporação inédita dessas línguas até hoje desconhecidas lança uma nova luz sobre certos subgrupos arawak (Japurá-Colômbia, Central, Médio Rio Negro, Purus) e permite estruturá-los melhor. Nossa nova classificação organiza a família arawak em 12 subgrupos (subfamílias) e em 56 línguas. No diagrama seguinte, uma cruz (†) indica uma língua extinta e uma cruz sobrescrita $\left(^{\dagger}\right)$ assinala que não sabemos ao certo se a língua ainda tem alguns falantes. Quatro línguas arawak extintas mal documentadas e de colocação taxonômica particularmente duvidosa aparecem em código vermelho. Dois traços verticais entre subgrupos sugerem um potencial supergrupo que é argumentado dentro da enciclopédia. O Mapa 1 indica a localização dos subgrupos e línguas arawak; o Mapa 2, as línguas arawak do subgrupo Bolívia. 


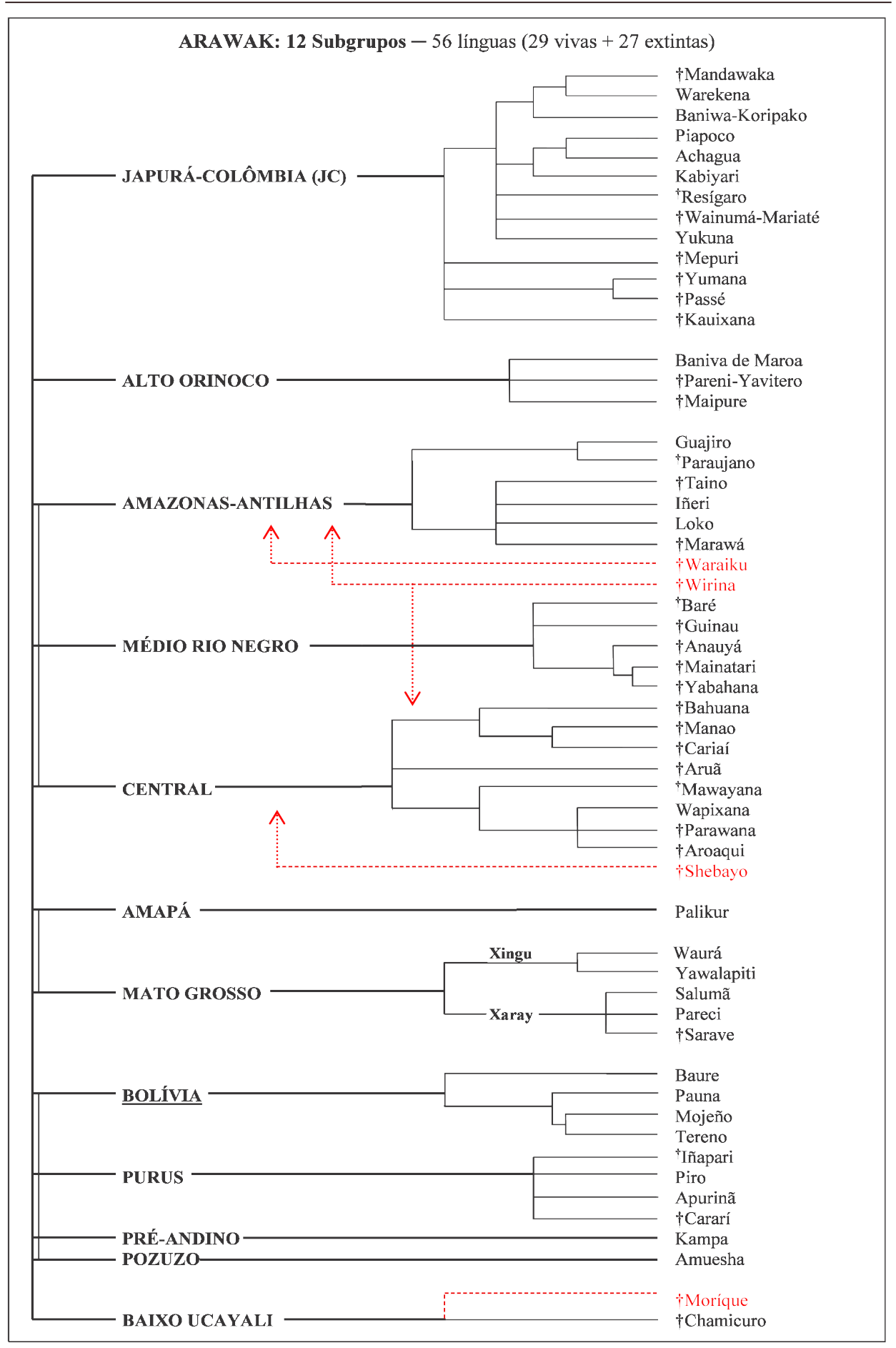

LIAMES, Campinas, SP, v. 19, 1-71, e019012, 2019 


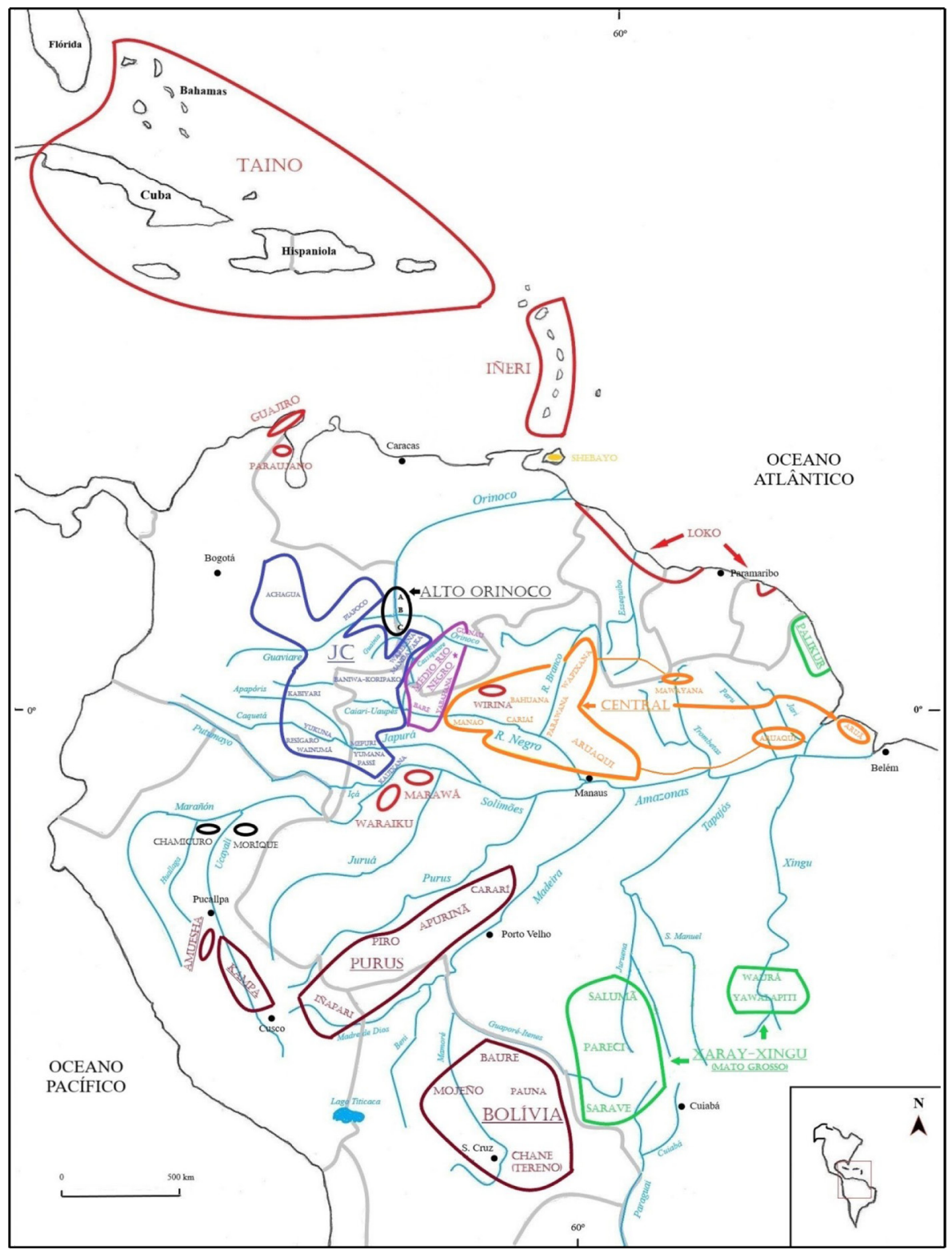

Mapa 1: Localização dos subgrupos e línguas arawak nos primeiros contatos. Extremamente diaspórico, o subgrupo Amazonas-Antilhas é indicado em código vermelho. No subgrupo Alto Orinoco, A, B e C indicam respectivamente o maipure, o pareni-yavitero e o baniva de Maroa. No subgrupo Médio Rio Negro, o asterisco (*) indica a localização aproximada do anauyá e do mainatari. 


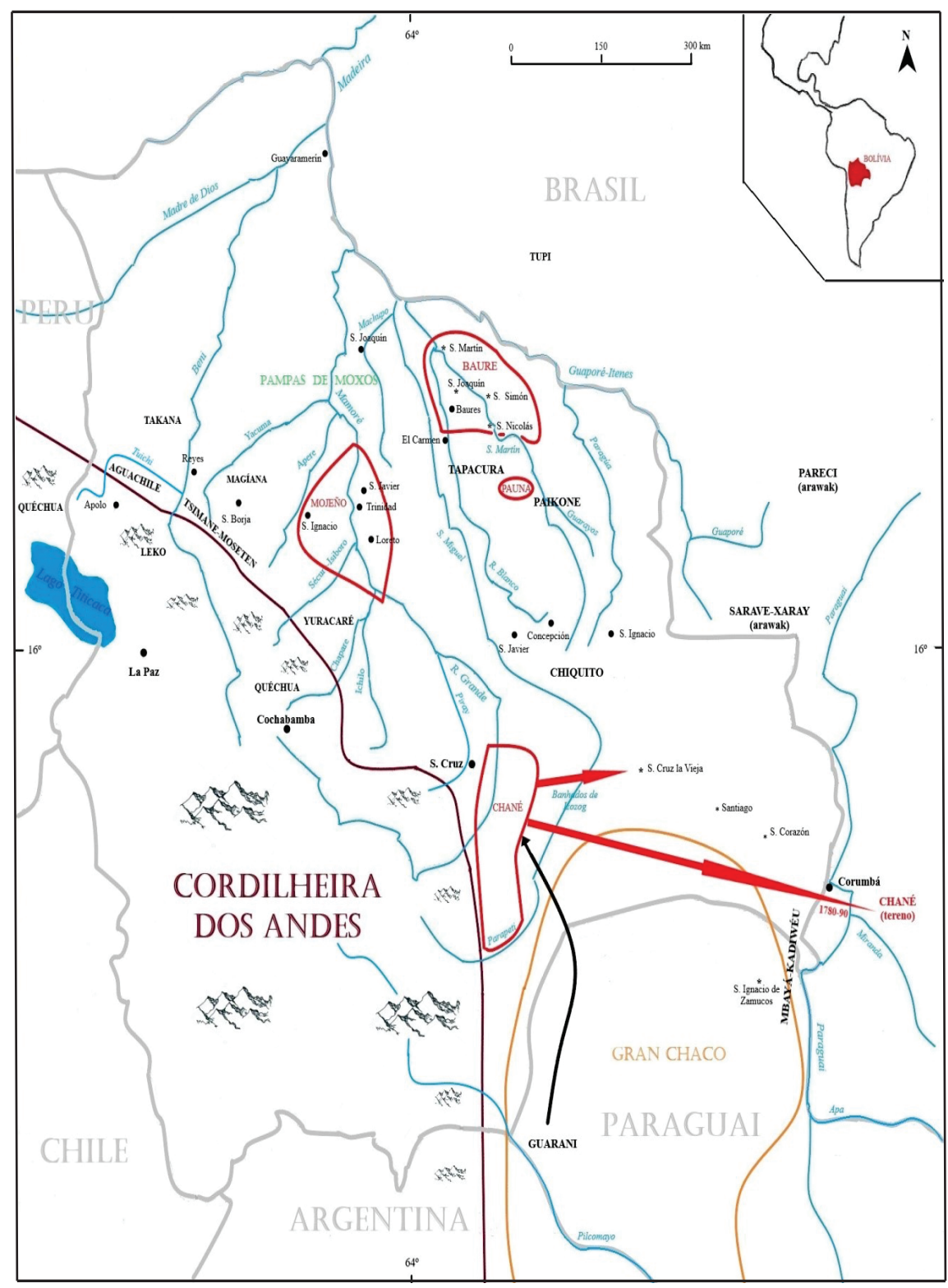

Mapa 2: Línguas arawak da Bolívia. A localização das línguas corresponde aos primeiros contatos (séculos $\mathrm{XVI-XVII).} \mathrm{O} \mathrm{traço} \mathrm{em} \mathrm{código} \mathrm{vermelho-escuro} \mathrm{separa} \mathrm{os} \mathrm{Andes} \mathrm{das} \mathrm{terras} \mathrm{baixas} \mathrm{dos} \mathrm{rios} \mathrm{Paraguai} \mathrm{e} \mathrm{Madeira.}$ $\mathrm{O}$ traço em código laranja indica os limites do Gran Chaco. 


\section{RAMIREZ \& FRANCCA - LÍNGUAS ARAWAK DA BOLÍVIA}

Nenhum ramo da família arawak apresenta tanta coesão como o subgrupo Bolívia. Uma unidade íntima entre suas línguas vê-se no léxico, na gramática e nos estranhos reflexos vocálicos das línguas atuais desse subgrupo, que são apenas quatro: o mojeño, o baure, o pauna(ka) e o tereno (chané). Depois de mostrar essa singular unidade (seção 1), apresentamos, uma por uma, essas quatro línguas, com enfoque na sua história e na sua destruição dialetal (séculos XVI-XVIII), com o essencial de suas fonologias e estruturas gramaticais (seções 2-5). O capítulo continua com a reconstrução interna do subgrupo Bolívia (seção 6) e com sua classificação externa (seção 7). As mudanças diacrônicas (dois jogos de mudanças vocálicas em cadeia, palatalização do fonema $\underline{\mathbf{k}}$, redução de grupos vocálicos ou ditongos) entram frequentemente em conflito umas com outras, e de forma tão complexa que a ordem das mudanças proposta se torna às vezes irritantemente hipotética. Nessas seções, tentamos também mostrar que os subgrupos Bolívia, Purus (apurinã, piro, iñapari, cararí), kampa e amuesha mantêm entre si uma relação estreita. Na seção 8, apresentamos os estudos comparativos desenvolvidos no subgrupo Bolívia desde o começo do século XX e explicamos por que todos falharam. Em geral, é arriscado reconstruir línguas sem considerar suas etapas anteriores, especialmente quando fontes escritas estão disponíveis. Com as línguas do subgrupo Bolívia, temos a sorte de ter um material escrito, às vezes excelente, que remonta ao fim do século XVII. As seções 9 e 10 pretendem resolver o estatuto das línguas magíana e apolista: verifica-se se realmente pertencem à família arawak e revela-se uma deplorável falsificação. $\mathrm{Na}$ seção 11 , avaliamos as adoções lexicais registradas entre o mojeño e as outras línguas indígenas da área. Enfim, o trabalho termina com uma lista provisória de mais de 500 jogos de cognatos pertencendo ao subgrupo Bolívia (seção 12).

\section{A extraordinária unidade achane}

Às vezes conhecido como "shani”" ou "achane" (a palavra achane é um dos reflexos de uma palavra do proto-Bolívia que designa o ser humano), o subgrupo Bolívia apresenta uma extraordinária unidade tanto no léxico básico como na sua estrutura morfossintática e nas suas originais mudanças vocálicas que ocorreram desde o protoarawak.

1.1. A unidade lexical. Apresentamos aqui uma centena de conceitos básicos com seus campos semânticos associados e com os significados correspondentes em mojeño, baure, pauna e tereno. Em mojeño, frequentemente várias formas aparecem separadas por uma barra oblíqua (/): trata-se de formas alternativas (dialetais ou individuais), a forma com asterisco (*) sendo a forma registrada pelo padre Marbán no fim do século XVII, que pode ser considerada como o ancestral do mojeño falado atualmente na região de Loreto e de Trinidad (Bolívia). Mesma apresentação foi seguida para o baure e o tereno. Note que as palavras que designam a fauna e a flora foram em geral descartadas por causa das numerosas adoções chiquito em pauna, e kadiwéu ou guarani em tereno. Observe também que o pauna é o "parente pobre" do subgrupo Bolívia: por ter sido menos estudado que seus parentes próximos, temos menos explicitações de muitos conceitos nessa língua, o que não deve levar o leitor a concluir que o pauna é mais afastado das três outras línguas da Bolívia, o que seria - como veremos - um erro. 
Pedimos que o leitor preste atenção a certas mudanças fônicas frequentes que estudaremos depois, como as alternâncias vocálicas a/o ou $\mathbf{\sigma} / \mathbf{u}$ : por exemplo, -maka / -moko "cabelo" e -t foti / -t futi "cabeça" em mojeño. Note também que, em contexto intervocálico, $\mathbf{r}$ cai frequentemente (como -siri / -sii "nariz" em mojeño), e k > ? (como *-na? [mojeño] / -inaku [tereno] "testa”, ou *-wa?ひ [mojeño] / -waki [baure] "mão").

Convidamos o leitor a examinar de perto os campos semânticos. Os numerosos cognatos que aparecem na tabela são tão diferentes do que se espera para uma língua arawak que o conjunto é por assim dizer diagnóstico das inovações lexicais que operaram no subgrupo Bolivia: ${ }^{1}$

\begin{tabular}{|c|c|c|c|c|}
\hline Português & $\begin{array}{l}\text { Mojeño } \\
\text { (*) Marbán (1701) }\end{array}$ & $\begin{array}{l}\text { Baure } \\
(*)(1750), \\
(* *)(1832)\end{array}$ & Pauna & $\begin{array}{l}\text { Tereno } \\
(*)(1793), \\
(* *)(1850-75)\end{array}$ \\
\hline cabeça & $\begin{array}{l}\text {-t } \text { futi / -t } \text { futi, -pv?i } \\
\text { redondo, -pvku } \\
\text { bochecha, -na?v / } \\
\text {-no?u / *-na?u testa, } \\
\text {-mira / -miro rosto, } \\
\text {-kuja-ra-si / kuja } \\
\text { cérebro }\end{array}$ & $\begin{array}{l}\text {-pø?e / *-pa?e, } \\
\text {-t fake-r / -panure } \\
\text { testa, -mira / -miru } \\
\text { rosto, -to-kié } \\
\text { cérebro }\end{array}$ & $\begin{array}{l}\text {-t fíti, -púku testa, } \\
\text {-wíke / -miu-iike } \\
\text { rosto, -kiju-raki } \\
\text { cérebro }\end{array}$ & $\begin{array}{l}\text { tûti, pûPi / po?e } \\
\text { redondo, apúku topo } \\
\text { da cabeça, inúku / } \\
\text { *inaku testa, nône } \\
\text { / *nane rosto, kâja } \\
\text { cérebro }\end{array}$ \\
\hline cabelo & $\begin{array}{l}\text {-maka / -moko cabelo/ } \\
\text { ninho, -hija / -hijo } \\
\text { pelo, -(i)-tfa?u / -t } \int \mathrm{o} u \\
\text { sobrancelha, -josu-se } \\
\text { pena }\end{array}$ & $\begin{array}{l}\text {-t } \int \mathrm{a}-,-\mathrm{e} \int-\mathrm{i} \int / *_{-} \int \mathrm{ei} \\
\text { pena }\end{array}$ & $\begin{array}{l}\text {-múki-hi / -moku- } \\
\text { hi, -hiju pelo }\end{array}$ & $\begin{array}{l}\text { híjeu, ifé-?o, } \\
\text { moko ninho, fôv } \\
\text { sobrancelha }\end{array}$ \\
\hline orelha & $\begin{array}{l}\text {-t faka / -t foka, -kina / } \\
\text { *-kina ouvido }\end{array}$ & 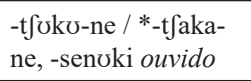 & 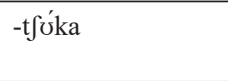 & keno / **kena \\
\hline olho & -óki(Pa) / *-uki & -(i)ki-se & -ke-wíke & uke \\
\hline nariz & -siri / -sii & -pa-siri / *-siri & -sísi & kiri \\
\hline boca & $\begin{array}{l}\text {-haka +*-paho, -nvku } \\
\text { bocado }\end{array}$ & -noki & $\begin{array}{l}\text {-niki, -haka } \\
\text { mandíbula }\end{array}$ & $\begin{array}{l}\text { pâho / poho, hako } \\
\text { bocejar, haháko- } \\
\text { cochichar, -nuku } \\
\text { feixe }\end{array}$ \\
\hline dente & -a?e / -o?e & -sera / -seru & -kewe & $\begin{array}{l}\text { oe, hâka dente de } \\
\text { siso }\end{array}$ \\
\hline língua & -nene & -pene(ne) /*-penene & -pénene & nene \\
\hline unha & -hipa-na / -hipo-no & -tipu & -sípo & hhîpo \\
\hline pé & $\begin{array}{l}\text {-íwa-pe / *-iwo-pe, } \\
\text {-paike perna, -hewe } \\
\text { canela, -pa?e coxa }\end{array}$ & $\begin{array}{l}\text {-puji, -pes perna, } \\
\text {-se(j)i canela, } \\
\text { **-tfanese coxa }\end{array}$ & -iwo & $\begin{array}{l}\text { hhêwe pé/perna, } \\
\text { pukúna canela }\end{array}$ \\
\hline joelho & -pojo & $\begin{array}{l}\text {-t } \int u \beta e-r a ~ / ~-t \int v \beta e-~ \\
k v-s e\end{array}$ & -síjkvke & pûju \\
\hline
\end{tabular}

${ }^{1}$ As referências bibliográficas relevantes para nossa pesquisa diacrônica sobre o mojeño, o baure, o pauna e o tereno serão fornecidas ao longo do artigo. Em relação às outras línguas, o leitor poderá consultar a Enciclopédia das linguas Arawak. 
RAMIREZ \& FRANCCA - LÍNGUAS ARAWAK DA BOLÍVIA

\begin{tabular}{|c|c|c|c|c|}
\hline mão & -wa?v / *-wo?u & $\begin{array}{l}\text {-wohi-su / -wohi-se / } \\
\text {-wai-s, -waki palma }\end{array}$ & -wới & wo?u / **wa(?)u \\
\hline braço & $\begin{array}{l}\text {-páwa-ki / -powo- } \\
\text { ki braço/asa, -hi?v } \\
\text { ombro, ta-tawa-ki / } \\
\text {-ta-tawo-çi galho }\end{array}$ & $\begin{array}{l}\text {-puwu-ki, -tusi / } \\
\text { *-tasi asa, e-tsié / } \\
\text { ewo galho }\end{array}$ & -síka, pv(w)ひ asa & $\begin{array}{l}\text { tâ-ki / **ta.a-ki, kêwi } \\
\text { asa, pôwo / pawa } \\
\text { ombro }\end{array}$ \\
\hline barriga & $\begin{array}{l}\text {-ho?e, -toropi / -tuupi } \\
\text { tripa, -itfika-hi / itfiko- } \\
\text { hi fezes }\end{array}$ & $\begin{array}{l}\text {-h(i)eki, -t } \int u k \mho(k i) \\
\text { estômago, -ti-se tripa }\end{array}$ & -emua, -tikehi & $\begin{array}{l}\text { hhûra, ásurupi tripa, } \\
\text {-isiko fezes }\end{array}$ \\
\hline cintura & -na?e & --- & --- & no?e \\
\hline corpo & -á-k(i)e?e / -ó-ke?e & $-P a /-P v$ & --- & -?o \\
\hline costas & $\begin{array}{l}\text {-t } \int \text { epa / -t } \int \text { epo }+ \text {-keku } \\
+ \text {-ékene } \text { atrás }\end{array}$ & -t fipi, -aseki axila & t $\int u p u-k e k i$ & $\begin{array}{l}\text {-ke?e / -ke-ku + } \\
\text {-akene atrás }\end{array}$ \\
\hline urina & -sene & -tene & -- & sêne- \\
\hline pescoço & $\begin{array}{l}\text {-píke-nu / -no, -érena / } \\
\text {-ereno garganta }\end{array}$ & $\begin{array}{l}\text {-pihi, -t } \int a n u-k i / \\
\text { *-s-einuki garganta }\end{array}$ & -pii-ni & -nu / a-nu, kere-nu \\
\hline seio & $-\mathrm{t}$ fene & 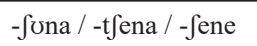 & $-\mathrm{t}$ fene & Sene \\
\hline coração & $\begin{array}{l}\text {-s-ámひ-re / *-omi- } \\
\text { ro / tu-kui, -ámi-t } \int \mathrm{a} \\
\text { respirar }\end{array}$ & [-e-tu]-kv?ine & -kina & $\begin{array}{l}\text { omifone, omife-ko } \\
\text { respirar }\end{array}$ \\
\hline osso & j-ape / j-ope-ra & $-u p(e)+-a p(e)$ & (a)-upe & ope \\
\hline sangue & iti & iti & íti & iti \\
\hline carne & -etfe, -pa?e & n-e $\int(e),-e-n-i \int-u n$ & 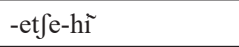 & ijé-u, hhîhhi músculo \\
\hline flor & -epu, -hipv / -hi(w)v & $\mathrm{t} \int \mho(\mathrm{mu}) \mathrm{m} \mho \mathrm{e} ?$ & (h)ipí-si / hiwi & hîu \\
\hline folha & $\begin{array}{l}\text {-pa-ka / -po-ko, itápe } \\
\text { / *itope espinho, ta- } \\
\text { jura ferrão, t-apare / } \\
\text {-t-apore / t-opore raiz }\end{array}$ & $\begin{array}{l}\text {-pone, kupon / } \\
\text { **kepuna espinho, } \\
\text {-purié raiz }\end{array}$ & (etfi)-pune & $\begin{array}{l}\text { tuti, tôpe + itápa } \\
\text { espinho, i-juifa } \\
\text { ferrão, -po?e raiz }\end{array}$ \\
\hline semente & $\begin{array}{l}\text {-aki, -j-áki pênis, [-a]- } \\
\text { Pi / -o-Pi fruta }\end{array}$ & $\begin{array}{l}\text { s-ðki / **seki, -(ひ) } \\
\text { i? fruta }\end{array}$ & t i-moke-hĩ, -i fruta & $\begin{array}{l}\text { ake semente/pênis, } \\
\text { há-Pi fruta }\end{array}$ \\
\hline $\begin{array}{l}\text { ovo, } \\
\text { pequeno, } \\
\text { filho }\end{array}$ & $\begin{array}{l}\text {-?a, (i)t fípitfu / -t } \int \mathrm{it} \int \mathrm{a} \\
\text { / -tsira pequeno, -ama- } \\
\text { pero / *amo-peru } \\
\text { menino(a) }\end{array}$ & $\begin{array}{l}\mathrm{n}-\mathrm{a} ?, \mathrm{ti} \text { a } / \text { - } \mathrm{t} \int \mathrm{i} / \\
*-\mathrm{t} \int \mathrm{i} /-\int \mathrm{i}-/ *_{-} \mathrm{e}-\mathrm{ra} \\
/-\int \mathrm{i}-\mathrm{ra} \text { pequeno, } \\
\text { man- } \mathrm{t} \mathrm{i} / \text { *ama-na-t } \mathrm{i} \\
\text { menino(a) }\end{array}$ & $\begin{array}{l}\mathrm{t} \int \mathrm{i}-\mathrm{t} \int \mathrm{et} \int \mathrm{a},-\mathrm{t} \int \mathrm{epi}-\mathrm{ti} \\
\text { pequeno }\end{array}$ & $\begin{array}{l}\text { Je?éfa / Je?a ovo/ } \\
\text { filho, *amme-ne } \\
\text { criatura }\end{array}$ \\
\hline cauda & (t)a-ihi-ki / (ta)-ehi-ki & -ehひ-s / -ihひ-se & $\mathrm{t} \int \mathrm{i}-\mathrm{ke}$-isi & ihi \\
\hline gordura & -rhe, -si-na & eskiap, $\mathrm{t} \int u$-meki & 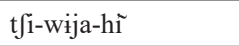 & 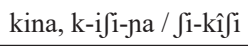 \\
\hline nome & -iha-re, -iha-ro & -(i)wvj(i) / *-ißvju & -íha & îha \\
\hline homem & ahaira / ahira / *ehoiro & hira / *ehiro / *ehira & toro & hojeno / *hajjena \\
\hline mulher & esena / *eseno & $\begin{array}{l}\text { etuna / eten } / \\
* \text { eten } / \text { / * etena }\end{array}$ & seð-nớwe / eséno & $\begin{array}{l}\text { seno / **sena, têno } \\
\text { moça }\end{array}$ \\
\hline pessoa & atfane & $\begin{array}{l}\mathrm{t} \int e n e-t i / t \text { ane-ti / } \\
\mathrm{t} \text { (in-ti }\end{array}$ & vtfane & fane \\
\hline árvore, fogo & jukv-ki + -wku-çi + -ki & $\begin{array}{l}\text { e-wokve / -wok(u)+ } \\
\text { jaki / joki fogo + -ki } \\
\text { / -si / -se / -su pau }\end{array}$ & jikí-ke $+-k e$ & $\begin{array}{l}\text { joko / juku / uku + } \\
\text {-ke, -mûku cerne }\end{array}$ \\
\hline
\end{tabular}




\begin{tabular}{|c|c|c|c|c|}
\hline sol & $\begin{array}{l}\text { satfe sol/dia, anú-ma } \\
\text { cé } u, \text { hara- + míka?u / } \\
\text { *miko?u luz, mơ⿱u ano }\end{array}$ & $\begin{array}{l}\text { sese, ani / **ane céu, } \\
\text { harei- dia, -mika } \\
\text { alumiar, morue-kue } \\
\text { ano }\end{array}$ & sátfe, ani-mu céu & $\begin{array}{l}\text { kat } \int \text { e sol/dia, wanú- } \\
\text { ke céu, míka luz, } \\
\text { mêũ tempo }\end{array}$ \\
\hline lua & kahe / kóhe & $\begin{array}{l}\text { kihe-re(s) / **kuðe- } \\
\text { ðe }\end{array}$ & kớhe & kohhê-e / kóhhe-a \\
\hline água & $\begin{array}{l}\text { une, -ama / -omo } \\
\text { líquido, jamama / } \\
\text { jomomo pântano }\end{array}$ & $\begin{array}{l}\text { ine, -aha / -are / } \\
\text { *-vmo liquido, } \\
\text { tfomori-wok } \\
\text { pântano }\end{array}$ & $\begin{array}{l}\dot{\mathrm{t}}(\mathrm{h}) \mathrm{ne},- \text {-vmo } \\
\text { líquido }\end{array}$ & $\begin{array}{l}\text { une, hô?o líquido, } \\
\text { átu suco, jomomo } \\
\text { pântano }\end{array}$ \\
\hline chuva & $\begin{array}{l}\text { ti-kiwa / t-çíwo, vka-hi } \\
\text { nuvem }\end{array}$ & soworn / sewana & íkv & uko, kêwo \\
\hline casa & $\begin{array}{l}\text { peti + -pena / -peno, } \\
\text { jusu-hi tapiri, -áwa-sa } \\
/ \text {-owo-sa [-awa viver }] \\
\text { povoado }\end{array}$ & $\begin{array}{l}\text {-weri + -penv, (a) } \\
\text { sora-ti / *asarv-ti } \\
\text { povoado }\end{array}$ & 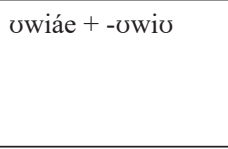 & $\begin{array}{l}\text { péti }+ \text {-peno, ówo-ku } \\
{[- \text { owo } \text { viver }] \text { povoado }}\end{array}$ \\
\hline pedra & mari, mapú-wa cedro & kohí / *kahi & mái & $\begin{array}{l}\text { mopôi / mapoi / } \\
\text { *mapai, mari(h) } \\
\text { i- terra }\end{array}$ \\
\hline terra & $\begin{array}{l}\text { mate-hi / mote(-hi) + } \\
\text {-pa(?)i + apake?e }\end{array}$ & pae / pue / -pai & moté-pa + apóke & $\begin{array}{l}\text { mote }+ \text { po } \mathrm{i}+\text { poké?e } \\
/ * \text { pake?e }\end{array}$ \\
\hline fumaça & $\begin{array}{l}\text { kihare / *kihore, ijaro / } \\
\text { *joru neblina }\end{array}$ & $\begin{array}{l}\text { **kitfare, top } \\
\text { neblina }\end{array}$ & (k)ehũe-pa & $\begin{array}{l}\text { kuríhoe / ikurihea, } \\
\text { jôu neblina }\end{array}$ \\
\hline cinzas & $\begin{array}{l}\text { tsima-pa / *tsima, } \\
\text { e-mani-ki / e-moni-ki } \\
\text { carvão }\end{array}$ & $\begin{array}{l}\text { pv?ip(ひ) / pa?ipø, } \\
\text {-muni-si carvão }\end{array}$ & $\begin{array}{l}\text { timá-pa, -moni } \\
\text { carvão }\end{array}$ & $\begin{array}{l}\text { po(P)ú, moni-ke } \\
\text { brasa }\end{array}$ \\
\hline caminho & 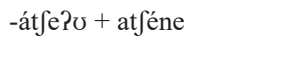 & 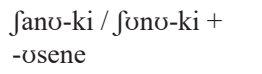 & -tfeneki & (o) $\int \mathrm{ene}+$ jono-ku \\
\hline roça & -ésane + isani-ti & tuer $/ *$ itaira-kv & asane & -isane + kawane \\
\hline noite & jati / joti / *jati & $\begin{array}{l}\text { jutve-r } / \text { jatio } / * \text { jatoi } \\
/ * * \text { jete } / * * \text { jote }\end{array}$ & jứti & joti \\
\hline quente & $\begin{array}{l}\text { (t)ihu-re, -asa-ka / } \\
\text {-oso-ko esquentar }\end{array}$ & $\begin{array}{l}\text { ku-piro-kon, -isami } \\
\text { esquentar }\end{array}$ & (ti)jísij, -ihi-e & $\begin{array}{l}\text { otu-ko, ihhu-we, oso } \\
\text { assar }\end{array}$ \\
\hline frio & $\begin{array}{l}\text {-k-asa-ra / -k-osra / } \\
\text { *-k-asa-ra }\end{array}$ & -mane / manv & -imanakv & $\begin{array}{l}\text { kasa-ti / asa-ko, } \\
\text { imáta-ko gelo }\end{array}$ \\
\hline seco & -ahi(hi) & $\begin{array}{l}\text { morø- / mora- / } \\
\text { *mara- }\end{array}$ & (ti)mirahi & mowo-, ahi?-o-ko \\
\hline branco & -hapv / -hopu / *-hapu & kv-tipø-kv / -tipa & (ti)súroro & hhopu / hhapu \\
\hline doce & -ítiwe & eto $\beta \mathrm{i}$ & --- & itíwe \\
\hline doer & -ka-ti / ko-ti- / *-ka-ti & -kv-ti- $\beta \mathrm{e} / *$-ka-ti- $\beta \mathrm{e}$ & -koti & kotiwe-ti \\
\hline esquerda & sapa / sopa & sap & --- & loope \\
\hline beber & $\begin{array}{l}\text {-era / -ero, -kawa?a / } \\
\text {-kowo?o bêbado }\end{array}$ & $\begin{array}{l}\text {-eru-n / *-eru-ne, } \\
\text { kawiari bêbado }\end{array}$ & -ea, kuwiu bêbado & $\begin{array}{l}\text { eno- / ena + ore-ko, } \\
\text { eróPufo sede, kohíhi } \\
\text { bêbado }\end{array}$ \\
\hline
\end{tabular}


RAMIREZ \& FRANÇA - LÍNGUAS ARAWAK DA BOLÍVIA

\begin{tabular}{|c|c|c|c|c|}
\hline comer & $\begin{array}{l}\text {-ni-ka / -ni-ko, -íhima } \\
\text { / *ihimo jejuar, -ahi / } \\
\text {-ohi mamar, -hiri-ka } \\
\text { / - hi(r)iko engolir }\end{array}$ & $\begin{array}{l}\text {-ni-ko, -ßei?inow } \\
\text { fome, -hi-k chupar/ } \\
\text { mamar, }{ }^{*} \text {-ero-ko } \\
\text { engolir }\end{array}$ & $\begin{array}{l}\text {-ní-ka / -ni-ku, } \\
\text {-vhi-k mamar }\end{array}$ & $\begin{array}{l}\text { ni-ko, hima-ka fome, } \\
\text { ohi-ko chupar, } \\
\text { t-huíri-ko engolir }\end{array}$ \\
\hline ouvir & -sama / -somo & $-\operatorname{sum}(\mho) /-\operatorname{sam} \mho$ & -sámひ & kamo \\
\hline saber & -etfa / -etfo & -(e)t $\int u /-(\mathrm{e}) \mathrm{t} \int \mathrm{a}$ & -itfú-pa & e $\int o-/ e$ a- / iso- \\
\hline dormir & $\begin{array}{l}\text {-íma-ka / -imo-ko, } \\
\text {-tfapu sonho }\end{array}$ & $\begin{array}{l}\text {-imひ-kv / *-ima-ka, } \\
\text {-hapi sonhar }\end{array}$ & -ímひ-ka & $\begin{array}{l}\text { imó-ko, hhopú-fo } \\
\text { sonho }\end{array}$ \\
\hline morrer & -épe-na, -ini defunto & $\begin{array}{l}\text {-epe-nv, -ven / -ini } \\
\text { defunto }\end{array}$ & -epa-ka & $\begin{array}{l}\text { épe-wo, -ikene / -ine } \\
\text { defunto }\end{array}$ \\
\hline matar & -kapa / -kopa & -(i)kumuri-ku, -ipara & -kópa(ka) & koépe-ko / káupa \\
\hline ir & $\begin{array}{l}\text {-jana / -jono, -pa(na) } \\
\text { centrifugo, -ama / -omo } \\
\text { levar }\end{array}$ & $\begin{array}{l}\text {-jono / *-jana, -pa } \\
\text { centrifugo, --omo / } \\
\text { *-ama levar }\end{array}$ & -jøna, -ømu levar & $\begin{array}{l}\text { jôno, -po(no) } \\
\text { centrifugo, ama / } \\
\text { omo / oma levar }\end{array}$ \\
\hline dizer & $\begin{array}{l}\text {-ka?e / -ko?e, -etfa } \\
\text { falar, -meta avisar, } \\
\text {-a?v / -o?u / *-a?u voz, } \\
\text {-ema som }\end{array}$ & $\begin{array}{l}\text {-kitfo / -kitfa + -ke, } \\
\text {-(a)ße-kv falar, -enu } \\
\text { / -ena avisar }\end{array}$ & -kue, -k-ét $\int u$ falar & $\begin{array}{l}\text { ko?-e + kifo- dizer, } \\
\text { ifo-mo conversar, } \\
\text {-emo voz/lingua, } \\
\text { ene-ko aconselhar }\end{array}$ \\
\hline lavar & $\begin{array}{l}\text {-sipa-, -ka-wa / -ko-wo } \\
\text { banhar-se }\end{array}$ & $\begin{array}{l}\text {-sipa, *-kv-wo / } \\
\text { *-ka-wa banhar-se }\end{array}$ & $\begin{array}{l}\text {-kipv, -kuw } \\
\text { banhar-se }\end{array}$ & $\begin{array}{l}\text { kipo-?i / kipe-, ahhi- } \\
\text { ko-wo banhar-se }\end{array}$ \\
\hline vomitar & -a?i-ka / *-a?i-ko & -ewsuPin / -useia & - -vi(ka) & $\begin{array}{l}\text { o?e-ko-wo / a?e-ko- } \\
\text { wo / ai-ko-wo }\end{array}$ \\
\hline ter medo & -pika / -piko & -pikv & -pikv & piko \\
\hline voar & -ara / -oro & -arv /*-ara & -wiwi(ka) & ôo- / -aa \\
\hline $\begin{array}{l}\text { dançar, } \\
\text { cantar }\end{array}$ & -hira / -hiro & -hiro /*-diro / -hiri-p & --- & hí(j)o- \\
\hline encontrar & $\begin{array}{l}\text {-ákapahi-ka / *-akopo- } \\
\text { hi }\end{array}$ & *-akapin & --- & t-okopo / t-aukopaa \\
\hline enterrar & -ékara / -ekoro & -ekuru & --- & eko-fo \\
\hline coletivo & -hi & -hi & -hi & -hi(ko) \\
\hline causativo & $\mathrm{e}-$ & i- & --- & i- \\
\hline subjuntivo & $\mathrm{a}-$ & $* a-$ & a- & a- \\
\hline benefactivo & -ina / -ino & -inv & --- & -ino \\
\hline já & -pa / -po & $-p \mho$ & -pv & -po \\
\hline reportativo & -hi & -hi & -hi & -hi \\
\hline $\mathrm{eu}, \mathrm{me}$ & 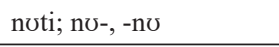 & niti?; n(i)- & níti, ni- & u-ndi, N- \\
\hline $\mathrm{tu}$, te & piti; pi-, -wi & piti?; p(i)- & piti, pi- & -pi \\
\hline nós & witi; wi-, -Pawi & $\beta$ Biti?; $\beta(\mathrm{i})-$ & wíti; wi- & u-ti \\
\hline vós & éti & $*$ jeti & eti & îti \\
\hline um & apa- / apo- outro & pu- / pa- / *apa- & $\mathrm{t}$ fina- $\mathrm{t} f \mathrm{i}$ & po-hha, *pa-hh-, pô?i \\
\hline dois & ápi- & (m)api- & ros-t $\int \mathfrak{i}[<$ espanhol $]$ & pi?a, api?i-fo \\
\hline três & mapa- / mopo- & mopv- / mapa- & tres- $\mathrm{t} \int \mathfrak{f}[<$ espanhol $]$ & mopo?a / mapo?a \\
\hline
\end{tabular}


LIAMES 19

\begin{tabular}{|c|c|c|c|c|}
\hline $\begin{array}{l}\text { animal } \\
\text { doméstico }\end{array}$ & -pera / -pero & $-\operatorname{per}(\mho) / *$-per $v$ & -pev & -pejo \\
\hline tamanduá & atikure / *atikure & (i)muwa / vmuw & atíkie & tikoa \\
\hline $\begin{array}{l}\text { preá (Cavia } \\
\text { sp.) }\end{array}$ & mojukv & majaka / mojoku & --- & mujuká-tata \\
\hline anta & sama / samo & sumv & sámo & kamo \\
\hline $\begin{array}{l}\text { queixada } \\
\text { (porco) }\end{array}$ & simáro / smóru & simuri & fwa & kimõũ \\
\hline veado & kahawa / *kohowo & kahawa / kohowa & kusuwv & kohhowe / kohhówoi \\
\hline onça & itfini & (i)t $\mathrm{t}$ ini & isíni & síni \\
\hline morcego & wite & Bite-re & wíte & wite-te \\
\hline pato & vpahi / *upoji & (v)poh(i) / *ipahi & upvhĩ & póhi \\
\hline ema, nandu & sipa & sipa-re / *sipa-re & kípa & kipâ-(h)e \\
\hline $\begin{array}{l}\text { cobra } \\
\text { (genérico) }\end{array}$ & kitfare / ktfóre & kiwor / *kißure & $\operatorname{ket} \int \mho(w) e$ & koefoe \\
\hline piranha & oroma / *urumo & (ひ)rima / vrimu & ímo & uruma / arumo \\
\hline $\begin{array}{l}\text { muçum, } \\
\text { enguia }\end{array}$ & itire & (i)ti(re) & itíe & tie \\
\hline $\begin{array}{l}\text { larva de } \\
\text { mosca }\end{array}$ & -kane & -kane & -kane & kanee-t $\int \mathrm{i}$ \\
\hline
\end{tabular}

\begin{tabular}{|c|c|c|c|c|}
\hline cipó, liana & épire / -pi & kuru-pi & hupí-pi & hhepí-pi \\
\hline urucu & inire / (e)nire & unir & eníe & nijé \\
\hline batata-doce & kae-re / *koe-re & se-re(?) & kvé-pi(a) & ko?ê-e \\
\hline abóbora & maku-re / moku-re & mokuwi-se & moki-e & mo?ĩ / mókoa \\
\hline amendoim & kurike-re & kiriki-ri & kíike & kurîke \\
\hline pimenta & 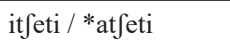 & (i)jiti / ijeti / jati & otféti & têti + étetea \\
\hline
\end{tabular}

Em particular, o leitor deve ter visto os cognatos para "cabeça", "cabelo/ninho", "boca", “joelho", “coração", "sangue", "nome”, "pessoa”, "árvore”, "sol”, "chuva”, "terra", "noite", "saber", "vomitar", "ter medo", etc. Deve também ter percebido que o mojeño compartilha muito mais cognatos com o tereno que com o baure. Para os que ainda alimentam dúvidas, note também o extraordinário isomorfismo formal e conceitual nos termos de parentesco (mais uma vez, faltam-nos dados sobre o pauna). Isso poderia sugerir que esses povos tivessem vivido em um espaço limitado até tempos recentes:

\begin{tabular}{|c|c|c|c|c|}
\hline Português & MOJEÑO & BAURE & PAUNA & TERENO \\
\hline pai & $\begin{array}{l}-\mathrm{i}(\mathrm{j}) \mathrm{a},-\mathrm{jane}-\mathrm{l} \text {-jene- } \\
\text { pais }\end{array}$ & $\begin{array}{l}\text {-i-á, -iruna / -ireno } \\
\text { pais }\end{array}$ & $-(\mathrm{i}) \mathrm{a}$ & há-?a, ijeno pais \\
\hline mãe & -ena / -eno & -en $/ *_{\text {-en }} / *^{*} *_{\text {-ena }}$ & -env & eno / *ena \\
\hline filha & --- & -hin /*-hine & -hine & ihíne \\
\hline esposo & -ima & $-a \beta i n u n(e)$ & -ima & îma \\
\hline esposa & -jena / -jeno & -ejon / *-jen & - jenv & -jeno \\
\hline
\end{tabular}


RAMIREZ \& FRANCCA - LÍNGUAS ARAWAK DA BOLÍVIA

\begin{tabular}{|c|c|c|c|c|}
\hline avô & -atfu / -ot $\int u$ & a $\int 0-k a / * *-a \int i-k$ & $-v t \int i-k v$ & $\mathrm{o} J \mathrm{u}$ \\
\hline avó & -atse / -otse & -use & -use & ose \\
\hline tio & -e-kwka / -(e)kuko & $\begin{array}{l}\text {-kik / *-kika / **_ } \\
\text { kiku }\end{array}$ & $-k i k v$ & eúko / ekú-seno \\
\hline tia & -aka / -oko & -ak(a) / - vka & --- & oko \\
\hline sogro & 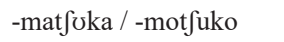 & -mofuka & mot $\int \mathrm{fk} v$ & imófuko \\
\hline sogra & -mase / -mse & -musa & -muse & imose \\
\hline sobrinho & -anewa / -anewo + -t $\int \mathrm{e}-$ & $* * \mathrm{t} \int$-enohrus $+-\int \mathrm{i}(\mathrm{i})$ & --- & newo / *newa \\
\hline genro & $-\mathrm{t}$ fina & -Siná & --- & $\operatorname{sina}$ \\
\hline nora & -t $\mathrm{t}$ inena / - $\mathrm{t}$ fineno & -(i) funona & --- & sine-na \\
\hline neto(a) & -ama-ri / -am(o)-ri & -(i)ha & --- & amo-ri \\
\hline irmão & aja & aja & --- & ajo \\
\hline irmão + novo & -ati & --- & -ati & âti \\
\hline irmão + velho & $\begin{array}{l}\text {-etfawi / -etfowi / } \\
\text { *-etfawi }\end{array}$ & -piri / -et(a) / -Paij & --- & e fowi / e Jawi \\
\hline
\end{tabular}

1.2. Um morfema gramatical singular. $O$ tereno apresenta um estranho morfema, i.e., $o$ suprafixo A (Butler 1978: 1-14, Ekdahl e Butler 1979: 34-38, 78-79). Para passar do factual (indicativo) ao não-factual (subjuntivo), os verbos trocam todos seus $\underline{\mathbf{a}} \mathrm{em} \underline{\mathbf{a}}$, inclusive os afixos, com a exceção do sufixo - wo "reflexivo", que se torna - $p u$. Por exemplo:

\section{FACTUAL}

ojéreko "ela cozinha"

ahhíko-wo-ti "está tomando banho"

imo-ko "ela dorme"

poré-fo-a "ele o deu"

na jóno? "aonde ele foi?"

ojéreko "ela cozinha"

ojéreko "ela cozinha"

ikeróko-wo-ti-mo "você cairá"

\section{NÃO-FACTUAL}

ajéreka "que ela cozinhe!"

j-áhhika-pu "tome banho!"

ima-ka "que durma!, ela dormirá"

ako paré-fa-a "não o deu" [ako "não"]

na jána? "aonde será que foi? [na "aonde"]

(enepo) aje?éka-a "se ela o cozinhar" [еnepo "se"] eneponi ajereka-a "se ela o tivesse cozinhado" ikeráka-pu(mo) "talvez você caia"

Nos segundo e último exemplos, o leitor observa que -wo "reflexivo" torna-se -pu. Como se vê nos exemplos acima, o não-factual ou subjuntivo, que Ekdahl e Butler chamam de "potencial" e outros ainda de "irreal", usa-se, em tereno, em certas formas imperativas e negativas, no condicional ("se"), em certos futuros hipotéticos e em perguntas conjecturadas.

Tudo sugere que esse suprafixo seja um antigo prefixo $a$ - "não-factual", que desapareceu, mas deixou como vestígio o espraiamento da vogal a (todos os $\underline{\mathbf{a}}$ tornam-se a). Em tereno, esse prefixo $a$ - ainda existe com os adjetivos e com o mesmo sentido de não-factual. Por exemplo: ka?arine "quando ficou doente" $\rightarrow$ a-ka?árine "quando ficar doente", úna-ti "é bom" $\rightarrow$ ako á-una-ti "não é bom!", etc., de forma que os exemplos de não-factual apresentados acima com verbos deveriam ser reescritos com o prefixo $A$ "não-factual”: A-ojéreko [ajéPeka] "que cozinhe!”, A-imo-ko [imaka] “que durma!", etc. 
- E em baure? Os missionários do século XVIII registram igualmente duas formas verbais (Adam e Leclerc 1880: 9-10, 57, 66-70, 82): uma forma "presente-pretérito" e outra "futuro-subjuntivo". Na forma futuro-subjuntivo, os verbos transformam seus 므 em $\underline{\mathbf{a}}$, inclusive os afixos, com exceção do sufixo -wo "reflexivo", que se torna -po (note que, ao contrário do tereno, não há oposição o/u em baure). Por exemplo:

\section{PRESENTE}

ni-niko "como"

n-omo "trago"

n-emaniko-wo "eu me amo"

$n i$-jono "eu vou"

\section{FUTURO-SUBJUNTIVO}

ni-nika "comerei", ni-nika-ni "tomara que coma!" n-ama "trarei"

n-emanika-po "eu me amarei"

ni-jana-ni "que eu vá!"

No penúltimo exemplo, constata-se que -wo "reflexivo" torna-se -po. Como se vê nos exemplos acima, em baure, o futuro-subjuntivo usa(va)-se no futuro, no subjuntivo, no optativo, no condicional ("se quiser levar isso", "se tivesse levado um pau [o cão não te teria mordido]"), com o negativo $m a$-, etc. Isso sugere que esse suprafixo seja também um antigo prefixo $a$ - "não-factual", que desapareceu mas deixou como vestígio o espraiamento da vogal $\underline{\mathbf{a}}$ (todos os $\underline{\mathbf{0}}$ tornam-se $\underline{\mathbf{a}}$ ). Em baure, esse prefixo $*^{*} a$ - ainda existia no século XVIII com os verbos estativos (adjetivos) e com o mesmo sentido. Por exemplo: ni-momani "tenho sede/estou sedento" $\rightarrow$ n-a-momani "terei sede", ni-katiwe "estou doente" $\rightarrow n$ - $\underline{a-k a t i w e ~ " e s t a r e i ~ d o e n t e ", ~ e t c ., ~ d e ~ f o r m a ~ q u e ~ o s ~ e x e m p l o s ~ b a u r e ~ d e ~}$ futuro-subjuntivo apresentados acima deveriam também, como em tereno, ser reescritos com o prefixo $A$ - "futuro-subjuntivo".

Assim, o tereno e o baure têm a mesma estrutura: um suprafixo $A$ "não-factual, conjectural, subjuntivo", que transforma os $\underline{\mathbf{0}}$ da raiz verbal e de seus sufixos em $\underline{\mathbf{a}}$, com a singular exceção do sufixo reflexivo $(-w o \rightarrow-p u / p o)$. Essa "bizarria tipológica" não pode ser o fruto do acaso e não deixa margem à menor dúvida de que o tereno e o baure têm uma origem comum e bem divergente das outras línguas arawak.

E os mecanismos são bem semelhantes em mojeño: o morfema $a$ - "futuro" usa-se, não somente para expressar o futuro, mas também o subjuntivo, o imperativo, o optativo, o condicional ("se", "quando"). Por exemplo: nu-semo "estou zangado" $\rightarrow n$-a-semo "estarei zangado". Com a maioria dos verbos, mais uma vez, esse prefixo transforma-se no suprafixo $A$, como $n$-imo'o "vejo" $\rightarrow$ n-ima'a "verei", $n$-emunako "amo" $\rightarrow$ n-emunaka "amarei", nu-tanuko "busco" $\rightarrow$ nu-tanuka "buscarei", etc. Quanto ao sufixo reflexivo, mais uma vez, ele sofre a mesma mudança bizarra: -wo $\rightarrow-$ po, como em nu-niko-wo "eu me mordo" $\rightarrow$ nu-nika-po "eu me morderei” (Marbán 1701: 33-38).

Em resumo: encontrada em tereno, em baure e em mojeño, a "bizarria tipológica" do morfema suprafixo $A$ "não-factual" e a metamorfose do reflexivo -wo em -po/-pu são mais do que suficientes para considerar que essas três línguas, junto com o menos conhecido pauna, formam um subgrupo.

1.3. A deriva vocálica achane. Na lista extensa de cognatos acima apresentada, o leitor notou uma singular e muito produtiva variação dialetal entre as vogais a e o/ठ em muitas

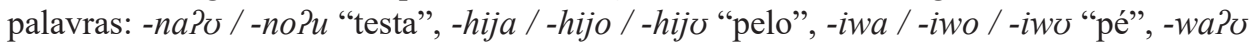
/ -wo?u "mão", -spana / -upono "fígado", etc. Na dialetologia mojeño moderna, por 


\section{RAMIREZ \& FRANCCA - LÍNGUAS ARAWAK DA BOLÍVIA}

exemplo, os próprios falantes estão bem conscientes dessa variação quando dizem: "eu falo $\boldsymbol{O}$, mas ele fala $\boldsymbol{A}$ ".

Essa variação é o produto de uma mudança diacrônica extremamente recente: *a > o/ช (o em certos dialetos mojeño e em tereno, $\boldsymbol{\sigma}$ em baure e em pauna), cuja direção pode ser facilmente rastreada em três caminhos inteiramente independentes:

- na adoção de palavras castelhanas;

- na comparação entre o mojeño, o baure e o tereno do século XVIII com as línguas de hoje;

- e na comparativa com as outras línguas da família arawak.

(1) A apresentação de alguns empréstimos é mais do que suficiente para mostrar a direção da mudança. Parece que não há palavras adotadas em que uma vogal $\underline{\mathbf{0}}$ teria

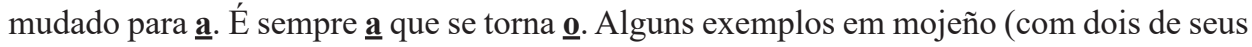
atuais dialetos: o ignaciano e o trinitario) e em baure:

- caballo [kaßáKo] “cavalo”> kawájo (ignaciano), kwóju (trinitario), kowoj (baure)

uanana "marreca-uanana (pato)"> wanána (ignaciano), wnóno / unóno (trinitario), wonon (baure)

matico "corrupião (pássaro)" > matíku (ignaciano/trinitario), motik (baure)

guarayo "índio selvagem"> warájo (ignaciano), woroj (baure)

piraquina "embira"> prókno (trinitario)

papaya "mamão"> apápa-hi (ignaciano), póp-hi (trinitario)

camisa "camísa" > kamísa (ignaciano), komis (baure)

- camba "habitante das Terras Baixas da Bolívia" > kampv (baure), zapato "sapato"> sopvt (baure), escalera

"escada" > [arv-]skorer (baure), lámpada "lâmpada" > lampor (baure), hacha "machado" > rafók (baure), vaca "vaca" > waku-pi "chicote de vaca" (baure), maestro "mestre" > moestor (baure), Isabel "Isabel" >

Sower (baure), pícaro "malandro"> pikwr (baure), etc.

Como se vê, a mudança $\mathbf{a}>\mathbf{o}$ aparentemente não se fez nos termos adotados em ignaciano (e em loretano), enquanto ela é muito mais frequente em trinitario (e em javeriano). Quanto ao baure, a mudança $\mathbf{a}>\boldsymbol{\sigma}$ foi quase frenética e bem maior do que ocorreu com o trinitario ou o javeriano, e a isso se juntou um enorme desgaste vocálico. Diferentemente do mojeño, nenhum dialeto baure atual conservou tantos $\underline{\mathbf{a}}$ como, por exemplo, o dialeto ignaciano dentro do mojeño.

Os empréstimos tereno ao português são geralmente mais recentes. Por exemplo: carreta $>$ koreta, canário $>$ konehie, etc.

(2) Podemos também comparar o mojeño, o baure e o tereno do século XVIII com as línguas de hoje. Comparando o mojeño de Marbán (M), do fim do século XVII, com um de seus dois descendentes diretos, o trinitário $(\mathrm{T})$, vê-se imediatamente a mudança *a $>\mathbf{0}$ durante esses últimos séculos. Alguns exemplos no vocabulário básico: 


\begin{tabular}{|c|c|}
\hline$-n \underline{a} ? u(\mathrm{M})>-n \underline{o} ? u(\mathrm{~T})$ "testa" & -king $(\mathrm{M})>$-çino $(\mathrm{T})$ "orelha" \\
\hline -t eja $\underline{a}(\mathrm{M})>-t \int e j \underline{j}$ (T) "lábio" & $-s \underline{a} k \underline{a}(\mathrm{M})>-s \underline{o} k \underline{o}(\mathrm{~T})$ "defecar" \\
\hline$-j-\underline{a} k i(\mathrm{M})>-j-\underline{o} k i(\mathrm{~T})$ "pênis" & $\underline{a} t f u(\mathrm{M})>\underline{o} t / \rho^{-}-(\mathrm{T})$ "avô" \\
\hline -etfáwi $(\mathrm{M})>-\dot{e} t \int \underline{\rho} w i(\mathrm{~T})$ "irmão" & kajure $(\mathrm{M})>$ kój(u)re $(\mathrm{T})$ "ave" \\
\hline are / ope $(\mathrm{M})>$ ope $(\mathrm{T})$ "arco-íris" & kahakure $(\mathrm{M})>$ khókre $(\mathrm{T})$ "rio" \\
\hline kakiure $(\mathrm{M})>$ koçiúre $(\mathrm{T})$ "lago" & tatfat $\int \underline{a} k u(\mathrm{M})>\operatorname{tat} \int \underline{o} t \int \underline{\rho} k u(\mathrm{~T})$ "beira" \\
\hline jati $(\mathrm{M})>$ joti $(\mathrm{T})$ "noite" & -kasara $(\mathrm{M})>$-kosara $(\mathrm{T})$ "frio" \\
\hline$-h a p u(\mathrm{M})>-h o p u(\mathrm{~T})$ "branco" & -kạtsi (M) > -kótsi (T) "azedo" \\
\hline$-k \underline{a}-t i(\mathrm{M})>-k \underline{\underline{o}}-t i(\mathrm{~T})$ “doer” & etfa-si $(\mathrm{M})>P t f \underline{\rho}-s i(\mathrm{~T})$ "velho" \\
\hline$-\underline{a} P u(\mathrm{M})>-\underline{o} P u(\mathrm{~T})$ “voz" & - $\underline{a} t \int a u-(\mathrm{M})>-\underline{o} t f u-(\mathrm{T})$ "soprar" \\
\hline$-k u t f \underline{a}-(\mathrm{M})>-k u t f \underline{o}-(\mathrm{T})$ "esperar" & -naru $(\mathrm{M})>-n \underline{o} r u(\mathrm{~T})$ "cerca" \\
\hline na $(u)$ rope $(\mathrm{M})>$ noope $(\mathrm{T})$ "remo" & $\operatorname{pira} \underline{k} i(\mathrm{M})>\operatorname{proçi}(\mathrm{T})$ "vassoura" \\
\hline pari $(\mathrm{M})>\operatorname{pori}(\mathrm{T})$ "jiboia" & $\operatorname{amat} \underline{a}(\mathrm{M})>$ mátfó $(\mathrm{T})$ "vespa" \\
\hline$k i j \underline{a}(\mathrm{M})>c ̧ i j \underline{j}(\mathrm{~T})$ "caracol" & $k \underline{a} t / i(\mathrm{M})>$ kót $f /(\mathrm{T})$ "certa palmeira" \\
\hline kurina $(\mathrm{M})>$ krino $(\mathrm{T})$ "flecha" & hajuno $(\mathrm{M})>$ hojno $(\mathrm{T})$ "ambaúba" \\
\hline
\end{tabular}

Mesma coisa pode ser diacronicamente observada com o baure: $*_{\mathbf{a}}>\boldsymbol{\boldsymbol { \sigma }}$. Por exemplo, compare arama "chefe" (1749) > ramo (1877) > rom (baure atual), ou a gênese do empréstimo caballo $>$ kawaju (1749) $>$ kowoj (baure atual). As formas de 1749 são tiradas do padre Magio (Adam e Leclerc 1880) e a forma de 1877 é de Fonseca (1986(2): 238). Outros exemplos baure de 1749 comparados com as formas atuais:

\begin{tabular}{|c|c|}
\hline -ane (1749) > -vne- "estômago" & ehira $(1749)>$ hira/hirv "homem" \\
\hline jatvi (1749) > jotve- "noite" & mara- $(1749)>$ morv- "seco" \\
\hline -katiße (1749) >-kotiße "doer" & -t fanese (1749) > -t/ones "coxa" \\
\hline -pa?e (1749) > -pvie "cabeça" & -tfaka (1749) >-t/vkv "orelha" \\
\hline
\end{tabular}

O vocabulário "guaná" cuidadosamente recolhido em 1793 por Aguirre (1898), provavelmente elaborado por missionários, mostra claramente que a mudança *a $>\mathbf{0}$ estava então em andamento em tereno. Compare Aguirre (A) com o tereno atual (T):

\begin{tabular}{|ll|}
\hline pake?e $(\mathrm{A})>$ poke?e $(\mathrm{T})$ "terra" & mapai $(\mathrm{A})>$ mopoi $(\mathrm{T})$ "pedra" \\
aka $(\mathrm{A})>$ ako $(\mathrm{T})$ "não" & hajjena $(\mathrm{A})>$ hojeno $(\mathrm{T})$ "homem" \\
saena $(\mathrm{A})>\operatorname{seno}(\mathrm{T})$ "mulher" & newa $(\mathrm{A})>$ newo $(\mathrm{T})$ "sobrinho" \\
jeka-ti $(\mathrm{A})>$ jeko-ti $(\mathrm{T})$ "velho" & Aawenoena $(\mathrm{A})>$ howenoeno $(\mathrm{T})$ "velha" \\
pahh $-(\mathrm{A})>$ pohha $(\mathrm{T})$ "um" & akawa-ti $(\mathrm{A})>$ okowo $(\mathrm{T})$ "alma" \\
inikane $(\mathrm{A})>$ inikone $(\mathrm{T})$ "amigo" & nane $(\mathrm{A})>$ none $(\mathrm{T})$ "rosto" \\
aje- $(\mathrm{A})>$ oje- $(\mathrm{T})$ "cozinhar" & akawa $(\mathrm{A})>($ o $)$ kowo $(\mathrm{T})$ "rosto" \\
\hline
\end{tabular}

A mudança *a > $\mathbf{o}$ também se vê um pouco no "guaná-layaná" de Fonseca coletado em 1875 (1986(1): 327-331) e no "guaná" de Castelnau (1851: 274-276). Note também que, apesar de bem fazer a diferença entre $\underline{\mathbf{0}}$ e $\underline{\mathbf{u}}$ nas outras línguas que ele descreve, o vocabulário guaná de Aguirre quase nunca usa a vogal ụ para o guaná, mas escreve quase todas as palavras com ‥ Por exemplo: wanokee "céu", onne "água", yoco "fogo", aronoe 
"moça", que podemos comparar com o tereno atual: wanú-ke "céu", une "água", joku / juku "fogo", arunoe "moça". Isso poderia sugerir que o sistemo vocálico do guaná-tereno, na época de Aguirre, ainda estava com quatro vogais $(\mathbf{a}, \mathbf{e}, \mathbf{i}, \boldsymbol{\mho})$ e/ou começava a mudar para um sistema de cinco vogais $(\mathbf{a}, \mathbf{e}, \mathbf{i}, \mathbf{o}, \mathbf{u})$.

(3) Enfim, a mudança *a $>\mathbf{o} / \mathbf{u}$ é comprovada por toda a comparativa arawak, e é assim que, há mais de 20 anos, Payne (1991: 472) já tinha observado que o dialeto ignaciano do mojeño tinha conservado a vogal *a do protoarawak melhor que as outras línguas do subgrupo Bolívia. Alguns exemplos (o traço oblíquo separa formas diferentes de dialetos atuais da mesma língua):

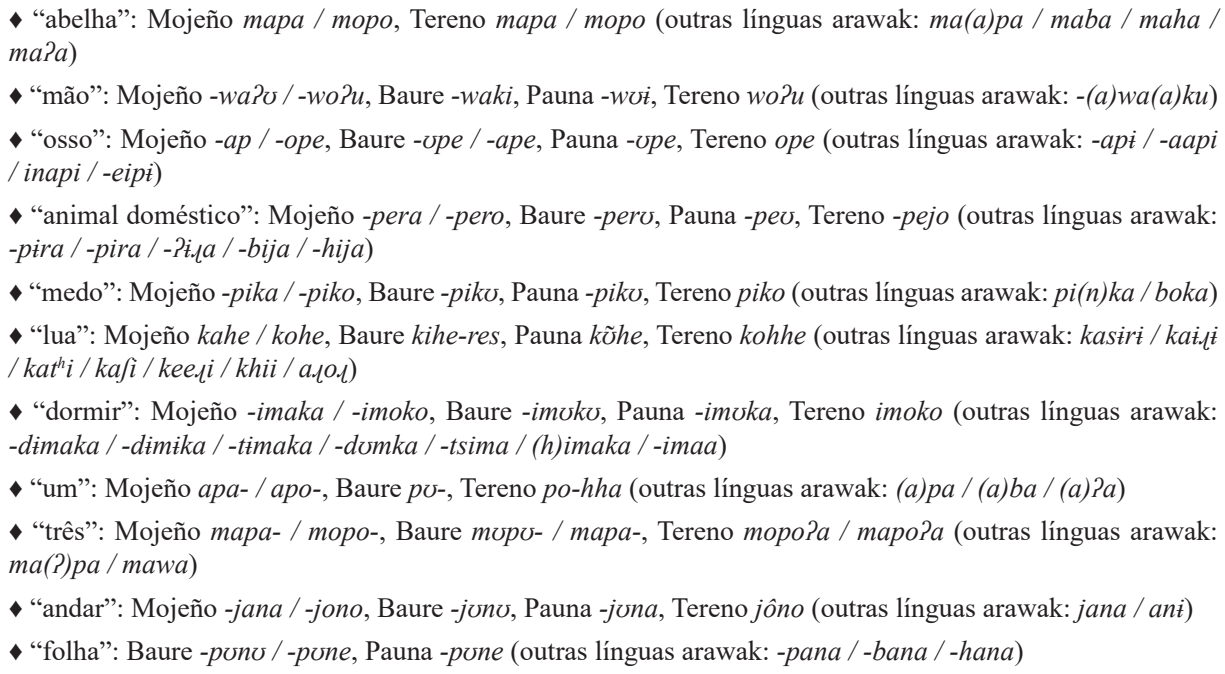

Para determinar a direção da mudança a / o, Payne aplica a "lei da maioria", regra que nem sempre é recomendada. No entanto, neste caso específico, a regra parece segura: com a suposta mudança oposta $(\mathbf{0}>\mathbf{a})$, ninguém poderia explicar por que TODAS as outras subfamílias arawak teriam realizado essa pretensa mudança.

Payne (1991: 472) procura também o contexto condicionante dessa deriva vocálica, mas sem grande sucesso: na realidade, parece que a mudança $\mathbf{a}>\mathbf{0} / \boldsymbol{\mho}$ praticamente pode afetar qualquer a no subgrupo Bolívia, independentemente do acento, das consoantes ou das vogais adjacentes. Além disso, muitos a não são atingidos, e o ignaciano, embora conservador, também pode sofrer o processo. Em resumo, nesta deriva vocálica, cada palavra tem sua história. Voltaremos ao assunto.

No entanto, o que Payne não percebeu é que esta mudança vocálica *a $>\mathbf{0} / \boldsymbol{\mho}$ era apenas a ponta de um iceberg que escondia duas enormes derivas vocálicas (mudanças em cadeia) e que redefinia TODAs as protovogais do arawak. Essas derivas vocálicas constituem a própria essência do subgrupo Bolívia. Podemos representá-las pelo seguinte esquema, com um diagrama levemente simplificado: 


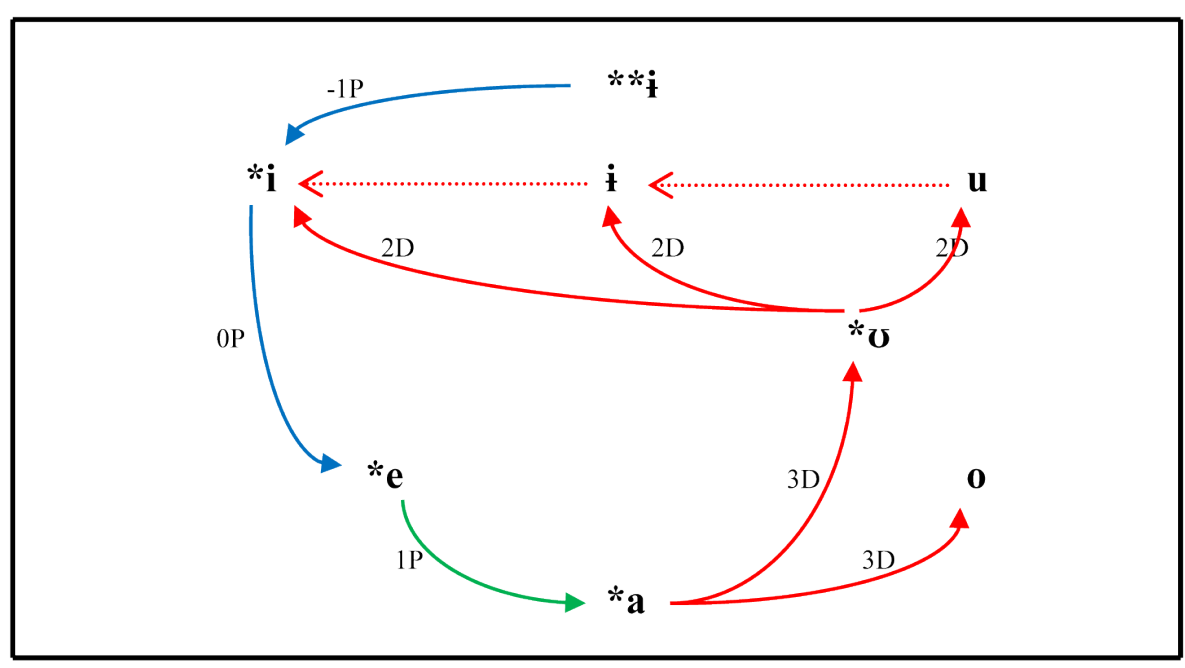

DRIFTS VOCÁLICOS DO SUBGRUPO BOLÍVIA

$\mathbf{P}$ (Push Chain) cadeia de propulsão (escape à superlotação)

D (Drag Chain) cadeia de tração (tendência à simetria)

Isso significa que a mudança *a > o/ $\mathbf{\mho}$ é o efeito de uma cadeia de tração (drag chain): em mojeño e em tereno, o levantamento de $\underline{\mathbf{v}}$ para a posição cardinal $[\mathrm{u}]$ força ou, melhor dito, favorece o levantamento de a para a posição cardinal [o], a fim de preencher a lacuna deixada na posição de $\underline{\boldsymbol{\Xi}}$, i.e. $\boldsymbol{*}_{\boldsymbol{U}}>\mathbf{u} \Rightarrow *_{\mathbf{a}}>\mathbf{0}$. Em baure e em pauna, o levantamento de $\underline{\underline{\mathbf{v}}}$, respectivamente para as posições cardinais [i] e [i], favorece o levantamento de a para a posição $[\mho]$ a fim de preencher a lacuna deixada na posição de $\underline{\boldsymbol{v}}$, i.e. $\underline{*_{\boldsymbol{U}}>\mathbf{i} \Rightarrow *_{\mathbf{a}}>\boldsymbol{U}}$ (baure), $\stackrel{*_{\boldsymbol{v}}>\mathbf{i}}{\Rightarrow} \Rightarrow *_{\mathbf{a}}>\boldsymbol{v}$ (pauna).

- O subgrupo Bolívia tinha assim quatro protovogais (*i, *e, *a, * $\boldsymbol{w})$, que foram submetidas a um conjunto de mudanças em cadeia, com a seguinte ordem diacrônica:

$$
* \mathbf{i} \stackrel{(0)}{>} * \underset{(0) \text { antes de (1) antes de (2) antes de (3) }}{\mathbf{e}} \underset{\mathbf{( 1 )}}{>} * \underset{(2)}{>} \mathbf{i} / \mathbf{i} / \mathbf{u} ; * \mathbf{a})
$$

Neste trabalho, suporemos que a regra $* \mathbf{i}>* \mathbf{i}(-1 \mathrm{P})$ é anterior ao protoboliviano: a fusão do protofonema arawak $* \mathbf{i}$ com o protofonema $* \mathbf{i}$ teria ocorrido em um estágio anterior ao protoboliviano. Como argumento decisivo, os $\underline{\underline{\dot{t}}}$ de todas as outras línguas arawak tornaram-se $\mathbf{i}$, ou e com a deriva (0), nos reflexos do subgrupo Bolívia (como exemplos, cf. "osso", "animal doméstico", "lua", "dormir" no quadro anterior). Note que o fonema $\underline{\dot{i}}$ da língua pauna é reflexo do protoboliviano * $\boldsymbol{\mho}$ e do protoarawak * $\boldsymbol{\sigma}$, como resultado da deriva (2). 
A fim de ajudar o leitor a entender essas mudanças complexas, damos a seguir alguns exemplos da correspondência $\boldsymbol{\sigma} / \mathbf{i} / \mathbf{i} / \mathbf{u}$ :

$\boldsymbol{\sigma}[$ mojeño: ignaciano] / $\mathbf{u}[$ mojeño: trinitario] / i [baure $/ \mathbf{i}[$ pauna $] / \mathbf{u}[$ tereno $]$

Nos exemplos, as formas protoarawak que aparecem entre parênteses são apenas sugestivas e constata-se também algumas mudanças consonânticas, como a palatalização de *k antes de *i/e (mas não em tereno), assim como, em contexto intervocálico, a perda de *r ou a lenição de *k em $\mathbf{P}(>\boldsymbol{\varnothing})$ :

• *oni / *one “água” (<*(h) onì): Mojeño (ignaciano) one, Mojeño (trinitario) une, Baure ine, Pauna ine, Tereno une

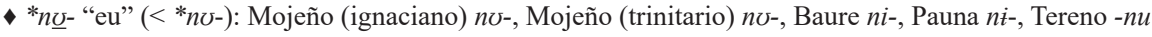

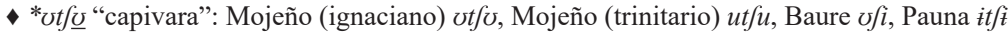

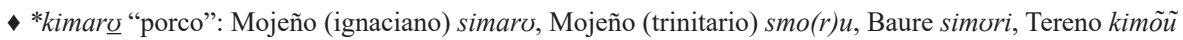

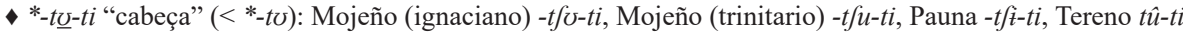

* *wakw “mão" (<*-wakv): Mojeño (ignaciano) -wa?v, Mojeño (trinitario) -w(o)u, Baure -waki, Pauna -wot, Tereno wo? $u$

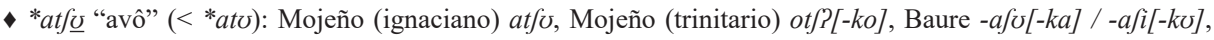
Pauna $\delta t f \hat{t}-k v$, Tereno $o f u$

- *-i-kw-ka/*-e-kv-ka "tio" (<*-i-kv-): Mojeño (ignaciano) -ekvka, Mojeño (trinitario) -(e)kuko, Baure -kikv, Pauna -kikw, Tereno e(?)uko

• *jvku "pau, fogo" (< *lvkv): Mojeño (ignaciano) jvkv, Mojeño (trinitario) juku, Baure jvki, Pauna jikt, Tereno juku

Sobre a mudança (1) *e > *a, cf. abaixo *kema "anta" e outros exemplos indicados na seção 6.1. Na realidade, os fatos não são sempre tão facilmente explicáveis como nos exemplos acima. Os conflitos criados pela interação dessas derivas vocálicas com certas palatalizações e a simplificação de certos ditongos deixam algumas reconstruções extremamente delicadas e complexas. Alguns exemplos:

(1) *kema "anta" (< *kema): Mojeño (ignaciano) sama, Mojeño (trinitario) samo, Baure somo, Pauna samo, Tereno kamo

(2) *-pira /*-pera "animal de criação" (<*_pira): Mojeño (ignaciano) -pera, Mojeño (trinitario) -pero, Baure -perv, Pauna -peø, Tereno -pêjo

(3) *-ki / *-kai "pau" (<*-ke): Mojeño (ignaciano) -ki, Mojeño (trinitario) -çi, Baure -si, Pauna -ke, Tereno -ke

(4) *koriki / *korikvi "amendoim" (<?): Mojeño (ignaciano) korike-re, Mojeño (trinitario) kriç(e)-re, Baure kiriki-ri, Pauna kïke, Tereno kurîke

Se admitimos que a palatalização de *k antes de *i/e precedeu as derivas vocálicas, o exemplo (1) parece não apresentar grandes problemas: 


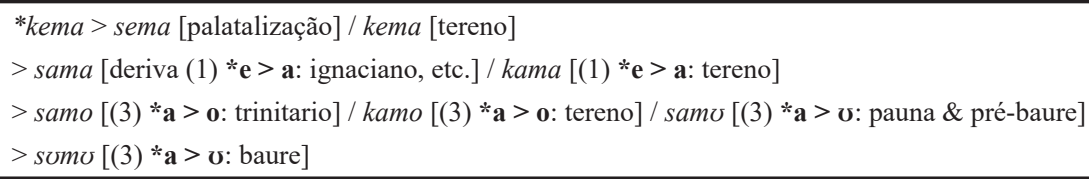

O exemplo (2) tenta responder às perguntas seguintes: "Quando a deriva (0) $* \mathbf{i}>\mathbf{e}$ ocorreu realmente? Antes do protoboliviano (i.e. em um estágio pré-boliviano) ou depois (i.e. durante o desenvolvimento dos reflexos do subgrupo Bolívia)? A protoforma seria *-pira ou *-pera?" Escolhendo a primeira protoforma, teríamos a seguinte ordem cronológica de mudanças diacrônicas:

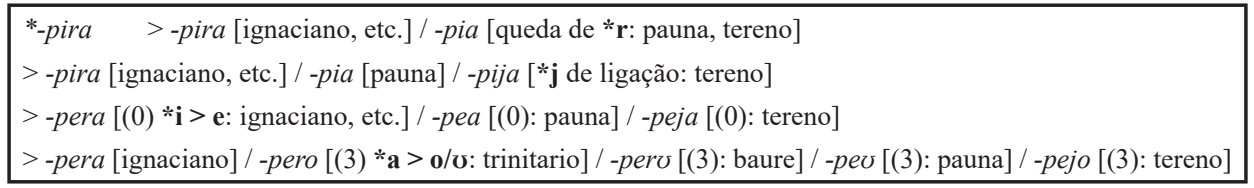

Admitindo que a queda de * $\mathbf{r}$ precedeu todas as derivas vocálicas, o que não é muito convincente, uma aproximante *j de ligação (*ia $>$ *ija) explicaria bastante bem a forma tereno atual. Escolhendo a segunda protoforma *-pera, teríamos mais dificuldade para justificar a presença da aproximante de ligação em tereno (*ea $>$ *eja). Sendo assim, a deriva $(0) * \mathbf{i}>\mathbf{e}$ parece ter ocorrido depois da formação do protoboliviano. Isso mostraria, por exemplo, que a forma reconstruída para "água", no penúltimo quadro, seria *oni e não *one. Como se vê, os argumentos são algo tênues e não totalmente convincentes, de forma que não temos certeza absoluta sobre a ordenação da deriva (0).

E que dizer dos exemplos (3) e (4)? Com as protoformas *-ki "sufixo: pau, árvore" e *koriki "amendoim", o mojeño -ki "pau", o baure kiriki- "amendoim" e outras formas não apresentam a palatalização de *k antes de *i. A introdução de um ditongo, como ai ou $\boldsymbol{0 i}$, daria protoformas como*-kai "pau", *korikai "amendoim", etc., que poderiam ajudar a resolver o problema. Quando tais ditongos são introduzidos exclusivamente para eliminar uma dificuldade e não são comprovados pela comparativa arawak, a forma reconstruída não tem um álibi sólido: ela pode ser simplesmente uma forma $a d$ hoc que não corresponde a nenhuma protoforma, como a suposta metátese amuesha que apresentamos na Enciclopédia das Linguas Arawak.

\section{O mojeño}

Nesta seção e nas três que seguem, apresentaremos brevemente os sistemas fonológicos e morfossintáticos das línguas achane. Essa apresentação será sempre precedida pela história dos contatos e pela desintegração dialetal devido a eles.

2.1. História e estudos linguísticos mojeño. Com mais de $3.300 \mathrm{~km}$ de extensão, o rio Madeira já tem uma descarga de $17.600 \mathrm{~m}^{3} / \mathrm{s}$ na junção de seus formadores: o Beni, o Madre de Dios, o Mamoré e o Guaporé-Itenes. Esses rios nascem nos Andes bolivianos ou peruanos, com a exceção do Guaporé-Itenes que nasce no Brasil. O Mamoré e o Itenes 


\section{RAMIREZ \& FRANCCA - LÍNGUAS ARAWAK DA BOLÍVIA}

drenam $567.860 \mathrm{~km}^{2}$, uma área duas vezes maior que a do Beni e do Madre de Dios. Quanto ao comprimento, é o rio San Miguel (1.200 km), afluente do Guaporé-Itenes, que ganha dos outros. Com o nome de Parapetí, o San Miguel nasce nos Andes perto de Pomabamba e dirige-se mais adiante para o norte. Segue seu curso no norte do Chaco e atravessa os banhados do Izozog. Desde esse ponto, segue sempre para o norte com o nome de Quimome, chamando-se sucessivamente San Miguel, San Julián, San Pablo, San Luís e Itonama, até desembocar no Guaporé-Itenes. Apesar de seu comprimento, em muitos trechos, o San Miguel é um rio estreito e quase sem água na época da estiagem. A paisagem que predomina no alto Madeira boliviano é extremamente diversificada. Ao sul da luxuriante floresta amazônica, os Pampas de Moxos formam grandes savanas, em parte alagadas na época das chuvas. Ao sueste, o vale do Madeira é delimitado pela flora de transição de Santa Cruz e da Chiquitania e pelas pastagens e desertos do Chaco.

As informações étnicas no alto Madeira são numerosas durante os séculos XVI e XVII. Do lado espanhol, a ocupação das cabeceiras do Madeira ocorreu bem cedo. Em 1537, os conquistadores fundam Assunção no rio Paraguai e procuram ouro por todos os lados. Em 1561, Nuflo de Chávez sobe o Paraguai e funda Santa Cruz la Vieja, perto de San José de Chiquitos, bem no sul da Chiquitania. Entre 1590 e 1622, Santa Cruz é transferida para o oeste: para o rio Grande, um formador do rio Mamoré, com o nome de San Lorenzo e, logo depois, para sua posição atual no rio Piray, um afluente do rio Grande. Do lado português, o avanço efetua-se mais lentamente pelo rio Amazonas e pelo Mato Grosso: o reconhecimento do Guaporé-Itenes começa apenas em 1740.

O mapa étnico do século XVI poderia mostrar uma certa deslocação dos povos arawak da Bolívia: em primeiro lugar, há mais de 1.000 anos, uma possível intrusão dos chiquito, vindos do leste ou do sul, que separou os pauna dos chané, e, em tempos mais recentes (séculos XV-XVI), uma invasão guarani vinda do leste (rio Paraguai), que aniquilou, assimilou ou deslocou certos grupos arawak, como os chané, os ancestrais dos atuais tereno.

- No fim do século XVI e no século XVII, os jesuítas fundaram duas províncias: uma nos Pampas de Moxos e outra na Chiquitania. Em 1586, os jesuítas do Alto Peru (Bolívia) chegaram a San Lorenzo (Santa Cruz) e logo começaram o estudo das línguas chané, guarani e gorgotoqui (chiquito?). A importância dos povos encontrados nesta região chegou a influenciar o castelhano falado hoje nas Terras Baixas da Bolívia: em particular, as línguas chané, guarani e, sobretudo, chiquito.

Sob o nome de morocosi ou mojo, os mojeño são mencionados pela primeira vez em 1595. Os morocosi subiam o Mamoré e o rio Grande até as imediações de San Lorenzo para trocar escravos e produtos amazônicos com os chané. Os jesuítas estabeleceram-se definitivamente com os morocosi a partir de 1675. O território mojeño e sua população exata são difíceis de definir com exatidão. De 6.000 a 10.000 mojeño viviam:

- em parte no rio Mamoré: da junção do Mamoré com o rio Grande ou Piray (os suberiano) até a junção do Mamoré com os rios Tijamuchí e Apere;

- e em parte nos pampas ocidentais, ao oeste do rio Mamoré, onde viviam os punuana e outros grupos mojeño numerosos. 
Parece que as diferenças dialetais entre os mojeño-morocosi eram poucas: conforme o padre Marbán (1898: 133), haveria vários dialetos compreensíveis uns com os outros, mas, na sua gramática, as diferenças dialetais não são explicitadamente repertoriadas. Marbán (1701: 35, 49, 363-364) nota que os mojeño usam às vezes "indiferentemente" a vogal $\mathbf{A}$ ou $\mathbf{O}$ no começo dos verbos (referência à deriva vocálica *a $>\mathbf{0}$ ), assim como algumas diferenças entre os "índios dos pampas" e "os índios do rio Mamoré". A oposição a / o (deriva vocálica *a > o) vê-se também claramente nos nomes dos grupos locais, como os suberi-ano do rio Mamoré e os numerosos punu-ana dos pampas ocidentais (note a terminação -ana ou -ano "plural").

Os conflitos entre aldeias mojeño eram constantes e não foi pouco o trabalho dos primeiros jesuítas para agregar mais de 70 pequenos povoados em quatro missões: em 1683, os jesuítas fundaram Loreto, perto da atual Camiaco, na margem do rio Mamoré (entre a foz do Sécure-Isiboro e do Chapare-Ichilo) com os moremono. No fim do século XVII, além de Loreto, havia mais cinco missões jesuítas onde se encontravam grupos mojeño: Trinidad (na margem do Mamoré, um pouco abaixo da balsa atual), San Ignacio (nos pampas ocidentais), San Francisco Javier (na margem ocidental do rio Mamoré), San José (entre San Ignácio e San Borja) e San Luis (ao norte de San Ignácio). Quase todas essas missões mudaram de lugar no século XVIII: Loreto, Trinidad e San Javier foram afastadas do Mamoré por serem suas enchentes incontroláveis e extremamente destrutivas, enquanto San José e San Luis desapareceram do mapa por causa de epidemias.

Os jesuítas aprenderam a língua mojeño e a fixaram por escrito no fim do século XVII. Para isso, adotaram a língua dos loretanos e trinitarios como base da língua mojeña que havia de superar a extrema fragmentação linguística das etnias locais (Barnadas e Plaza 2005: 49). O leitor achará mais detalhes em Chávez Suárez (1986: 189-246) e em Métraux (1942: 53-58). Sobre a localização dos grupos, cf. Métraux (1948a: 408) e Tormo (1972: 159). Sobre as dificuldades para reagrupar os grupos em grandes reduções, os conflitos gerados e o plano linguístico dos primeiros jesuítas, cf. Chávez Suárez (1986: 200-228). Depois da expulsão dos jesuítas (1767), as missões do Mamoré entraram em decadência e vários movimentos messiânicos surgiram (Métraux 1942: 58; Chávez Suárez 1986: 279499).

- Hoje, fala-se mojeño na região de Trinidad, Loreto, San Javier, em San Ignacio e ao sul deste povoado até o rio Isiboro. Linguisticamente muito próximos entre eles, como também provavelmente o eram no século XVII, os dialetos mojeño atuais têm todos a mesma gramática e o mesmo léxico, mas apresentam certas diferenças de ordem fonológica ou fonética que não impedem a intercompreensão. Um "trinitario" não tem dificuldade alguma para entender um "ignaciano", mesmo se não é tão evidente no sentido inverso, por causa do enorme desgaste fonético ocorrido no trinitario (e no javierano) durante os séculos XIX-XX. A situação da língua mojeño atual poderia ser comparada com a da língua portuguesa: enquanto todos os habitantes de Portugal entendem perfeitamente o que os brasileiros dizem, muitos brasileiros não conseguem entender a fala de Lisboa.

$\mathrm{Na}$ atualidade, parece haver 4.000-5.000 falantes "ignaciano", 3.000-3.500 falantes "trinitario", e alguns falantes e semifalantes "javeriano" e "loretano". 
- Além da pesquisa feita por um de nós sobre o trinitario do rio Isiboro e sobre o "loretano" (2006 -2012), usamos o seguinte material linguístico mojeño: a gramática e o excelente dicionário elaborado no fim do século XVII pelo padre Marbán (1701) com os ancestrais dos atuais loretanos e trinitários, as notas gramaticais e o dicionário de Ott e Ott (1983) [ignaciano], os estudos gramaticais e lexicais de Gill (1957, 1993) [trinitario], a enorme gramática de Olza Zubiri et al. (2004) [ignaciano] e a preciosa comparação dialetal de Becerra Casanovas (1980) [ignaciano, loretano, trinitario, javeriano], que inclui a gramática de Marbán em uma apresentação mais agradável, com certas páginas que, infelizmente, faltam na versão de Marbán disponível em PDF. ${ }^{2}$

2.2. Fonologia mojeño. Os quadros seguintes apresentam os fonemas mojeño. Note que há quatro fonemas vocálicos $(\mathbf{a}, \mathbf{e}, \mathbf{i}, \boldsymbol{\sigma})$ em ignaciano (I), enquanto o trinitario (T), o loretano $(\mathrm{L})$ e o javeriano $(\mathrm{J})$ têm cinco vogais $(\mathbf{a}, \mathbf{e}, \mathbf{i}, \mathbf{0}, \mathbf{u})$ :

MOJEÑO (Consoantes)

\begin{tabular}{|c|c|c|c|c|}
\hline $\mathbf{p}$ & $\mathbf{t}$ & & $\mathbf{k}$ & $\mathbf{P}$ \\
\hline & $\mathbf{t s}$ & $\mathbf{t} \boldsymbol{J}$ & & \\
\hline & $\mathbf{s}$ & $\mathbf{( J )}$ & & $\mathbf{h}$ \\
\hline $\mathbf{w}[\mathrm{w}, \beta]$ & $\mathbf{r}[\mathrm{r}]$ & $\mathbf{j}$ & & \\
\hline $\mathbf{m}$ & $\mathbf{n}$ & $\mathbf{( j )}$ & & \\
\hline
\end{tabular}

IGNACIANO (I)

\begin{tabular}{|c|c|c|}
\hline $\mathbf{i}$ & & $\boldsymbol{U}$ \\
\cline { 1 - 2 } $\mathbf{e}[\varepsilon, \mathrm{e}]$ & & {$[\mathrm{u}, \mathrm{w}, \mathrm{o}, \mathrm{v}]$} \\
\hline & $\mathbf{a}$ & \\
\hline
\end{tabular}

$\mathbf{T} / \mathbf{L} / \mathbf{J}$

\begin{tabular}{|c|l|l|}
\hline $\mathbf{i}$ & & $\mathbf{u}$ \\
\hline $\mathbf{e}[\varepsilon]$ & & $\mathbf{0}$ \\
\hline & $\mathbf{a}$ & \\
\hline
\end{tabular}

O fonema $\int$ do ignaciano é extremamente raro (alguns empréstimos, interjeições). $\mathrm{O}$ fonema $\mathbf{j}$ nasce frequentemente de uma palatalização de $\underline{\mathbf{n}}$ contíguo a $\underline{\mathbf{i}}$, como: -ine (I, T) "piolho" (compare com baure -ine "id."), anî? (I) > anî́? (T) "pernilongo", etc. Parece também que, às vezes, $\mathbf{j}>\mathbf{n}$, como $n \mho \dot{?} v(\mathrm{I})<$ ? jú? $i$ (T) "certo gavião". No entanto, essa palatalização já se encontrava em Marbán (1701): ni- "3msg”, -ine "piolho", ani?u "pernilongo", etc.

As principais diferenças fonéticas e fonológicas encontradas entre os dialetos mojeño podem ser resumidas no quadro seguinte:

\begin{tabular}{|l|c|c|c|c|}
\cline { 2 - 5 } \multicolumn{1}{c|}{} & IGNACIANO & LORETANO & TRINITARIO & JAVERIANO \\
\hline Palatalização de $\mathbf{k} /$ i,e & não & média & forte & fraca \\
\hline Síncope de $\mathbf{V}$ átona & nula & fraca & forte & forte \\
\hline Deriva vocálica: *a $>\mathbf{v / o}$ & leve & moderada & forte & forte \\
\hline
\end{tabular}

(1) A palatalização de $\underline{\mathbf{k}}$ antes de $\mathbf{i} / \mathbf{e}$ não ocorre em ignaciano, é fraca no mojeño de Marbán (1701) e em (J), e é forte em (T) (ki/ke > [çi]/[çe]), (L) ocupando uma posição intermediária. Por exemplo: $-k i$ [ki] (ignaciano) > [çi] (T) "árvore", kiha- [kiha]

${ }^{2}$ Neste artigo, as referências bibliográficas que se referem a estudos descritivos e lexicais não são exaustivas, pois a relevância de nosso trabalho é diacrônica. Além disso, há muitos trabalhos incipientes que são geralmente o fruto de uma pesquisa de poucas semanas ou de poucos meses, o que não é tempo suficiente para resolver certos problemas delicados. No caso do mojeño, falta-nos uma descrição sistemática do trinitário. 


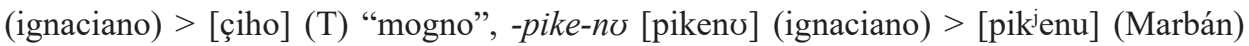
/ [piçenu] (T) "pescoço", -(i)kene [kene] (ignaciano) > [kjene] (Marbán) / [çene] (T) "nominalizador", koríkere [kuríkere] (ignaciano) > [kuríkjere] (Marbán) / [kríçiere] (L) / [kríçre] (T) "amendoim", atsíkerv [atsíkero] (ignaciano) > [?tsíçeru] (T) "joão-de-barro", waréke [waréke] (ignaciano) / [wréçe] (T) “cobra-cascável”, etc.

Da mesma forma $\mathbf{t i V} / \mathbf{t e V}\left[\mathrm{tiV}^{\mathrm{i} V} \sim[\mathrm{cV}]\right.$, pelo menos em $(\mathrm{T})$ e em registro coloquial.

(2) Com exceção do ignaciano e de (L), houve um grande desgaste vocálico desde Marbán (1701), época na qual o mojeño ainda tinha provavelmente seu padrão silábico original $(\mathbf{C}) \mathbf{V}$. De fato, $(\mathrm{T})$ e $(\mathrm{J})$ modernos suprimem geralmente as vogais átonas no interior da palavra (síncope) e, também nesses dialetos, o $\underline{\mathbf{r}}$ intervocálico pode cair. Exemplos de síncope em (T): koríkere (ignaciano) > [kríçre] (T) "amendoim", atsíkerv (ignaciano) $>$ [? ใ̂́íçeru $](\mathrm{T})$ "joão-de-barro", kaháwa (ignaciano) $>\left[\mathrm{k}^{\mathrm{h}} \mathrm{owo}\right](\mathrm{T})$ "veado", katfiru (ignaciano) $>$ [ktfíru] $(\mathrm{T})$ "formiga-de-fogo", pakớre (ignaciano) $>$ [pkúre] $(\mathrm{T})$ "canoa", -s-ámore (ignaciano) > [sámre] (T) "coração", -óki-?a (ignaciano) > [uç?a] (T) "olho", etc.

Nos casos em que a vogal inicial desaparece, aparece no seu lugar uma oclusão glotal: atfáne $\rightarrow$ Ptfáne "pessoa", itfini $\rightarrow$ Ptfini "onça", atíkure $\rightarrow$ Ptíkre "tamanduá", etc. Isso poderia mostrar que muitas palavras iniciando por vogal começariam na realidade por uma oclusão glotal, como o mostra o processo de possessão (em que geralmente nu- "1sg" $+\mathbf{- V} \rightarrow \mathbf{n V}$ ), por exemplo em: (?)úne "água" $\rightarrow$ nu-Púne-ra-ma "minha água", (P)ánu "ano" (< castelhano año) $\rightarrow$ nu-Pánu-ra "meus anos, minha idade", (P)épre "cipó" $\rightarrow$ nu-?épre-ra "meu cipó". Para outras interpretações, cf. Jolkesky (2016: 32).

(3) A deriva vocálica $* \mathbf{a}>\boldsymbol{\sigma} / \mathbf{o}$, desencadeada por $* \boldsymbol{v}>\mathbf{u}$ (cf. 1.3.). segue a escala seguinte: ignaciano $>(\mathbf{L})>(\mathbf{T}, \mathbf{J})$, i.e. de leve (ignaciano) a forte $(\mathrm{T}, \mathrm{J})$.

Tudo isso torna a reconstrução das vogais mojeño extremamente fácil. São "quase" iguais ao ignaciano: *i $>\mathbf{i}$ (ignaciano, $\mathrm{T}, \mathrm{L}, \mathrm{J}),{ }^{*} \mathbf{e}>\mathbf{e}$ (ignaciano, T, L, J), *a $>\mathbf{a} / \boldsymbol{\sigma} / \mathbf{0}$, $*^{\boldsymbol{U}}>\boldsymbol{\mho}$ (ignaciano) / u (T, L, J). São quase, mas não totalmente iguais às do ignaciano, porque, mesmo neste último dialeto, a deriva $* \mathbf{a}>\boldsymbol{v}$ ocorreu levemente. Por exemplo, compare: amója (ignaciano) / amója (T) "bebê", pớ?e (ignaciano) / pó?e (T, L, J) "preguiça (animal)", patứre (ignaciano) / patóre ( $\mathrm{T}, \mathrm{L}, \mathrm{J})$ "macaco-cuatá", onde temos a correspondência $\boldsymbol{\mho}$ (ignaciano) / o (T), e não a correspondência esperada: $\boldsymbol{\mho}$ (ignaciano) / u $(\mathrm{T}, \mathrm{L}, \mathrm{J})$. Isso evidencia as formas reconstruídas *ama-ja (cf. ama-perv "menino" e ama$k i$ "milho verde" em trinitario), *pa?e (cf. tasira-pa?e "tamanduá-colete" em trinitario) e *patáre. Nesses exemplos, não há nenhuma harmonia vocálica em jogo, já que temos também: pakứre (ignaciano) / p (a)kúre (T, L, J) "canoa", tfớje (ignaciano) / tfúje (T, L, J) "raposa", kájore (ignaciano) / kájure (T, L, J) "ave", etc.

Essa deriva *a $>\boldsymbol{\sigma}$ é tão leve em ignaciano que ela não permitiu, neste dialeto, a criação de uma oposição fonêmica entre o e $\underline{\mathbf{u}}$. Qual é o contexto fônico condicionante desta deriva *a $>\mathbf{0} / \boldsymbol{v}$ ? Parece que não há: essa deriva pode ou não afetar qualquer $\underline{\mathbf{a}}$, e cada palavra tem sua própria história (cf. 1.3.). Note que a vogal a resiste melhor à mudança vocálica em começo de palavra, principalmente em posição tônica; note também que ha é muito resistente à deriva (por exemplo: hane "vespa", -haka "boca" em todos os dialetos mojeño). 
- Acentuação: em ignaciano (e, provavelmente, nos outros dialetos mojeño), o acento primário recai na primeira sílaba de dissílabos e na segunda sílaba de polissílabos. A primeira vogal de uma raiz dependente é sempre tônica, como, por exemplo, em: -ápera "osso", -érena "garganta", -íteka "chegar", etc.

2.3. Aspectos gramaticais mojeño. O quadro seguinte apresenta os afixos pessoais do mojeño, assim como seus pessoais independentes e seus artigos. Daqui em diante, as formas são em dialeto ignaciano, o trinitario (T) e Marbán (*) aparecendo somente quando necessário:

\begin{tabular}{|c|c|c|c|}
\hline & $\begin{array}{l}\text { Pessoais Independentes } \\
\text { \& Artigo Definido }\end{array}$ & $\begin{array}{c}\text { Possuidor, } \\
\text { Sujeito de v.(in)tr. }\end{array}$ & $\begin{array}{l}\text { Sujeito de v.estativo, } \\
\text { Objeto de v.tr. }\end{array}$ \\
\hline $1 \mathrm{sg}$ & nóti / núti (T) eu & $\mathbf{n}(\boldsymbol{\theta})-/ \mathbf{n}(\mathbf{u})-(\mathbf{T})$ & -nv / -nu (T) \\
\hline $2 \mathrm{sg}$ & píti $t u$ & p(i)- & -wi \\
\hline $3 \mathrm{fsg}$ & éso / ésu (T) ela / a & so- / s(u)- (T) & eso \\
\hline $3 \mathrm{msg}$ ( $(\widehat{\text { falando) }}$ & éma / éma (T) ele / o & ma- / ma- (T) & ema / ema (T) \\
\hline $3 \mathrm{msg}$ ( $(9$ falando) & éni / éni (T) / *ini ele / o & n(i)- & eni \\
\hline 3não-humano & $\begin{array}{l}\text { éta / eto (T) ele (a) / o (a), } \\
\text { eta...-ana os }(a s)\end{array}$ & $\begin{array}{l}\text { ta- / to- }(\mathrm{T}) / * \text { ta- } / * \text { to- }(\mathrm{sg}), \\
\text { ta-...-ana }(\mathrm{pl})\end{array}$ & eta \\
\hline $1 \mathrm{pl}$ & wíti nós & w(i)- & -Pawi / -Powi (T) / *-awi \\
\hline $2 \mathrm{pl}$ & éti vós & e- / a- (T) / *e- & $-2 e$ \\
\hline 3pl.humano & $\begin{array}{l}\text { éna / eno (T) eles(as), } \\
\text { ena...-ana / os(as) }\end{array}$ & na- & ena \\
\hline $\begin{array}{l}3 \text { não-específico } \\
\text { (somente com } \\
\text { verbos) }\end{array}$ & --- & t(i)- (sg), ti-...-ana (pl) & 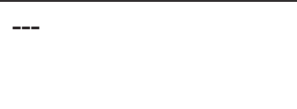 \\
\hline
\end{tabular}

Note a originalidade da terceira pessoa mojeño em relação a todas as outras línguas arawak: há formas diferentes que ocorrem para o masculino singular (homem ou mulher falando), o feminino singular, o não-humano e o plural-humano. Sobre o uso especial do marcador pessoal $t i-$, cf. Olza Zubiri et al. (2004: 481-533).

Os alomorfes dos prefixos pessoais são: $n u-\sim n$ - (antes de qualquer vogal ), $p i-/ n i$ - / $w i-/ t i-\sim p-/ n-/ w-/ t$ - (antes de i ou e), na-/ma-/ta- $\sim n-/ m-/ t$ - (antes de a).

A seguir, alguns elementos gramaticais mojeño: 
- A marca do plural é: -ana / -na [depois de a: i.e. fusão a+a] ou -ono [depois de i/e/u] / -no [depois de a/o] (T). Exemplos em (T): ráta-no "lata-s", jóna-no "surubin-s", sámo-no "anta-s".

- Como sufixos independentizadores: -ti, -re (por exemplo: -jawa "machado de" $\rightarrow$ jawa-ti "machado"), e como sufixos dependentizadores: - ra / -ra (T), -ne (por exemplo: sipáni "milho" $\rightarrow$-sípani-ra "milho de"). O nome -je?e "pertences" serve para formar a possessão, como em: nv-je?e reló "meu relógio".

- Alguns afixos nominais: -tfitfa / -t fitfa (T) + -tsitsa + çira (T) "diminutivos", -tatahi / -t(á)tahi (T) "depreciativo1", -(i)nawahi / -Pohnihi "depreciativo2", -hiwa "mesmo", -t/v / -t fu (T) "somente", si- / si- (T) "intensificador".

\section{- A ordem básica é: VSO.}

- Os demonstrativos dividem o espaço em três zonas: - $k a /$ *-ka "1a zona (este)", -ra / *-ro "2a zona (esse)", -(e)na / *-ena " 3 a zona (aquele)". Os advérbios demonstrativos são: áni / óni (T) / *ani "aqui", ánaki / onoki (T) / *anaki "aí", ára / oro (T) "ali".

- O advérbio $t e+/ t e+(T)$ [não-humano] / se+ [humano.fsg] / me+ [humano.msg] / ne+ [humano.msg]/ne+ [humano.pl] "em, para, desde, por" usa-se como preposição universal. Exemplo: te mesa "na mesa", te vne "na água".

• Interrogativos: táha-?a / taha (T) “o quê?”, náha-?a / naha (T) “quem?”, ája- / oi-na (T) / *aja- "quanto?”, táwi-?a "onde?".

- Os classificadores/qualificadores são morfemas incorporados nos adjetivos, numerais ou verbos como sufixos (incorporação nominal), que são marcas de concordância com o sujeito (adjetivos e verbos intransitivos) ou com o objeto (verbos transitivos). As partes do corpo podem também ser incorporadas. Alguns classificadores: -ama / -omo (T) "líquido", -e / -e (T) "água (lago)", -(?)a /-?o (T) "corpo, redondo, feixe", -?e "caixa, barriga, saco, tubérculo", $-2 i$ / - $2 i(T)$ "arredondado (ave, cabaça, cântaro, fruta)", $-h i$ / -hi (T) "montão, coletivo", $-k i$ / -çi $(T) / *-k i+-k e$ "árvore, dedo, perna, semente", -kv/ -ku (T) "côncavo (oco, cavidade)", -tfe / -t fe-po (T) "superfície plana perpendicular (parede, etc.)", -me / -me (T) "pele, papel", -na "genérico", -ne "banana", -pa1 / -pa (T) "pó", -pa2 "objeto alongado (agulha, tábua)", -pa(P)i /-pai (T) "piso, chão", -pe "lâmina (remo, terçado, moeda)", -pi / -pi (T) "filiforme (fio, cobra)", -pv(?)i "bola, ovo", -se / -se (T) "pena", -si / -si (T) "esférico e convexo (cabeça, fruta)".

- Sufixos temáticos verbais: $-k a /-k o(T),-t f a /-t f o(T),-2 a /-20(T)$ ou -Ø. Marbán (1701: 29) explica que os sufixos temáticos -ko e -?o tornam-se -ka e -?a com certos sufixos. Por exemplo: nu-ni-ko-po "já comi" (pretérito), mas: $n u-n i-k a-r i$ "estou comendo" (progressivo, atual), nu-ni-ka-ri-po "tinha comido", etc.

- Prefixos verbais: $k a-/ k o-(T) / * k a-/ * k o-$ "positivo", ma- / mo- (T) "negativo", imi- / imi- (T) "causativo1", $e-/ e-(T)$ "causativo2", $k a-/ k a-(T)$ "causativo3", $a ́-/ a-(T) / * A$ - [o > a, cf. 1.2.] "futuro, subjuntivo, optativo, imperativo, condicional (se, quando)".

- Sufixos verbais: -wa / -wo "reflexivo", -kaka /-koko (T) "recíproco", -kasi / -ka...si (T) + -hi "voz passiva", -ina /-ino (T) "benefactivo",;,; -ja(re) /-jore (T) / *-jare "futuro1", -pvka /-puka (T) "futuro2", -(i)ni /-ini (T) "passado, ex-", -pa / -po (T) "puntual, passado (já)", -Pi / -(re)?i (T) / -ri?-i (T) + -pai "factual, progressivo", $-r a /$-ra (T) "frequentativo (repetição, costume)", -ne "intensificador (somente, pois)", -tfa?a / -tfo?o (T) "ainda", -waka "a cada um”, ;, -hi /-hi (T) "reportativo", -Pini /-Pini (T) "frustrativo", -ra /-ro-je (T) "tomara que...", -sesi / -esi (T) "desiderativo".

- Nominalizadores: -ira / -ira $(T)+$-ija / -ija $(T)+$-ipa + -ine "relativizadores", -rerv "oriundo de", -ro /-ru $(T)+$-re /-re $(T)+$-kare /-kore $(T)+$-kene / -çene $(T) / *$-kiene + -wa / -wo $(T)+$-sa(re) / -sa (T) "nominalizadores". Muitos verbos estativos (adjetivos) aparecem com o prefixo $t i-$.

\section{O baure}

3.1. História, dialetologia e estudos linguísticos baure. As primeiras notícias sobre os baure (maure, bauro) aparecem em 1560, logo depois da fundação de Santa Cruz la Vieja (Combès 2010: 194). Os baure viviam entre os baixos rio Blanco e San Martín, afluentes 


\section{RAMIREZ \& FRANCCA - LÍNGUAS ARAWAK DA BoLÍvia}

do Guaporé-Itenes. Depois das primeiras missões com os mojeño, os jesuítas planejaram reduzir os baure por serem eles, como dizia o padre Marbán em 1700, “os mais dóceis e racionais, em que até as crianças andam vestidos" (Barnadas e Plaza 2005: 65). O padre Cipriano Barace visitou os guarayos (sirionó), os tapacuras e os pacíficos baures a partir de 1693. Os baure tinham povoados maiores e mais organizados que os dos mojeño-morocosi, com ruas e praças. Viajando naquela região durante dois anos, Barace encontrou muitos povoados baure. O padre Eguiluz fala de 65 aldeias baure (Eguiluz 1696: 24). Altamirano (1979: 117) fala de 40.000 baure, mas o mesmo autor indica somente 30.000 índios para toda a província de Mojos em 1713, este último número parecendo bastante correto (Barnadas e Plaza 2005: 71). Portanto, o número baure indicado por Altamirano deve ser exagerado: a população baure total oscilava provavelmente entre 6.000 e 10.000 pessoas.

Em 1702, os "dóceis e pacíficos" baure acabaram matando o padre Barace (Chávez Suárez 1986: 236-240). Com os baure, os padres jesuítas tiveram ainda mais dificuldades que com os mojeño em convencê-los a deixar os conflitos violentos que entre eles existiam e a reagrupar seus povoadinhos em reduções grandes. As missões baure criadas pelos padres foram: Concepción de Mojos (Concepción de Baures) em 1708, San Joaquín em 1709 (20 km ao norte de Concepción de Baures), San Martín nos anos 1713-1717 (no rio San Martín, perto de sua confluência com o rio Blanco), San Nicolás em 1740 (no rio San Martín acima, perto do atual Puerto Saucedo) e Santos Simón y Judas em 1744 (abaixo de San Nicolás). As missões de San Martín, San Nicolás e Santos Simón y Judas tiveram uma existência efêmera e deixaram de existir entre 1770 e 1775. Em 1794, por razões pouco claras (presença perigosa dos portugueses que ocupavam o Guaporé-Itenes, doenças, brigas), o governo obrigou os baure de San Joaquín a mudar-se para o seu lugar atual, no rio Machupo, a mais de $150 \mathrm{~km}$ de seu lugar original. Ajudados por seus parentes de Concepción de Baures, os joaquinianos deixaram para sempre o território tradicional baure. O leitor achará muito mais detalhes em Chávez Suárez (1986: 261-271).

Visitando Concepción de Baures em 1832, Orbigny (2002[4]: 1438) notou que os baure estavam divididos em um certo número de seções, bairros ou "parcialidades", que deviam corresponder às várias aldeias da época pré-jesuítica. Ele repertoriou 20 dessas "parcialidades" ou "tribos", como os abeabanos, os muchojeonos, etc.

Em 1793-1794, o governador Zamora fundou Nuestra Señora del Carmen de Mojos (ou de Guarayos), com 314 baure de Concepción de Baures, que subiram o rio Blanco e misturaram-se com 200 "guarayos" ou "tapacura" (família chapacura) na margem do rio Blanco, no lugar Marquiriqui, 12 léguas rio acima da posição atual. As pragas e as doenças fizeram que, a partir de 1801, o povoado baixasse para sua posição atual. A partir de 1799, os habitantes de El Carmen eram conhecidos como carmelitas. Em 1801, havia 514 habitantes em El Carmen (314 baure + 200 chapacura) e, em 1830, 932 habitantes (Chávez Suárez 1986: 439-441). Em 1832, Orbigny (2002[4]: 1431) visitou El Carmen e notou que os índios chamados de "chapacura" pelos administradores do povoado pertenciam por sua língua à mesma nação que os quitemoca (família chapacura), já missionada em parte pelos jesuítas em Concepción de Chiquitos. Havia então 897 habitantes em El Carmen, pertencendo às duas nações quitemoca e baure. Desses últimos (os baure), Orbigny afirma que a tribo dos muchojeono falava um dialeto "um tanto diferente" dos baure de Concepción, que por sua vez "não eram mais que uma tribo da grande nação dos 
moxos", i.e. que os baure e os mojeño eram aparentados, formando a família que Orbigny chamava de "moxos" e que hoje é conhecida como "arawak". Somando tudo, Orbigny achou em El Carmen 362 baure, 320 muchojeono e 215 quitemoca (=897). Tudo isso não está muito claro e até algo incompreensível: já vimos que Zamora trouxe 314 baure que vinham de Concepción de Baures e não mencionou os muchojeono que, como já vimos, eram também baure de Concepción de Baures. De onde então vieram os 320 muchojeono suplementares de Orbigny?

Métraux (1948a: 409) mostra que não entendeu Orbigny ou não soube ler: quando este último disse que os muchojeono eram "moxos", Métraux entende que os muchojeono eram uma subtribo dos mojeño, enquanto Orbigny simplesmente queria dizer que os muchojeono pertenciam ao mesmo grupo linguístico arawak que os mojeño e os baure. Em outro estudo, Orbigny (1944: 344-350) deixa bem claro que, dentro de sua família "moxos" (i.e. arawak), o baure e o mucheojono formam um subgrupo estreitamente ligado, o que é bem diferente do mojeño. O leitor poderá consultar a Enciclopédia das Linguas Arawak para testar esta estreita relação muchojeono-baure.

\section{O muchojeono: uma bola de neve}

Orbigny deixou bem claro que o muchojeono é um dialeto da língua baure, e não da língua mojeño. Aliás, tirando erros evidentes, como pihirika "deite-se!" em vez de "sente-se!", esse dialeto muchojeono, que Orbigny qualifica de "um tanto diferente" do baure, parece, até para um leigo, apresentar pouca ou nenhuma diferença com o baure de Concepción de Baures. De qualquer forma, desde o começo do século, o mucheojono entra nas classificações, como a de Rivet (Meillet e Cohen 1924: 650), que o classifica muito bem como codialeto do baure, como Orbigny em 1832. Tudo está dito, e ponto final? Nada disso! Vimos como Métraux (1948a), sem dar uma olhada na classificação de Rivet, acabou confundindo o "moxo" de Orbigny com o mojeño e fez assim do muchojeono um codialeto do mojeño, e não do baure. A bola de neve já estava formada e ia crescer de tamanho com o tempo. Copiando Métraux, Mason (1950: 213) considera novamente o muchojeono como um dialeto do moxo (mojeño), e não do baure, e lendo Jolkesky (2016: 15), vemos classificações recentes (2011-2014) feitas por linguistas especialistas do baure, em que o muchojeono aparece junto com o trinitario e o ignaciano, dialetos mojeño, e não com o baure: quantos descaminhos!

- Além da pesquisa de campo realizada por um de nós, usamos o seguinte material linguístico baure: duas gramáticas elaboradas por dois missionários, Antonio Magio e Asis de Coparcari, nos meados do século XVIII (Adam e Leclerc 1880) e, sobre o baure de hoje, a gramática de Danielsen (2007). Haveria um vocabulário ou dicionário baure do século XVIII, que foi provavelmente elaborado pelo padre Magio, mas que, infelizmente, não foi encontrado até hoje. O desaparecimento desse dicionário nos impede entender melhor certas derivas vocálicas extremamente complexas que ocorreram em baure entre os séculos XVII e XX.

Contrariamente ao que se lê na introdução de Adam e Leclerc (1880), Antonio Magio era um padre jesuíta bem conhecido que trabalhou, de 1749 (e provavelmente antes) até a expulsão dos jesuítas em 1767, com os baure de Concepción de Baures, de San Martín e, principalmente, de San Nicolás. Quanto a Asis de Coparcari, não conseguimos informações exatas. Na introdução, Adam e Leclerc sugerem que sua gramática foi composta depois da expulsão dos jesuítas (1767), mas o trabalho devia ter sido elaborado antes de 1770, já que Coparcari menciona frequentemente San Nicolás, que deixou de existir nessa data.

Qual era a dialetologia baure antes da colonização jesuíta? É impossível saber. Com o apoio do exército espanhol, que interveio depois do assassinato do padre Barace em 


\section{RAMIREZ \& FRANCCA - LÍNGUAS ARAWAK DA BOLÍVIA}

1702 e deixou os baure bastante intimidados, os jesuítas impuseram pela força sua política de uniformização linguística nos Pampas de Baure. A maioria dos baure aceitou a vida em missões grandes onde as diferenças dialetais foram total ou parcialmente suprimidas. Alguns grupos fugiram para o sul, nas florestas que separam os Pampas de Moxos da Chiquitania. Mesmo assim, os jesuítas conseguiram capturá-los e integrá-los nas suas missões da Província de Chiquitos.

Nem sabemos ao certo a localização original das "tribos" ou "parcialidades" baure antes de serem todas misturadas. Na sua gramática, o padre Magio fala às vezes dos grupos abeavano, mochogiono (muchojeono), itamavano, macanereno, mas sem localizálos. Apesar disso, devia haver uma certa heterogeneidade linguística que foi destruída pela vida em missões. Por exemplo, o próprio Magio notava que certas palavras eram pronunciadas "com grande variedade", como maraicai, ou moroicai, ou moraikei "época seca" (Adam e Leclerc 1880: 52). Compare também as formas n-ope "osso" e -ape "osso de". Magio observa também que o $\mathbf{h}$ de Concepción, em certos povoados e em certas palavras, realiza-se como [d] ou [ð] (Adam e Leclerc 1880: 36-37). Essa pronúncia parecia ainda generalizada no vocabulário muchojeono recolhido por Orbigny em 1832. No entanto, como já notamos em 1., nenhum dialeto baure moderno conservou tantos $\underline{\mathbf{a}}$ como o dialeto ignaciano dentro do mojeño, i.e. a mudança $\mathbf{a}>\boldsymbol{v}$ foi bem maior em baure que em mojeño.

- A língua baure está atualmente em grande perigo de extinção. Parece ainda haver 20 falantes idosos em Concepción de Baures, 2 ou 3 semifalantes em El Carmen e, em San Joaquín, onde se falava um baure foneticamente mais conservador, parece que a língua desapareceu completamente.

Nessas condições, o que podemos dizer sobre a dialetologia moderna do baure? Todas as variedades modernas (o baure de Concepción, o "carmelita" de El Carmen e até o "joaquiniano" de San Joaquín) sofreram um enorme desgate vocálico desde o século XIX, ainda mais que o trinitario ou o javeriano. Além de um óbvio processo de obsolescência linguística, nota-se uma certa influência do português no "joaquiniano" (por exemplo, a palavra jabuti "'tartaruga") e uma intrusão muito pequena de palavras chapacura no "carmelita" (como oram "macaco-cuatá, marimono") [< chapacura huram]. O baure de hoje é uma só língua, com vários microdialetos moribundos muito próximos uns dos outros, diferindo principalmente na apócope da vogal final e no drift vocálico.

3.2. Fonologia baure. Os quadros abaixo apresentam os fonemas baure:

\begin{tabular}{|c|c|c|c|c|}
\hline $\mathbf{p}$ & $\mathbf{t}$ & $\mathbf{t} \boldsymbol{j}$ & $\mathbf{k}$ & $\mathbf{P}$ \\
\hline & $\mathbf{s}$ & $\boldsymbol{\int}$ & & $\mathbf{h}$ \\
\hline & $\mathbf{r}$ & $\mathbf{j}$ & $\mathbf{w} / \boldsymbol{\beta}$ & \\
\hline $\mathbf{m}$ & $\mathbf{n}$ & & & \\
\hline
\end{tabular}

\begin{tabular}{|c|c|c|}
\hline $\mathbf{i}$ & & $\boldsymbol{U}$ \\
\cline { 1 - 2 } $\mathbf{e}[\varepsilon, \mathrm{e}]$ & & {$[\mathrm{u}, \mathrm{u}, \mathrm{o}, \mathrm{v}]$} \\
\hline & $\mathbf{a}$ & \\
\hline
\end{tabular}

- Note que as oclusivas e africadas $\mathbf{p}, \mathbf{t}, \mathbf{k}, \mathbf{t} \boldsymbol{\int}$ têm alofones sonoros [b, d, g, dz] que aparecem depois de $\mathbf{m}$ e $\mathbf{n}$. Por exemplo: $n$-tori [ndori] "meu amigo", $n$-poria [mboria] "costuro". A elisão da vogal final átona (apócope) e as sílabas fechadas são comuns em 
baure, menos em joaquiniano e nas gerações mais velhas (Baptista e Wallin 1968). Tal desgaste vocálico ainda não existia no século XVIII. Em 1749, o padre Magio escrevia que a língua baure "não tem duas consoantes seguidas" e que "nenhuma palavra termina por uma consoante" (Adam e Leclerc 1880: 1), i.e. que o baure do século XVIII, como o mojeño do século XVIII, tinha o padrão silábico: $\mathbf{C}(\mathbf{V})$.

Observe que a sequência Coe realiza-se como uma consoante labializada: [ $\left.\mathrm{C}^{\mathrm{w}} \mathrm{e}\right]$.

- $\mathrm{O}$ acento recai em geral na penúltima sílaba, ou na última sílaba quando a vogal final caiu: kahápa > kaháp "mandioca". Muitas oclusões glotais finais [?] indicam que o acento está na sílaba final: $n$ - $t i$ [ndí?] "eu”, mas elas não têm valor fonêmico.

3.3. Aspectos gramaticais baure. $\mathrm{O}$ quadro seguinte apresenta os pessoais independentes e os afixos pessoais da língua baure. Daqui em diante, o asterisco (*) indica formas do século XVIII:

\begin{tabular}{|c|c|c|c|}
\hline & $\begin{array}{c}\text { Pessoais } \\
\text { Independentes }\end{array}$ & $\begin{array}{c}\text { Possuidor, } \\
\text { Sujeito de } \\
\text { v.(in)tr. }\end{array}$ & $\begin{array}{l}\text { Objeto de v.tr., } \\
\text { Sujeito de adjetivo \& nome }\end{array}$ \\
\hline $1 \mathrm{sg}$ & n-ti / *ni-ti eu & ni- & $-n i$ \\
\hline $2 \mathrm{sg}$ & pi-ti $t u$ & pi- & $-\mathbf{p i}$ ou $-\boldsymbol{\beta} \mathbf{i} / / *-\mathbf{p i}$ ou $*-\boldsymbol{\beta} \mathbf{i}$ \\
\hline $3 \mathrm{msg}$ (não-feminino) & ro-ti / *re-ti ele & ro- / *re- & -r(o) / -(i)er [depois de C] / *_(ie)re \\
\hline 3 fsg (sexo feminino) & ri-ti ela & ri- & -(i)ri $/ *-(\mathbf{j} e) r i$ \\
\hline $1 \mathrm{pl}$ & $\boldsymbol{\beta} \mathbf{i}-\mathbf{t i} / * \mathbf{a} \boldsymbol{\beta} \mathbf{i}-\mathrm{ti}$ nós & $\beta \mathbf{i}-/ * a \beta \mathbf{i}-$ & $-\beta \mathbf{i} / *-\mathbf{a} \beta \mathbf{i}$ \\
\hline $2 \mathrm{pl}$ & $\mathbf{j i}-\mathbf{t i} / * \mathbf{j e}-\mathbf{t i}$ vós & ji- / *je- & $-j \mathrm{ji} /-\mathrm{ij} / *_{-} \mathrm{e}$ \\
\hline $3 \mathrm{pl}$ & no-ti / *ne-ti eles(as) & no- / *ne- & -n(ס) / -(i)en [depois de C] //*-no / *-(je)ne \\
\hline
\end{tabular}

Note um fato aparentemente estranho em baure moderno: enquanto -rit-ri " $3 \mathrm{msg}$ " e $-r \mho$ "3fsg" são quase sempre, nas línguas arawak, respectivamente as marcas da terceira pessoa masculina e feminina do singular, o baure moderno parece ter invertido essas formas. Esse aparente paradoxo explica-se facilmente pelas derivas vocálicas próprias ao baure: $-r \dot{t} /-r i>-r e$ "3msg" e *-rv>-ri "3fsg".

As regras morfofonêmicas que afetam os prefixos pessoais são: $\mathbf{V}-\mathbf{V}>\mathbf{V}$ (por

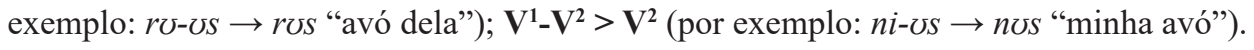

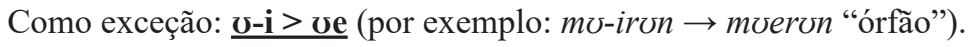

Certas regras morfofonêmicas afetam os sufixos pessoais quando precedidos por uma raiz que termina por uma consoante. Por exemplo: -nik "comer" $\rightarrow$-nik-iri "como-a", mas: -nik-ier "como-o", -nik-ien "como-os(as)", etc. Essa "pseudo-metátese" (apócope + vogal epentética) vê-se muito bem nos empréstimos: lißor "livro", kwatur "quatro", horon "forno", etc.

Alguns elementos gramaticais baure: 
- Os morfemas -r(v) / *-ra ou *-je "pertences de, posse de" eram usados para expressar a possessão (cf. mojeño), por exemplo: $n t i$ "eu" $\rightarrow n t i-r$ "meu". Em baure moderno, esses morfemas são somente usados em poucas palavras, como nos empréstimos, por exemplo: piti-r aßvel "tua avó" (aßvel < castelhano abuela "avó").

- Como sufixos independentizadores, temos: $e^{-} / *_{i-,}-(v) k / *_{-} k v$, -tik, -re. Por exemplo: -kis "olho de" $\rightarrow e-k i s$ "olho", -wer "remédio de" $\rightarrow$ wer-øk"remédio".

Como sufixo dependentizador, temos -(v)n / *-na. Por exemplo: jakis / *jwki-se "lenha" $\rightarrow$-jakis-on / *jwkise-na "lenha de".

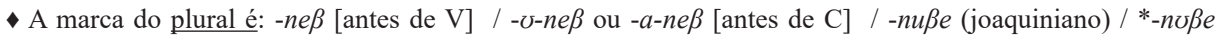
"plural".

- Artigo \& Demonstrativos: O artigo to "o(s)/a(s)" [não-feminino] / $t i$ "a(s)" [feminino] pode usar-se com formas possuídas: to $n$-ia "o meu pai", ti n-en "a minha mãe”. Os demonstrativos dividem o espaço em três zonas:

- te / *ate [não-fem.] + ti [fem.] + to [plural] "1a zona (este)"

- te-t $\int / * t e-t \int \mho$ [não-fem.] $+t i-t \int / * t i-t \int \mho[$ fem. $]+t \mho$ net $\int[$ plural] " 2 a zona (esse)"

- te- $n / * a t e-n \sigma$ [não-fem.] + ti-n/*ati-nv[fem.] + to nen [plural] " 3 a zona (aquele)"

Os advérbios demonstrativos são: né "aqui", noij / naka / nokv / *noje "lá".

- Interrogativos: kon + woji-kv-won "o quê?, quem?", rekitfin "quando?", ro-wo-kv / re-wo-ka "quanto?", ka- "como?".

- Alguns afixos nominais: $-t \int i / *-t / i$ *-t foi "diminutivo", - $t$ fa "aumentativo", -je "em (locativo)", -ina- "com (instrumental)".

- Os classificadores são morfemas incorporados nos adjetivos, numerais ou verbos como sufixos (incorporação nominal), que são marcas de concordância com o sujeito (adjetivos e verbos intransitivos) ou com o objeto (verbos transitivos). As partes do corpo também podem ser incorporadas. Alguns classificadores: - $a$ "animais,

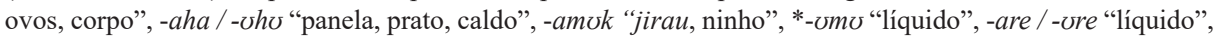
- e "cuia, tubérculo", - $i$ /-ve "fruta, ave", -irv/-erv "pedra, roda", - a-ki/-e-ki/-i-ki "côncavo (oco, cesto, lago, roça)", -mpe "aplastado (papel, arraia)", -mv(k) / *-mv(kv) / *-maikv "roupa", -nv / -vn / -na (joaquiniano) "pessoa, corpo celeste", -pa "cuia", -pe "lâmina (remo, terçado, moeda)", *-pai "chão", -pi "filiforme (fio, cobra)", -pv1 "pescados, insetos, bichinhos", -pv2/*-pa "pó", -pve "bananas", -pvki "rede de dormir", -se

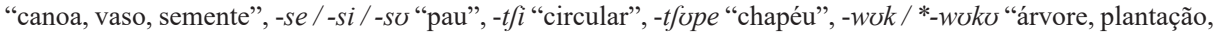
lugar".

- Sufixos temáticos verbais: $-k v,-t$ fo ou $-\varnothing$.

- Prefixos verbais: $k(v)$ - / *ka- "positivo", $m(v)$ - / *ma- "negativo", imv- / $i$ - "causativo1", * $k a$ - "causativo2", $* a$ - / $A$ - [o $>$ a: suprafixo cf. 1.2.] "futuro, subjuntivo, optativo, condicional (se)".

- Sufixos verbais: $-p v / *_{-} \beta \sigma \sim *_{-}-p v$ [no futuro/subjuntivo: cf. 1.2.] "reflexivo", -kvkv "recíproco", $-t / v$ "aplicativo (causativo)", -inv "benefactivo", -si + *-konv "passivo" ;; -pa / *-pa + -pik "futuros", -ini / -əen "passado, ex-", - $i$ i $i+-w \mho / *_{-} \beta u / *_{-} \beta a$ "imperfectivo, progressivo (atual)", -if "somente", * fia "ainda",

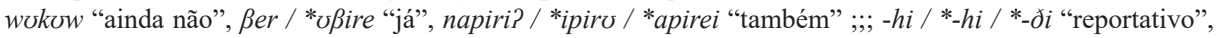
- $a$ " "tomara que...".

- Verbalizadores e nominalizadores: -wapa + -wa "verbalizadores (tornar-se, ser)", -tfo "verbalizador (fazer com)", *-ira / *kari / *-kv/*-na / *-ri / *-t/v "nominalizadores".

\section{O pauna}

4.1. Os pauna(ka) e os paikone(ka). Copiando palavra por palavra várias observações de Orbigny (1944: 326-328, 2002[3]: 1272), Métraux (1942: 134) informa que os 
pauna $(k a)^{3}$ são um subgrupo dos paikone(ka), que viviam ao norte de Concepción de Chiquitos, ${ }^{4}$ entre as cabeceiras do rio Blanco e do rio Verde. Como não há nenhum rio Verde ao norte de Concepción, as informações de Orbigny e Métraux estão muito imprecisas. Os paicuno ou paiçono mencionados perto de Santa Cruz la Vieja em 1560 (Combès 2010: 236; Métraux 1948a: 284) poderiam ser os próprios paikone-ka. No entanto, informações precisas sobre a localização desses grupos somente aparecem no começo do século XVIII. Nos anos 1730-1740, os paunaka e os paikoneka já viviam nas missões de San Javier e de Concepción de Chiquitos, pelo menos, todos os paunaka e uma parte dos paikoneka.

A melhor localização dos paunaka aparece em um mapa de Chiquitos de cerca de 1716 (Archivum Romanum Societatis Iesu, Roma), que foi reproduzido na capa de uma obra de Matienzo et al. (2011). Nesse mapa, San Javier, San José de Chiquitos e San Rafael, assim como o curso do rio Parapetí (San Miguel-San Julián-San Pablo), são tão bem localizados que podemos confiar nele. No mapa, as missões efêmeras de Concepción de manasicas e de San Ignacio de Bohococas, que foram fundadas em 1699 e desapareceram em 17041707, eram localizadas juntas na latitude $15^{\circ} 20^{\prime} \mathrm{S}$, perto da confluência do rio Negro com o rio Zapacos de Concepción (rio Blanco); os Tapacuras (família chapacura) perto do lugar chamado hoje Chapacura e do lago Huachi; e os Paunacas na latitude $14^{\circ} 50^{\prime} \mathrm{S}$, bem ao norte de San Javier, no médio curso do rio San Joaquim (Rio Negro), na atual Reserva de Vida Silvestre Rios Blanco y Negro. Tudo isso é também confirmado pelo padre Lucas Caballero em 1707 (Matienzo et al. 1911: 46-83). O mapa boliviano oficial coloca os Paiconecas na latitude $15^{\circ}$, ao leste dos paunaka, no rio Guarayos, afluente do rio San Martín, um pouco fora da reserva mencionada. Isso nos parece certíssimo, já que uma expedição jesuíta que saiu de Concepción de Chiquitos rumo ao norte, em agosto de 1730, capturou 80 Payconé, "gente mansa e lavradora", exatamente no lugar indicado pelo mapa oficial boliviano, perto dos Pizocos ou Puyzocas que tinham assassinado o padre Lucas Caballero em 1711 (conhecemos a localização exata dos Pizocos pelo mapa de Chiquitos de 1716). Naquela época, a captura violenta e desumana de índios livres para colocá-los em missões era costume consagrado pelos jesuítas. Esses 80 Payconé foram levados para Concepción de Chiquitos. Chegando lá, os índios pediram aos jesuítas de Chiquitos que não fizessem outra expedição para sua terra natal porque "pertenciam" à jurisdição dos jesuítas de Mojos, i.e. às missões baure (Matienzo et al. 2011: 160-161). Muitos baure foram também levados às missões de San Javier e de Concepción de Chiquitos a partir de 1731. Em 1743, havia 201 baure em San Javier, 452 paikoneka em San Javier [294] e em Concepción de Chiquitos [158], e 226 paunaka em Concepción de Chiquitos (Matienzo et al. 2011: 164-166, 328).

Em resumo, o leitor poderá consultar nosso mapa e constatar que todos esses grupos (chapacura, paunaka, paikoneka e baure fugindo das missões dos Pampas de Baure) viviam, no começo do século XVIII, nas florestas que separam os Pampas de Baure da Chiquitania, em lugares muito mais próximos das missões jesuítas de Baure que de

${ }^{3}$ Pauna e paikone no singular, paunaka e paikoneka no plural, o sufixo - $k a$ "plural" pertencendo à língua chiquito.

${ }^{4}$ Não confundir Concepción de Chiquitos (na Chiquitania) com Concepción de Baures (nos Pampas de Baure).

LIAMES, Campinas, SP, v. 19, 1-71, e019012, 2019 
Concepción de Chiquitos ou de San Javier (Chiquitania). No entanto, os paunaka e os paikoneka acabaram fixados à força na Chiquitania.

- Pelo que sabemos, os padres jesuítas não deixaram nenhum estudo sobre as línguas pauna e paikone. Hoje, o pauna ainda é falado por semifalantes nas imediações de Concepción de Chiquitos. Em Santa Rita (10 km de Concepción), um de nós encontrou alguns paunaka trilíngues, falando o castelhano, o chiquito e o pauna. A pesquisa linguística foi feita com aqueles informantes, entre 2006 e 2008. O leitor poderá consultar a Enciclopédia das Linguas Arawak e constatar a adoção de muitas palavras chiquito no vocabulário básico. De qualquer forma, não há dúvida de que o pauna é bem próximo do mojeño e seu estatuto como membro do subgrupo Bolívia não pode ser contestado. Os quadros abaixo apresentam os fonemas pauna:

\begin{tabular}{|c|c|c|c|c|}
\hline $\mathbf{p}$ & $\mathbf{t}$ & $\mathbf{t} \boldsymbol{k}$ & $\mathbf{k}$ & $\mathbf{( ? )}$ \\
\hline & $\mathbf{s}$ & & & $\mathbf{h}$ \\
\hline $\mathbf{w}[\mathrm{w}, \beta]$ & $\mathbf{r}[\mathrm{r}]$ & $\mathbf{j}$ & & \\
\hline $\mathbf{m}$ & $\mathbf{n}$ & $\mathbf{( n )}$ & & \\
\hline
\end{tabular}

\begin{tabular}{|c|c|c|}
\hline $\mathbf{i}$ & $\mathbf{i}$ & $\boldsymbol{U}$ \\
\hline $\mathbf{e}$ & & {$[\mathrm{u}, \mathrm{o}, \mathrm{v}]$} \\
\hline & $\mathbf{a}$ & \\
\hline
\end{tabular}

Algumas vogais são nasais ou nasalizadas. O padrão silábico é sempre: (C)V. As regras morfofonêmicas que afetam os prefixos pessoais são: $\mathbf{V}-\mathbf{V}>\mathbf{V} ; \mathbf{V}_{\mathbf{1}}-\mathbf{V}_{\mathbf{2}}>\mathbf{V}_{2}$. Temos poucos elementos gramaticais sobre a língua pauna. A marca do plural é -hane. Por exemplo: samv "anta" $\rightarrow$ samv-hane "antas", owiáe "casa" $\rightarrow$ owiáe-hane "casas". Outros afixos pauna serão apresentados na lista de cognatos do subgrupo Bolívia, na última seção deste estudo.

\subsection{A língua paikone: um dialeto baure ou uma língua inventada por Orbigny?} Sobre o †paikone, temos apenas o vocabulário de Orbigny organizado em Concepción de Chiquitos (1831). Supondo que esse vocabulário seja verídico, o que talvez não seja o caso, as grandes afinidades entre o paikone $(\mathrm{P})$ e o baure (B) não deixam a menor sombra de dúvida. Por exemplo, compare: -senvki $[\mathrm{P}]$ /-senvki $[\mathrm{B}]$ "orelha", -serv $[\mathrm{P}] /$-serv $[\mathrm{B}]$ "dente", -waki [P] / -waki [B] "mão", tomomo [P] / t fo(mo)mve? [B] "flor", t faki $[\mathrm{P}] / j a k i$ $[\mathrm{B}]$ "fogo", isese $[\mathrm{P}] /$ sese $[\mathrm{B}]$ "sol", $v$-wira $[\mathrm{P}] / \operatorname{\beta ir}(a)[\mathrm{B}]$ "vento", kahe $[\mathrm{P}] /$ kahi $[\mathrm{B}]$ "pedra", mosere-ko [P] / moserv [B] "vermelho", itsomo [P] / -ifomo [B] "levantar-se",

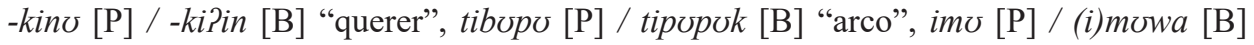
"tamanduá", kvpire [P] / kopire [B] "tatu", t tiie [P] / /ije? [B] "raposa", sipvri $[\mathrm{P}] /$ sipvri [B] "sapo", t/vmo?e [P] / jomve [B] "abelha", vmose [P] / mose [B] "milho", sitfore [P]/ tfittire [B] "feijão", suni [P] / suni [B] "tabaco" (cf. outros exemplos na Enciclopédia das Linguas Arawak).

Contrariamente ao que Orbigny afirmou e, desde então, infelizmente, muitos estudiosos que se contentam em repetir o que foi sempre dito sem mesmo dar uma conferida na lista de palavras de Orbigny, há poucas semelhanças com o pauna $(\mathrm{Pa})$ : pini $[\mathrm{P}] /$-pïini $[\mathrm{Pa}]$ "pescoço", ikv [P] / ikv [Pa] "chuva", Pimv-?a [P] / -imo [Pa] "ver", ihino [P] / ihino $[\mathrm{Pa}]$ "arraia". Talvez essas semelhanças pauna-paikone sejam empréstimos, já que os paikoneka e os paunaka viviam juntos nas missões de Chiquitos (cf. 4.1). Há também 
vários erros no vocabulário de Orbigny: a palavra paikone pini significa "pescoço" e não "seio", a palavra peme significa "língua" (pene) e não "boca", etc.

Pelos dados de Orbigny, qualquer pessoa sensata, seja linguista ou não, concluirá que o paikone era um dialeto baure, com algumas diferenças fonéticas ou fonológicas menores, como: $\mathbf{n}>\mathbf{n} / \mathbf{i}, \mathbf{e}_{-}$(palatalização) e $\mathbf{j}>\mathbf{t} \int$ (em certas palavras). No entanto, vejamos o que Hervás y Panduro (1800: 160-161) disse sobre a identidade linguística entre as línguas paikone e baure:

\begin{abstract}
Devo advertir que, embora se ache registrado que as línguas baure e paicone têm afinidade, não se deve afirmar tal afinidade, porque ela é absolutamente falsa. Para tirar as dúvidas que eu tinha sobre isso, consultei o senhor Abade Dom Christobal Rodriguez, de grande autoridade, o qual por vinte anos [...] foi missionário dos baures e dos paicones, que estavam aos seus cuidados na missão de San Javier, e ele me disse que não encontrou sombra alguma de afinidade entre as línguas baure e paicone; e nunca ouviu dizer que houvesse uma só palavra que fosse comum a elas; a tal ponto que, no começo da catequização dos paicones, embora ele sabia perfeitamente a língua baure, foi-lhe necessário o auxílio de intérpretes, mas teve que desistir porque achava que eles o enganavam na tradução.
\end{abstract}

É um bom exemplo de controvérsia não resolvida. A partir de seu vocabulário, Orbigny coloca o paikone e o pauna em uma família linguística independente, o que é pelo menos estranho, já que seus vocabulários são obviamente arawak. Rivet (Meillet e Cohen 1924: 646,650) examina os mesmos vocabulários e nota que essas duas línguas pertencem à família arawak, mais precisamente em um subgrupo chamado por ele de Groupe Bolivien, que contém, além delas, o mojeño, o muchojeono e o baure. Enfim, Ramirez (2010: 212) fez do paikone um dialeto baure. Como Hervás y Panduro adverte, todas essas opiniões estariam erradas: como aquele abade ao qual Hervás se refere, pode ser que Orbigny também tenha sido enganado no seu vocabulário.

$\mathrm{Na}$ ausência de outro manuscrito paikone, achamos prudente ainda não classificar o paikone e deixá-lo como problema não resolvido: Um dialeto baure? Um dialeto de qualquer outra língua arawak da região? Um dialeto chiquito? Uma língua isolada?

\title{
5. O tereno (chané)
}

5.1. História e estudos linguísticos tereno. Limitamo-nos aqui ao mínimo de informações históricas: para mais detalhes, o leitor poderá consultar Combès (2010: 116-123) e Métraux (1948b: 465-485; 1946: 199 [mapa], 238-241). No século XVI, os chané moravam nas margens norte, oeste e talvez leste do Chaco Boreal, e eram conhecidos como grandes agricultores. Mais precisamente, os chané estavam localizados:

(1) No norte do Chaco Boreal, na região de Santa Cruz la Vieja, onde logo desapareceram: por mestiçagem ou por fuga, para escapar dos colonizadores espanhóis?

(2) No ocidente, entre o Guapay (rio Grande) e o rio Pilcomayo, onde eram escravos dos chiriguano (guarani). A presença chané era maciça na Cordilheira Chiriguana e nos vales férteis que se estendem no pé dos Andes entre o rio Grande e o rio Parapetí. Nessa região, os chané eram constantemente perseguidos pelos chiriguano que os capturavam 
como vítimas de rituais antropofágicos ou para transformá-los em escravos. A partir de 1561, os chané fugiram em massa dos chiriguano e dos espanhóis para os banhados do Izozog. Também havia grupos chané na região da atual Santa Cruz, no rio Grande. Em toda a região, a língua chané era a mais falada no século XVI, junto com o guarani e o gorgotoqui (Chávez-Suárez 1986: 190).

Os chané que viviam no pé dos Andes participavam ativamente do comércio do ouro andino que, no leste, estendia-se até o rio Paraguai. Eram pacíficos e profundamente influenciados pelas culturas andinas (roupa, cerâmica, uso de ferramenta metálica, etc.). Muitos chané foram chacinados e devorados pelos guarani que chegaram do Paraguai no fim do século XV e no começo do século XVI. Lizárraga fala de 60.000 chané comidos no século XVI. O que restou tornou-se servos dos guarani. Chegando com poucas mulheres, os guarani casavam-se com as mulheres chané, de forma que a língua chané devagar cedou passo à língua guarani, provavelmente a partir do século XVII. Hoje, a guaranização linguística está completa: o idioma chané desapareceu entre os rios Grande e Pilcomayo.

(3) No oriente, onde os chané eram vassalos dos mbayá (guaycuru), sem que aparentemente tenha havido mistura de sangue. Com menos influências andinas, os chané orientais do Chaco Boreal foram conhecidos como guaná desde o século XVIII. Métraux afirma que os guaná eram vassalos dos mbayá bem antes da chegada dos espanhóis no Chaco, o que nos parece estranho e até equivocado, porque os layana, um grupo guaná-chané sem aparente diferenciação dialetal com os outros grupos guaná, não são mencionados como escravos dos mbayá no século XVI, mas sim a partir do século XVIII (Combès 2010: 185186). Isso poderia sugerir que os guaná-chané chegaram e estabeleceram-se recentemente perto do rio Paraguai: entre os séculos XVI e XVIII. Em 1793, Aguirre (1898) define a relação social entre guaná e mbayá como um tipo de pedágio: um direito de passagem que os mbayá exigiam quando os guaná-chané cruzavam suas terras e que eles cobravam com produtos agrícolas oferecidos pelos guaná. Isso também parece implicar que a origem desses guaná-chané deve ser procurada no centro ou no oeste do Chaco, bem longe dos territórios mbayá.

Os guaná viviam então ao oeste do rio Paraguai, entre a foz do rio Apa (fronteira Paraguai-Brasil) ao sul e a foz do rio Miranda (perto da atual Corumbá) ao norte. No fim do século XVIII (talvez já em 1661 para alguns grupos), os mbayá-kadiwéu atravessaram o rio Paraguai e estabeleceram-se no Brasil, junto com seus vassalos guaná-chané. Nos meados do século XIX, todos os guaná viviam na região de Miranda (Brasil) e os laços de vassalagem entre os guaná e os mbayá-kadiwéu pareciam apagados. Vejamos alguns grupos guaná-chané com a data de sua primeira menção:

a) Os layana, layano ou layono (1548): era o nome dado a eles pelos mbayá. Como dissemos, parecem ter mudado do centro do Chaco (no século XVI) para as proximidades do rio Paraguai (no século XVIII).

b) Os queliaquiano ou equiniquinao (1548): era o nome dado a eles pelos mbayá. Em chané, são os kainaco-na, kainocoe ou koinoco-noe (< ka-inaku "frente", -na(e) "plural"). Hoje, são os koenuku-noe (Souza 2008), mais conhecidos como kinikinau, o seu nome em mbayá. Note a deriva vocálica ai > oi de kainaco para koenuku. 
c) Os echoaladi, choarana, chaawaraane ou chooworoono ( $<\int a$ ?a "peito", -hana(i) "grande"): um grupo hoje extinto.

d) Os tereno, etelenoe ou (e)telena (<? têre "traseiro", -noe "plural") não são mencionados nos séculos XVI-XVII. Os jesuítas de Chiquitos chegam aos tereno (Chaco Boreal Oriental) em 1731, a partir de San Ignacio de Zamucos, uma missão jesuíta do Chaco de localização incerta que foi abandonada em 1745 (em 1748, reaparece com o mesmo nome de San Ignacio, mas dentro da Chiquitania). São os "tereno do sul", os únicos guaná-chané a ter adotado o cavalo como seus donos mbayá, que já montavam a cavalo desde os meados do século XVII (Matienzo et al. 2011: 170-174). Em 1762, os tereno são novamente mencionados, mas, desta vez, mais ao norte, perto das missões meridionais da Chiquitania (Santo Corazón e Santiago), com os mbayá-kadiwéu que atacavam os arredores da missão jesuíta de Santo Corazón (Matienzo et al. 2011: 388-389). Note que o mapa de Métraux (1946: 199) não menciona a posição dos guaná-chané do século XVI, como ele pretende, mas do século XVIII, seguindo as informações de Sánchez Labrador e de Azara.

- Em 1793, Aguirre, capitão espanhol que trabalhava na Comissão de Demarcação de Fronteira entre a Espanha e Portugal, viveu entre os índios da região e fez o primeiro vocabulário guaná-chané de 107 palavras, provavelmente com a ajuda de missionários (Aguirre 1898: 489, 493, 497). Não sabemos onde e com que grupo o vocabulário foi coletado. No entanto, seu vocabulário guaná é obviamente igual ao tereno. Os guaná já tinham abandonado o Chaco, entre 1780 e 1790, e atravessado o rio Paraguai para viver no Brasil. Aguirre afirma que os guaná, no seu próprio idioma, autodenominam-se de chané, que eles têm sido habitantes do Chaco desde as margens do rio Paraguai até os confins do Alto Peru, sendo a nação mais numerosa do Chaco (8.200 pessoas) e bons agricultores (Aguirre 1898: 471, 487). Afirma também que há diferenças dialetais entre certos grupos guaná, particularmente os layana, tanto na pronúncia como no léxico, mas nem sequer dá um exemplo dessas diferenças (Aguirre 1898: 502). Enfim, o autor nota também que, do outro lado do Chaco, no caminho de Santa Cruz, há muito mais chané, uns vivendo com os chiriguano (guarani) e outros separados.

- Qual era a dialetologia chané antes da chegada dos espanhóis? Ninguém sabe. Parece que os jesuítas, que estudaram o chané de Santa Cruz durante os séculos XVI-XVII, não deixaram nada escrito sobre essa língua. Em 1908, Nordenskiöld (2002: 147) consegue anotar as seis últimas palavras desses chané de Santa Cruz, perto do rio Parapetí: úne "água" [mojeño, tereno: une], sopóro "milho" [tereno: sopôro], yucu "fogo" [mojeño, tereno: juku], tamúcu "cão" [mojeño, tereno: tamuku], liqui "chicha (buena)" [?], cóvo "rato" [?]. Estas poucas palavras sugerem que devia haver pouca ou nenhuma diferença entre o chané de Santa Cruz e o tereno atual.

Nos séculos XVII-XIX, várias listas de vocábulos guaná-chané (layaná, tereno, kinikinau) foram compiladas. Como observamos em 1.3., todas essas listas, especialmente as de Aguirre (guaná), Fonseca (guaná-layaná), Boggiani (kinikinau) e Castelnau (guaná), evidenciam claramente a deriva vocálica $* \mathbf{a}>\mathbf{0}$ então em processo progressivo. Além disso, elas mostram pouca ou nenhuma diferença com o tereno falado atualmente na região do rio Miranda, afluente do rio Paraguai. 


\section{RAMIREZ \& FRANCA - LÍNGUAS ARAWAK DA BOLÍVIA}

E o que podemos dizer sobre a dialetologia atual do chané? Notamos que o tereno é falado com algumas diferenças fonéticas e lexicais menores nas aldeias de Cachoeirinha (perto de Miranda) e de Bananal. No seu trabalho, Souza (2008) esforçou-se em vão para achar diferenças significativas entre o tereno e o kinikinau, língua que ela estudou com os últimos falantes e que ela descreveu minuciosamente. À exceção da perda dos demonstrativos (artigos definidos) em kinikinau, e de duas ou três palavras diferentes, como: piwifu [kinikinau < kadiwéu pigitfee-na] / marakaja [tereno < guarani] "gato" e fuku-oe [kinikinau: lit. "dente canino"] / fịni [tereno: cf. mojeño, baure, pauna: itfini / isini] "onça", não vemos diferença alguma entre as "duas" línguas. No fim do estudo, a autora pretende que o kinikinau, com a ordem básica não-marcada para a ênfase VOS e a ordem intraverbal S-V-O, o que é típico das línguas arawak, "difere consideravelmente do terena na questão da ordem sintática” (Souza 2008: 115, 118, 121), o que está errado: o tereno tem as mesmas ordens básicas (Butler 2003: 5). Enfim, o material de Boggiani (1895) mostra que Fonseca não é o único autor a ter produzido lista de palavras kinikinau, como Souza (2008: 27) afirma. Loukotka (1949: 74) já tinha corretamente constatado que o primeiro material kinikinau era de Boggiani, e que o "kinikináo" de Fonseca não era kinikinau, mas um "dialeto estragado de Kaduveo".

Em resumo: talvez houvesse no passado diferenças dialetais significativas dentro da língua guaná-chané, mas que aparentemente se perderam para sempre. A partir desse ponto, deixaremos todos os etnônimos empregados outrora e falaremos somente do tereno ou chané.

- Além dos apontamentos linguísticos realizados por um de nós na Aldeia Água Branca, perto de Aquidauana, utilizamos todo o material linguístico tereno elaborado pelo SIL durante décadas: especialmente, o vocabulário e os estudos gramaticais de Ekdahl e Butler (1969, 1979). Tudo isso é insuficiente: falta um bom dicionário tereno e uma fonologia que explicaria melhor a realidade tonal.

A leitura do estudo de Martins (2009) torna-se impossível por causa das fontes fonéticas que saíram erradas, pelo menos no PDF de que dispomos. Escrita em algumas semanas, a pequena gramática tereno de Nascimento (2012) é praticamente uma cópia dos trabalhos do SIL, com os mesmos erros de segmentação (como o sufixo temático - ko que acaba segmentado em $-k-o$ ).

O estudo lexicográfico de Silva (2013) é ainda mais incipiente que o vocabulário do SIL. Na introdução (Silva 2013: 29-39), a autora critica um léxico anteriormente produzido por conter ilustrações equivocadas, como o verbete tikoa "tamanduá" ilustrado por uma anta, e pretende chegar a uma fauna e uma flora tereno mais apuradas, e até com o nome científico. Vejamos o resultado: na página 193, encontramos o verbete kokiriti opeti "anupreto", com uma bela fotografia de anu-preto, seu nome científico e uma longa descrição da ave, com um bico pontiagudo e penas amarelas, o que não corresponde a nenhum anu-preto deste planeta: na realidade, a palavra kokiriti opeti é o termo tereno para outro pássaro bem diferente, o japiim ou xexéu (Cacicus cela). Da mesma forma, o verbete xaka xaka "pacu, peixe da família Chacacidae [sic!]” não designa o pacu, mas o jeju (Hoplerythrinus unitaeniatus, família Erythrinidae), um peixe bem diferente, aparentado com a traíra. Pelo menos, o vocabulário do SIL, que contém muito mais entradas, faz a diferença entre um xexéu e um anu, ou entre um pacu e uma traíra! 
5.2. Influência kadiwéu em tereno. Há muitos termos comuns em tereno e em kadiwéu, sobretudo na nomenclatura animal e vegetal. Trata-se de palavras provavelmente kadiwéu que foram adotadas pelo tereno. Alguns exemplos: nótuwaka [T] / latoaGa [K] "riacho", ipe $[\mathrm{T}]$ / ipe $[\mathrm{K}]$ "cama", númiiko $[\mathrm{T}]$ / l-omiigo $[\mathrm{K}]$ "anzol", wateke $[\mathrm{T}]$ / wateke $[\mathrm{K}]$ "canoa", nipuku [T] / niboko [K] "cesto", ramoko $[\mathrm{T}] /$ l-amoGo $[\mathrm{K}]$ "farinha de mandioca", ewakafu [T] / ewaGatso [K] "capivara", ánakihe [T] / lanaaGidze [K] "cutia”, kutefu [T] / niGotet fo [K] "quati", napini [T] / napii-ni [K] "ariranha", ewerefe [T] / ewiletfe [K] "lontrinha", kufiaka [T] / Gotfii-Ga [K] "bugio", afiwanaka [T] / atfiwanaGa [K] "dourado (peixe)", kotépaka [T] / Gatepa-Ga [K] "pacu", tawaruru [T] / dawalolo [K] "saúva", anendakakai $[\mathrm{T}]$ / anadeegeGedi $[\mathrm{K}]$ "minhoca", náfaka [T] / natfaaGa [K] "araticum", efate [T] / etfate [K] "palmeira uricuri", namúkuri $[\mathrm{T}]$ / namokoligiwa-Ga $[\mathrm{K}]$ "palmeira pindoba", apeniko [T] / Gapeenigo [K] "pau-d'arco", nakaku [T] / naqakodiwaGa [K] "arroz", nutiku [T] / notike [K] “jenipapo", wâma $[\mathrm{T}]$ / wama $[\mathrm{K}]$ “jutá', etc. Há também empréstimos do espanhol, do português e do guarani paraguaio. ${ }^{5}$

5.3. Fonologia tereno. Os quadros abaixo apresentam os fonemas tereno:

\begin{tabular}{|c|c|c|c|c|}
\hline $\mathbf{p}$ & $\mathbf{t}$ & & $\mathbf{k}$ & $\mathbf{~}$ \\
\hline & $\mathbf{s}$ & $\int\left[(\mathrm{t}) \int\right]$ & & $\mathbf{h} / \mathbf{h h}$ \\
\hline $\mathbf{w}[\mathrm{w}, \beta]$ & $\mathbf{r}[\mathrm{r}] /(\mathbf{l})$ & $\mathbf{j}$ & & \\
\hline $\mathbf{m}$ & $\mathbf{n}$ & $\mathbf{( n )}$ & & \\
\hline
\end{tabular}

\begin{tabular}{|c|c|c|}
\hline $\mathbf{i}[i, \mathrm{i}]$ & & $\mathbf{u}$ \\
\hline $\mathbf{e}[\mathrm{e}, \varepsilon]$ & & $\mathbf{0}[\mathrm{o}, \mathrm{\rho}]$ \\
\hline & $\mathbf{a}$ & \\
\hline
\end{tabular}

- O fonema $\mathbf{l}$ aparece em poucas palavras; $\mathbf{n}$ também é raro e de estatuto fonêmico duvidoso (geralmente, palatalização de $\mathbf{n}$ antes de $\mathbf{i}$ ). Antes de i, os fonemas t e $\mathbf{n}$ são frequentemente palatalizados, respectivamente, em [t $\left.\int\right]$ e $[\mathrm{n}]$.

- A vogal i realiza-se (frequentemente) como [i] depois de h: póhi [póhi] "pato". Certas sequências vocálicas são proibidas: ia $\rightarrow \mathbf{e a}, \mathbf{i e} \rightarrow \mathbf{e e}, \mathbf{i o} \rightarrow \mathbf{e o}, \mathbf{u a} \rightarrow \mathbf{0 a}, \mathbf{u e} \rightarrow \mathbf{o e}, \mathbf{u o} \rightarrow$ oo (Ekdahl e Butler 1979: 35).

- Haveria também um fonema hh [ç] ainda usado por certas pessoas idosas, a maioria dos falantes substituindo-o por [h]. No vocabulário recolhido em 1820-1825 por Natterer em Albuquerque (rio Paraguai), a realização palatal desse fonema hh devia ser ainda muito forte. Natterer utiliza as grafias $\int \mathrm{ch}$ ou $\int$ para representá-lo, como em: fchura "barriga", fchoe "peixe", fchapu "branco", fchafcha "preto", fchikere "estrela", etc. Esta realização palatal às vezes encontra-se em Aguirre (1898), talvez realizada como [s, $\theta$, ç] (por exemplo, zawenoena [Өawenoena] "velha" e cimaka [Jimaka] "fome"), e também em kinikinau. A respeito da oposição $\mathbf{h} / \mathbf{h h}$, note que:

1) Quando precedido do prefixo N- $1 s g$ (cf. 5.4.), os fonemas $\mathbf{p}, \mathbf{t}, \mathbf{k}, \mathbf{s}, \boldsymbol{\int}, \mathbf{h}$ e hh realizamse com uma contraparte sonora: $\mathrm{p} \rightarrow \mathrm{b}, \mathrm{t} \rightarrow \mathrm{d}, \mathrm{k} \rightarrow \mathrm{g}, \mathrm{s} / \mathrm{h} \rightarrow \mathrm{z}, \mathrm{J} / \mathrm{hh} \rightarrow \mathrm{z}$. Por exemplo:

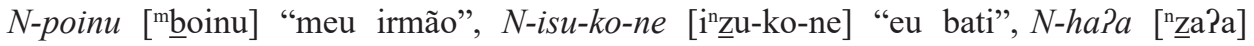

${ }^{5}$ Um dos pareceristas informou-nos que o mesmo tema foi recentemente desenvolvido por Carvalho (2018b), quando nosso artigo já se encontrava sob análise e aguardando publicação. 
"meu pai", $N$-hhewe ["zewe] "meu pé", etc. Com $\mathbf{h} / \mathbf{h h}$, as duas realizações [z] e[3] são frequentemente intercambiáveis: $N$-hhura $\left[{ }^{\text {zzura }}\right] \sim\left[{ }^{\text {zzura }}\right]$ "minha barriga".

2) Nos empréstimos (português, espanhol, kadiwéu), s e dz são substituídos por h ou por uma fricativa palatal: sapato > hapâtu, açúcar > aafúka, sandia [espanhol] > hándea "melancia", soldado > húndaaru, lanaaGidze [kadiwéu] > ánakihe "cutia", etc.

Tudo isso sugere, em pré-tereno, a existência de um único fonema *ç [ç] $>$ [h], i.e., que hh não é outro fonema, mas uma realização arcaica do fonema $\mathbf{h}$.

- Em tereno, haveria dois tons: o tom alto $(\mathbf{V})$ com alongamento da consoante subsequente, e decrescente $(\hat{\mathbf{V}})$ com alongamento da vogal.

5.4. Aspectos gramaticais tereno. O quadro seguinte apresenta os afixos pessoais e os possessivos do tereno:

\begin{tabular}{|c|c|c|c|c|}
\hline & Pessoais Independentes & Possessivos & Possuidor, Sujeito de v.tr. ou v.intr. & Objeto de v.tr. \\
\hline $1 \mathrm{sg}$ & un-di /Nu-ti/ eu & $\mathbf{i}^{\mathrm{n}}$-duke $m e u$ & $\mathbf{N}$ - (espraiamento do traço nasal) & $-n u$ \\
\hline $2 \mathrm{sg}$ & i-ti $t u$ & í-tike teu & i- [j] /_V harmonia vocálica / _ C & -pi \\
\hline $3 \mathrm{sg}$ & Ø (ou melhor: nada) ele (a) & í-tuke dele & Ø- (ou melhor: nada) & $\mathbf{- a}$ \\
\hline $1 \mathrm{pl}$ & û-ti / wotti / ũti nós & wí-tuke nosso & w(i)- & $-V w i$ \\
\hline $2 \mathrm{pl}$ & i-ti...-noe vós & & i-...-noe, i-...-hiko & -pi...-noe \\
\hline $3 \mathrm{pl}$ & Ø...-hiko eles(as) & & Ø-...-hiko & -a...-hiko \\
\hline
\end{tabular}

Note que a $1^{\mathrm{a}}$ pessoa do singular realiza-se com a sonorização e pré-nasalização da primeira oclusiva ou fricativa da raiz $\left(\mathrm{p} \rightarrow \mathrm{b} ; \mathrm{t} \rightarrow \mathrm{d} ; \mathrm{k} \rightarrow \mathrm{g} ; \mathrm{s} / \mathrm{h} \rightarrow \mathrm{z} ; \int / \mathrm{hh} \rightarrow 3\right)$, com nasalização das vogais e das aproximantes $\mathbf{j}$ e $\mathbf{w}$ que precedem; caso não haja oclusiva ou fricativa, todas as vogais e as aproximantes $\mathbf{j}$ e $\mathbf{w}$ são nasalizadas. Exemplos com os verbos pi-ho "ir", ko?itu-ke "trabalhar", arau-ko "nadar", isu-ko "bater", e os nomes uke "olho", ha? a "pai", hhewe "pé", jeno "esposa": mbi-ho-ti "vou", "goPitu-ke-ti "trabalho",

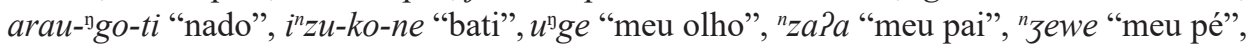
jẽnõ "minha esposa".

Quanto à $2^{\mathrm{a}}$ pessoa do singular e do plural, ela realiza-se:

- como [j] com raiz começando por vogal, menos i;

- ou com assimilação progressiva da primeira vogal da raiz começando por consoante (ou da segunda vogal da raiz se a primeira vogal for $\mathbf{i}$ ) : $\mathbf{a} \rightarrow \mathbf{e}, \mathbf{e} \rightarrow \mathbf{i}, \mathbf{0} \rightarrow \mathbf{e}, \mathbf{u} \rightarrow \mathbf{i}$ (mais explicações em Ekdahl e Butler 1979: 21, 30). Exemplos com pi-ho "ir", ko?ituke "trabalhar", arau-ko "nadar", isu-ko "bater", uke "olho", hhewe "pé": pi-he-ti "vais", kePitu-ke-ti "trabalhas", j-arau-ko "nadas", isi-ko-ne "bateste", j-uke "teu olho", hhiwi "teu pé".

Alguns elementos gramaticais tereno: 
- O sufixo independentizador mais usado é -ti, por exemplo: -owoku "casa de" (N-owoku "minha casa") $\rightarrow$ owoku-ti "casa". O sufixo dependentizador mais usado é -na, por exemplo: owoe "jabuti" $\rightarrow N$-owoe-na “meu jabuti”. Há também os sufixos dependentizadores - $\int a$ e - $a$, usados somente em algumas palavras, Uma dezena de palavras mudam todos os $\mathbf{O}$ em $\mathbf{A}$ na forma possuída, como: sopôro "milho" $\rightarrow$-sápara "milho de", $N$-sápara "meu milho", etc.

- Alguns sufixos nominais: -noe + -hiko + -fapa "plural", -ke / -ku "em, para, de (locativo)", fo(ko) "com, em, para, de".

- Os artigos definidos são $r a$ e $n e$. Os demonstrativos são: $e$-ne "anáfora (ele, o/a)", rã?a / ra " $1^{a}$ zona (este): perto" e ne-ko "2a zona (esse, aquele): mais longe". Como advérbios demonstrativos, temos: jaa "lá", ja-ra / jaa-je / ja-ku "aqui". Como interrogativos: kuti "o quê?, quem?", na "onde?, quando?".

- Os qualificadores são sufixos incorporados nos verbos (incorporação nominal), que são marcas de concordância com o sujeito (verbos intransitivos) ou com o objeto (verbos transitivos). As partes do corpo também podem ser incorporadas. Alguns qualificadores: -?o / -?a "corpo, animal", - $2 i$ "qualificador geral", - $h i$ / -he "plural, fio, capim", -ke "árvore, plural de coisas pequenas (arroz, etc.)", -ku "côncavo, dentro", -na "indivíduo", -no?e "líquido", -nuku "feixe", -pe "superfície", -pu?i / -po?e "redondo, bola", -so "fio", -?u "expansão".

- Os sufixos temáticos verbais do tereno são - $k o,-\int o,-h o$ ou -Ø (e não: $-k-o,-f-o,-h-o$, com um suposto sufixo -o "atual/real/indicativo" que não existe).

- Prefixos verbais: $k o-\sim k a$ - (se a primeira vogal da raiz for a) "positivo" ;;; mo- "negativo" (muito raro em tereno: mo-jeno "órfão, i.e. sem pais") ;; $i$ - "causativo $1 ", ; ; k o-\sim k a$ - (se a primeira vogal da raiz for a) “causativo2" ;; $a_{-} \sim o_{-}$(se a primeira vogal da raiz for $\left.\mathbf{0}\right) \sim A$ - (todos os $\mathbf{0}$ da raiz tornam-se a: é o singular suprafixo estudado em 1.2.) "subjuntivo/potential/irreal (negativo, imperativo, condicional, certos futuros hipotéticos)". Por exemplo: jono "ele foi" $\rightarrow$ ako jana "não foi", isú-ko-a "ele o bate" $\rightarrow i s i$-ka-a "bata nele!" (cf. mais exemplos em 1.2.).

- Sufixos verbais: -wo -pu (no subjuntivo, cf. 1.2.) "reflexivo", -koko "recíproco", -ino "aplicativo (benefactivo)", -kono "passivo" ;;; =mo "futuro", -Vwo "futuro imediato", -(i)ne "perfectivo, agora, próprio, finado", -pini "esquecido", ina-ti + -meku "há pouco tempo (passado recente)", - $t i$ + -ni "imperfectivo, progressivo, durativo", -kena + -fu "habitual", -heifo / -if "contínuo", -iko "ainda, por enquanto", awo "ainda não", -po "já, outra vez, de novo", -woko + fapa "entre”, -maka "também”, poeha "somente” ;,; -hi "reportativo", -nini "frustrativo", -mea + awaina "talvez (dubitativo)", -pera "será que...", -Vpepo "certeza", -po(no) "movimento", -hi "pejorativo", -inowo "coitadinho".

- Verbalizadores e nominalizadores: -fo "verbalizador ("fazer com")", -ko + -ku "lugar onde", $-e+-n e+-p e$ $+-k e+-u$ "nominalizadores".

\section{O subgrupo Bolívia: classificação interna}

6.1. Os protofonemas e seus reflexos. Na subfamília Bolívia, haveria oposição entre 15 proto-fonemas (11 consoantes e 4 vogais). Os quadros abaixo são provisórios, especificamente no que diz respeito às africadas e às fricativas: 
RAMIREZ \& FRANÇA - LÍNGUAS ARAWAK DA BOLÍVIA

\begin{tabular}{|c|c|c|c|c|}
\hline$* \mathbf{p}$ & $* t$ & & ${ }^{*} \mathbf{k}$ & $(* ?)$ \\
\hline & $\begin{array}{l}* \text { ts } \\
\left({ }^{*} \mathrm{~s}\right)\end{array}$ & $\begin{array}{l}* \mathrm{t} \boldsymbol{t} \\
{ }^{*} \mathrm{c}\end{array}$ & & $(* h)$ \\
\hline${ }^{*} \mathbf{m}$ & $\begin{array}{l}{ }^{*} \mathbf{n} \\
*_{\mathbf{r}}\end{array}$ & & & \\
\hline${ }^{*} \mathbf{W}$ & & $* \mathbf{j}$ & & \\
\hline
\end{tabular}

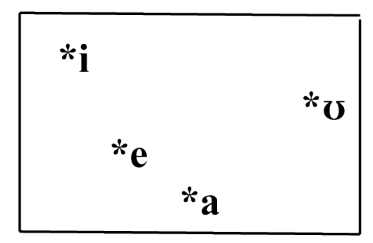

O quadro seguinte apresenta as correspondências fônicas encontradas nos reflexos das quatro línguas do subgrupo Bolívia:

\begin{tabular}{|c|c|c|c|c|c|}
\hline * ARAWAK > & * BOLÍVIA > & MOJEÑO & BAURE & PAUNA & TERENO \\
\hline$* p(* f)+* b$ & $\begin{array}{l}* \mathbf{p} \\
* \mathbf{p} /{ }^{*} \mathbf{i},{ }^{*} \mathbf{e}\end{array}$ & $\begin{array}{l}\mathbf{p} \\
\mathbf{p}, \mathbf{w}\end{array}$ & $\begin{array}{l}p \\
p, w\end{array}$ & $\begin{array}{l}\mathbf{p} \\
\mathbf{p}, \mathbf{w}\end{array}$ & $\begin{array}{l}\mathbf{p} \\
\mathbf{p}, \mathbf{w}\end{array}$ \\
\hline$* \mathbf{t}^{\mathrm{h}}+* \mathbf{r}$ & $* \mathbf{r}$ & $\mathrm{r},(?),(\varnothing)$ & $r,(?)$ & $\mathbf{r}, \varnothing,(?)$ & $\mathbf{r}, \emptyset,(?)$ \\
\hline$* t+* d /{ }^{*} a, * \sigma(?)$ & $* t$ & $\mathbf{t}$ & $t$ & $\mathbf{t}$ & $\mathbf{t}$ \\
\hline$* \mathbf{k}$ & 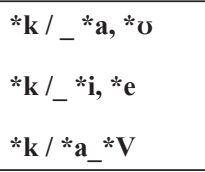 & $\begin{array}{l}\mathrm{k} \\
\mathrm{s} \\
?\end{array}$ & $\begin{array}{l}\mathrm{k} \\
\mathrm{s} \\
?\end{array}$ & $\begin{array}{l}\mathbf{k} \\
\mathbf{k}\left({ }^{*} \mathrm{i}\right), \mathrm{s}\left({ }^{*} \mathrm{e}\right) \\
\mathbf{P}>\boldsymbol{\emptyset}\end{array}$ & $\begin{array}{l}\mathrm{k} \\
\mathrm{k} \\
?\end{array}$ \\
\hline$*_{s}$ & $*$ ts & (t)s & $\mathbf{t}$ & $s, t$ & $s, t$ \\
\hline$* d / * t(\mathbf{t}), * t \int(?)$ & $* t \int$ & ts & $\mathbf{t} \int, \int$ & ts & (t) $\int$ \\
\hline$* \mathrm{t} \int / * \mathrm{ti}(?)$ & *s (???) & ts & $\int, \mathbf{t} \int$ & $\mathbf{s}$ & $\mathbf{s}$ \\
\hline$*^{*}(* h)+* t s i$ & ${ }^{*} \mathrm{c}\left({ }^{*} h\right)$ & h & $\mathbf{h}<* \boldsymbol{\delta}$ & h & ç (hh), h \\
\hline$* \mathbf{m}$ & $* \mathrm{~m}$ & $\mathbf{m}$ & $\mathbf{m}$ & $\mathbf{m}$ & $\mathbf{m}$ \\
\hline *n & $* \mathbf{n}$ & $\mathbf{n}$ & $\mathbf{n}$ & $\mathbf{n}$ & $\mathbf{n}$ \\
\hline${ }^{*} \mathbf{w}$ & ${ }^{*} \mathbf{w}$ & $\mathbf{w}[\mathrm{w}, \beta]$ & $\mathbf{w}, \boldsymbol{\beta}$ & $\mathbf{w}[\mathrm{w}, \beta]$ & $\mathbf{w}[\mathrm{w}, \beta]$ \\
\hline$* \mathbf{j}+* \mathbf{l}$ & $* \mathbf{j}$ & $\mathbf{j}$ & $\mathbf{j}$ & $\mathbf{j}$ & $\mathbf{j}$ \\
\hline$*_{\dot{i}}$ & $*_{\mathbf{i}}$ & $\mathrm{i}>\mathrm{e}$ & $\mathrm{i}>\mathrm{e}$ & $\mathrm{i}>\mathrm{e}$ & $\mathbf{i}>\mathbf{e}$ \\
\hline
\end{tabular}

- Reconstruímos a única oclusiva bilabial *p para o proto-Bolívia:

\begin{tabular}{|c|c|c|c|c|c|}
\hline & *BOLÍVIA & MOJEÑO & BAURE & PAUNA & TERENO \\
\hline unha & $*_{\text {-çipa }}$ & -hipa-na & -tipv & -sipv & hhîpo \\
\hline animal doméstico & *-pira & -pera & -perv & $-p e v$ & -pêjo \\
\hline um & *apa- & apa- & $p a-/ p v_{-}$ & --- & po-hha \\
\hline $2 \operatorname{sg}$ (Sujeito) & $* p i-$ & $p i-$ & $p i-$ & $p i-$ & --- \\
\hline 2sg (Objeto) & $*_{-p i}$ & $-w i$ & $-p i /-\beta i$ & $-p i /-w i$ & $-p i$ \\
\hline casa & *peti & peti & -weri & --- & péti \\
\hline
\end{tabular}


Essa oclusiva bilabial *p corresponde à fusão dos dois protofonemas arawak *p (*f) e *b: por exemplo, confira o protoarawak *pi- "2sg", *-huba "unha" e *aba- "um".

Note que, às vezes, há lenição de *p antes de *i e *e (*p > w / _ *i/*e) como em " $2 \operatorname{sg}($ Objeto)" e "casa". Confira também "morcego" (398), "varrer" (304).

Outros exemplos 6 : 57, 121, 125, 268, 360, 371, 466, 485, etc.

- A líquida reconstruída *r não apresenta grandes problemas:

\begin{tabular}{|c|c|c|c|c|c|}
\hline & *BOLÍVIA & MOJEÑO & BAURE & PAUNA & TERENO \\
\hline lua & *kaçere & kahe & kehere-s & kohe & kohhee \\
\hline beber & $*_{-i r a}$ & -era & -ero & $-e a$ & eró-?ufo "sede" \\
\hline nariz & *kiri & -siri/-sii & - siri-ki & --- & kiri \\
\hline animal doméstico & *-pira & -pera & -perv & -per & -pêjo \\
\hline independentizador & *-re & $-r e$ & $-r e$ & $-e$ & -- \\
\hline raiz & *-apare & t-apare & -pvrie & -- & -po?e \\
\hline
\end{tabular}

Essa líquida * $\mathbf{r}$ corresponde à fusão dos dois protofonemas arawak *th e *r: por exemplo, compare os exemplos acima com o protoarawak *kahith "lua", *-(d)ith a "beber", *-kiri "nariz", *-re "independentizador" e *-apare "raiz". Note que $\mathbf{r}$ é frequentemente reduzido a uma oclusão glotal ou cai (*k $>\mathbf{P}>\boldsymbol{\emptyset})$, especialmente em tereno e paunaka.

Outros exemplos: 136, 176, 188, 242, 398, 427, 445, 446, 447, 497, etc.

- Reconstruímos a única oclusiva dental *t para o proto-Bolívia:

\begin{tabular}{|c|c|c|c|c|c|}
\hline & *BOLÍVIA & MOJEÑO & BAURE & PAUNA & TERENO \\
\hline sangue & $*_{i-t i}$ & $i t i$ & $i t i$ & $i t i$ & $i t i$ \\
\hline morcego & *pite & wite & $\beta$ ite & wite & wite-te \\
\hline saúva & $*_{\text {mataro }}$ & mataro & matari & motvit & --- \\
\hline espinho & *itape & itape & --- & --- & tôpe / itapa \\
\hline jacu, galinha & *takore & takora & --- & takira & tokoe \\
\hline
\end{tabular}

Outros exemplos: 140, 195, 460, 476, 521, etc.

- Reconstruímos a única oclusiva velar *k para o proto-Bolívia:

${ }^{6}$ Os números correspondem à lista de jogos de cognatos exposta na última seção deste estudo. 
RAMIREZ \& FRANCCA - LÍNGUAS ARAWAK DA BOLÍVIA

\begin{tabular}{|c|c|c|c|c|c|}
\hline & *BOLÍVIA & MOJEÑO & BAURE & PAUNA & TERENO \\
\hline excremento & *-it(J)ika & -it/ika- & $-f i k v$ & -tike- & isiko \\
\hline tio & *-ekvka & -ekwka & -kika & $-k i k v$ & euko / eku-seno \\
\hline lua & *kaçere & kahe & kehere-s & kohe & kohhee \\
\hline comer & *-nika & -nika & $-n i k v$ & $-n i k v$ & niko \\
\hline nariz & *kiri & -siri / -sii & -siri-ki & --- & kiri \\
\hline sol & *ketfe & satfe & sese & satfe & katfe \\
\hline ouvir & *-kema & -sama & -svmv / -samv & $-\operatorname{sam} v$ & -kamo \\
\hline queixada (porco) & *kimarv & simarv & simori & --- & kimou \\
\hline ema (nandu) & *kipa-re & sipa & sipv-re & kipa & kipâ-e \\
\hline mão & *-waku & $-a P v$ & $-w a k i$ & $-w \sigma i$ & wo?v \\
\hline
\end{tabular}

Esta oclusiva velar *k do proto-Bolívia corresponde à fusão dos dois protofonemas arawak *k e * $\mathbf{k}^{\mathbf{h}}$. Alguns problemas não resolvidos ocorrem, por exemplo, em *-aki “semente" (61), *-ki "pau” (118), *apake?e "chão" (135), em que o mojeño, o baure ou o pauna não palatalizam. Essas "exceções" envolvem principalmente os sufixos $-k i$ e $-k e ? e$. O problema poderia ser resolvido com a introdução de ditongos, por exemplo: $-k i<-k a \dot{t}$ / kai. $-k e$ ?e $<-k a$ ?i (cf. 1.3.).

O valor fonêmico de *? é pouco provável em proto-Bolívia: a oclusão glotal parece sempre nascer da queda de certas consoantes $(\mathbf{k}, \mathbf{r}, \mathbf{j})$ em estágio posterior ao proto-Bolívia.

Outros exemplos: *k / *a, ${ }^{*} \boldsymbol{w}>*_{\mathbf{k}}: 12,45,192,195,263,298,334,337,385,445,463$, 497, etc. - *k / _*i,*e > $\mathbf{s}$ (menos o tereno, e o pauna antes de $\underline{\mathbf{i}}): 188,233,258,377,447$, etc. $-* \mathbf{k}>* \mathbf{p}>\boldsymbol{\varnothing}: 2,3,23,45$, etc.

- Exemplos do protofonema *t $\int$ do proto-Bolívia:

\begin{tabular}{|c|c|c|c|c|c|}
\hline & *BOLÍVIA & MOJEÑO & BAURE & PAUNA & TERENO \\
\hline seio & $*_{-t} t$ in $i$ & -tfene & $-(t) \int e n a$ & -t tene & $-(t)$ fene \\
\hline orelha & $*-t f a k a$ & $-t \int a k a$ & $-t \int v k v$ & $-t / \delta k a$ & --- \\
\hline pessoa & *atfane & atfane & tfane-t $i$ & otfane & (t) fane \\
\hline capivara & $*_{\sigma t} t / v$ & $\sigma t / \int_{v}$ & $v / i$ & $i t / \hat{t}$ & --- \\
\hline sogro & *-ima-at/vka & -matfoka & -mofoka & --- & $i m o(t) f u k o$ \\
\hline
\end{tabular}

Esta africada *t $\mathbf{f}$ do proto-Bolívia às vezes corresponde a *di ou *ti do protoarawak. Por exemplo, compare com o protoarawak: *-dini "seio", *adina / *atina "caminho" (*atfene em proto-Bolívia), *diwi "sal" (*itfewe em proto-Bolívia), *-dima "estar de pé" (*-tfema em proto-Bolívia).

Outros exemplos: $65,138,159,200,210,249,264$, etc.

- Exemplos do protofonema *s do proto-Bolívia: 
LIAMES 19

\begin{tabular}{|c|c|c|c|c|c|}
\hline & *BOLÍVIA & MOJEÑO & BAURE & PAUNA & TERENO \\
\hline onça & *isini & itfini & (i) $t /$ ini & isini & $\sin i$ \\
\hline $\begin{array}{l}\text { formiga-de- } \\
\text { fogo }\end{array}$ & *katfi-rv & katf-irv & $k v \int i-r i$ & $k u s i-\mho$ & kosi-u \\
\hline sol & *kese /*ketfe & satfe & sese & satfe & katfe \\
\hline
\end{tabular}

Esta fricativa *s do proto-Bolívia talvez corresponda ao *t $\int$ ou à sequência *ti do protoarawak. Talvez seja o mesmo protofonema que o precedente: *t $\int$.

Outros exemplos: $36,86,216,223,474$, etc.

- Exemplos do protofonema *ts do proto-Bolívia:

\begin{tabular}{|l|l|l|l|l|l|}
\cline { 2 - 6 } \multicolumn{1}{c|}{} & *BOLÍVIA & MOJEÑO & BAURE & PAUNA & TERENO \\
\hline urina & $*$-tsene & - sene & -tene & --- & sêne- \\
\hline mulher & $*(e)$ tsena & esena & etenv & eseno & seno / têno "moça" \\
\hline cinzas & $*$ tsima & tsima & --- & tima- & --- \\
\hline
\end{tabular}

Esta africada *ts do proto-Bolívia corresponde ao $\mathbf{\jmath}$ do wapixana, ao ts / $\mathbf{t} \int$ do bahuana, do piro, do apurinã e do kampa, e ao t do iñapari:

Outros exemplos: $145,192,436$.

- Exemplos do protofonema *ç do proto-Bolívia:

\begin{tabular}{|l|l|l|l|l|l|}
\cline { 2 - 6 } \multicolumn{1}{c|}{} & *BOLÍVIA & MOJEÑO & BAURE & PAUNA & TERENO \\
\hline vespa & *çani & hane & hane & hane & çane \\
\hline lua & *kaçere & kahe & kehere-s & kvhe & koçee \\
\hline quati & *kapeçi & kapehi & --- & kopehi & --- \\
\hline unha & *-çipa & -hipa & -t-ipv & -sipv & çipo \\
\hline
\end{tabular}

Esta fricativa *ç do proto-Bolívia corresponde a *ç/*h e, provavelmente também, a *tsi do protoarawak. Exemplos como reflexo do protoarawak *tsi: *kapitsi "quati", *-itsi-pi "cauda" (*-içi em proto-Bolívia), *kitsa-re "fumaça" (*kiça-re em proto-Bolívia).

Outros exemplos: $31,56,69,71,136,448$, etc.

- Os protofonemas *m, *n, *w e *j não apresentam problemas: 
RAMIREZ \& FRANCCA - LÍNGUAS ARAWAK DA BOLÍVIA

\begin{tabular}{|c|c|c|c|c|c|}
\hline & *BOLÍVIA & MOJEÑO & BAURE & PAUNA & TERENO \\
\hline abóbora & $*_{m a k v-(w) i}$ & makw-re & mokvi-re & moki-e & moko-a \\
\hline três & $*_{m a p a-}$ & mapa- & mopv- & -- & торо-?а \\
\hline água & $*_{\text {oni / }} *_{\text {one }}$ & one & ine & ine & une \\
\hline céu & $*(w)$ anv /*(w)env & $a n \mho-m a$ & ani & $a n i-m \sigma$ & wanu-ke?e \\
\hline $1 \mathrm{pl}$ & $*(a) w i-$ & $w i-$ & $\beta i-$ & $w i-$ & $w i-$ \\
\hline veado & *kaçawa & kahawa & kahawa & kosuwa & koçowoi \\
\hline esposa & $*_{\text {-jena }}$ & -jena & -ejon /-jenv & -jenv & jeno \\
\hline chorar & $*_{-i j a-k a}$ & $-i j a-? a$ & $-j a$ & $-j U$ & ijo-o \\
\hline
\end{tabular}

Esses protofonemas do proto-Bolívia são reflexos idênticos aos respectivos protofonemas arawak. Note que *j é o resultado da fusão dos dois protofonemas *j e *I do protoarawak. Exemplos como reflexo de *I: *lvkv "fogo" ( *jokv em proto-Bolívia), *lapa "paca" (*japa em proto-Bolívia), *lvkv-ri "ambaúba" (*jokv- em proto-Bolívia), *lana "jenipapo" (*jana em proto-Bolívia).

Outros exemplos: *m: 66, 209, 212, 377, 458, 466, etc. - *n: 12, 46, 74, 98, 125, 138, 203, 217, 30088, 465, 469, etc. - *w: 28, 29, 56, 159, 202, 344, etc. - *j $(<* \mathbf{j}): 217,397$ - *j (<*1): 41, 59, 116, 140, 370, 516, 519.

- As quatro vogais do proto-Bolívia (*a, *e, *i, *J) têm reflexos determinados pelas mudanças em cadeia descritas em 1.3., o que evidencia quatro derivas vocálicas:

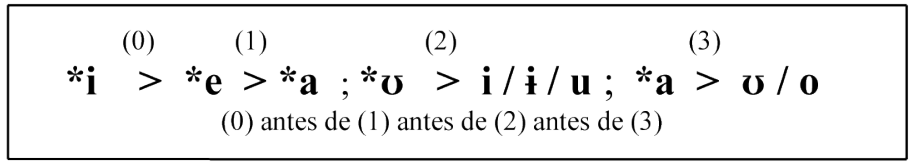

Como já argumentamos em 1.3., a regra *i (arawak) > *i (Bolívia) (fusão dos protofonemas arawak $* \mathbf{i}$ e $* \mathbf{i})$ deve ser anterior ao proto-Bolívia, os $\underline{\dot{\mathbf{j}}}$ de todas as outras línguas arawak tornando-se $\underline{\mathbf{i}}$, ou $\underline{\mathbf{e}}$ com a deriva (0), nos reflexos do subgrupo Bolívia. Como exemplos: cf. *-api /*-ape (< arawak: *-api) "osso," *-pira (< arawak: *-pira) "animal doméstico", *kaçiri / *kaçere (< arawak: *kaçîri) "lua", *-imaka (< arawak *-dimaka) "dormir". Outros exemplos de *i (arawak) > *i/e (Bolívia) em: 13, 46, 138, 159, 188, 371, 445, 465, etc.

(3) Começando pelo fim, iniciaremos pela deriva mais recente: a deriva vocálica (3), que é o processo destrutivo do protofonema *a, vê-se claramente diante de nossos olhos no transcorrer dos últimos séculos. Em 1.3., demos muitos exemplos da deriva (3): *a $>$ w/o, como *kema "anta": Mojeño (ignaciano) sama, Mojeño (trinitario) samo, Baure somo, Pauna samv, Tereno kamo. Essa mudança a $>\mathbf{o} / \mathbf{v}$ pode afetar qualquer a no subgrupo Bolívia, e muitos a não são atingidos. Como vimos em 2.2., o mojeño ignaciano mostra-se o mais resistente a essa deriva. Temos a seguinte escala de resistência a (3), da menos a mais produtiva:

Mojeño (ignaciano) $>$ Mojeño $($ loretano $)>$ Mojeño $($ trinitario, javeriano) $\&$ Tereno $>$ Pauna $>$ Baure 
(2) Em 1.3., demos muitos exemplos da deriva (2):

$$
*_{\boldsymbol{U}}>\boldsymbol{U} \text { (ignaciano) / } \mathbf{u} \text { (mojeño trinitario, tereno) / } \mathbf{i} \text { (baure) } / \mathbf{\mathbf { i }} \text { (pauna) }
$$

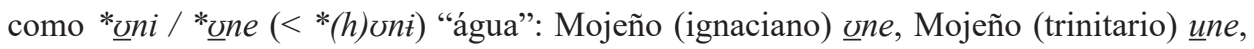
Baure $\underline{i n}$, Pauna $\underline{i} n e$, Tereno une. Mais exemplos em: 1, 28, 78, 80, 101, 116, 213, 305, $369,378,392,446,458,469,518$, etc.

(1) Sobre a deriva por propulsão (1): *e (arawak \pm Bolívia) $>\mathbf{a}$ (reflexos Bolívia \pm Bolívia), demos o exemplo *kema "anta" (<*kema): Mojeño (ignaciano) sama, Mojeño (trinitario) samo, Baure $\underline{\underline{v}} \tilde{m} \sigma$, Pauna $s \underline{a} m \sigma$, Tereno kamo. Neste exemplo, note que o baure sofreu a regra de propulsão (1) *e > a antes da regra de tração (3) *a > $\boldsymbol{\sigma}$. Mais exemplos em: 76, 98, 100, $101,122,209,468$, etc.

(0) Sobre a deriva por propulsão (0): *i (arawak Bolívia) > e (Bolívia), o leitor encontrará exemplos em: 8, 32, 53, 98, 122, 136, 258, 468, etc.

- A existência de vogais longas em proto-Bolívia é problemática. Poderia ajudar a explicar certos aspectos da deriva vocálica, como os reflexos de *ii- "2pl" (310), que seriam î (tereno), ji / je (baure), e- (mojeño, pauna). Poderia também explicar melhor a gênese do "tom descendente" $(\wedge)$ do tereno.

6.2. Classificação interna do proto-Bolívia. A seção anterior mostra uma certa dificuldade para definir certas africadas ou fricativas no proto-Bolívia e os reflexos associados a elas. Além disso, não temos certeza alguma de que a palatalização de *k seja anterior às derivas vocálicas e não podemos ordenar todas as outras mudanças diacrônicas que atingiram as protoconsoantes.

Nessas condições, vejamos o que o léxico do proto-Bolívia pode nos ensinar. A partir da longa lista de palavras do subgrupo Bolívia (mojeño, baure, pauna, tereno), que o leitor encontrará na Enciclopédia das Línguas Arawak, examinamos 100 conceitos básicos e calculamos, para cada par de línguas, a percentagem de cognatos compartilhados por eles. Obtemos os resultados seguintes:

\begin{tabular}{|ll|}
\hline Mojeño-Tereno: $\mathbf{7 4 \%}$ & Baure-Pauna: $\mathbf{5 8 \%}$ \\
Mojeño-Baure: $\mathbf{6 4 \%}$ & Baure-Tereno: $\mathbf{6 5 \%}$ \\
Mojeño-Pauna: $\mathbf{6 7 \%}$ & Pauna-Tereno: $\mathbf{5 9} \%$ \\
\hline
\end{tabular}

Essas percentagens não devem ser levadas ao pé da letra. Como já dissemos, o pauna é o parente pobre do subgrupo Bolívia. Em pauna, não temos o termo para “dar", e os termos para "dois" e "três" foram adotados do castelhano. Além disso, há empréstimos chiquito até dentro do vocabulário básico. Por exemplo, compare: torø [pauna] / toro [chiquito] "homem", ti-hápiko [pauna] / abe-ko [chiquito] "cheio", ti-písi [pauna] / kí-bisi [chiquito] "preto", -tiwwa [pauna] / -timo [chiquito] "sentado". No entanto, as percentagens sugerem que a língua mais próxima do pauna seria o mojeño. Por outro lado, o mojeño e o tereno têm entre si uma dezena de cognatos a mais que qualquer dessas duas línguas com o baure. 
RAMIREZ \& FRANCCA - LÍNGUAS ARAWAK DA BOLÍVIA

Tudo isso sugere a hierarquia abaixo, a não ser que os leitores mais prudentes prefiram contentar-se com uma politomia total:

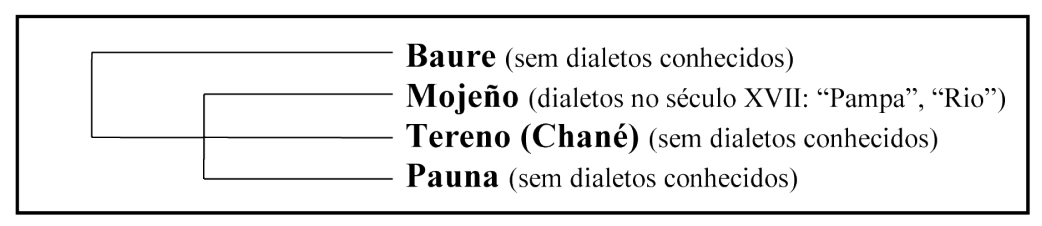

Como já dissemos, a dialetologia anterior à chegada dos europeus e a dos guarani é praticamente desconhecida: o repartimento em missões destruiu boa parte das diferenças, e a chegada quase simultânea dos europeus e dos guarani aniquilou o mundo chané (tereno) e obrigou os que ainda falavam sua língua a uma longa diáspora rumo ao rio Paraguai. Como exceção, sabemos que, antes da chegada dos jesuítas (fim do século XVII), devia haver certas diferenças fonéticas entre os mojeño do rio Mamoré e os dos pampas ocidentais. Atualmente, o que podemos ver são dialetos mojeño ("ignaciano", "loretano", "trinitario", "javeriano") e baure ("baure de Concepción”, “carmelita”, “†joaquiniano”) com $100 \%$ do vocabulário básico em comum e a mesma gramática, mas com algumas variações fonéticas e um número reduzido de palavras divergentes.

\section{O subgrupo Bolívia: classificação externa}

O quadro abaixo compara o proto-Bolívia com os reflexos de algumas outras línguas da mesma família, com as abreviaturas seguintes: BAN (baniva de Maroa), YAV (yavitero), MAIP (maipure), JC (Japurá-Colômbia), WAPI (wapixana) e BAHU (bahuana): ${ }^{7}$

\begin{tabular}{|c|c|c|c|c|c|c|c|c|c|}
\hline *ARAWAK & *BOLIVIA & $\begin{array}{l}\text { BAN/YAV/ } \\
\text { MAIP }\end{array}$ & BARÉ & LOKO & IÑERI & GUAJIRO & $* \mathrm{JC}$ & WAPI & BAHU \\
\hline$* \mathbf{p} / * \mathbf{f}$ & \multirow{2}{*}{$* \mathbf{p}$} & \multirow{2}{*}{$\mathbf{p} / \mathbf{h} / \mathbf{p}$} & \multirow{2}{*}{ b } & $\mathbf{f}+\mathbf{b}$ & $\mathbf{f}+\mathbf{b}$ & h & \multirow{2}{*}{$* \mathbf{p}$} & $\mathbf{p}$ & $\phi$ \\
\hline *b & & & & b & b & $p(w>\varnothing)$ & & b $>$ ? & $b>$ ? \\
\hline$* \mathbf{t} /{ }_{-}{ }^{\mathbf{i}, \mathbf{i}}$ & $*_{S}$ & ts / ts / Ø & \multirow{2}{*}{$\mathbf{s}$} & \multirow{2}{*}{$\mathbf{t}$} & \multirow{2}{*}{$\mathbf{t}$} & I & $* ? / \varnothing$ & \multirow{2}{*}{ d } & \multirow{2}{*}{ t } \\
\hline$* t /{ }_{-} * \mathbf{a}, \boldsymbol{\sigma}$ & $* t$ & t / t / O & & & & $\mathbf{t}$ & $* t$ & & \\
\hline${ }^{*} \mathbf{d} /{ }_{-}^{*} \mathbf{i}, \dot{i}$ & $* \mathrm{t} \int$ & ts / ts / Ø & \multirow{2}{*}{ d } & \multirow{2}{*}{ d } & \multirow{2}{*}{ f } & to & \multirow{2}{*}{$* ?$} & \multirow{2}{*}{ t } & \multirow{2}{*}{$\mathbf{t}$} \\
\hline${ }^{*} \mathbf{d} /{ }_{-}{ }^{*} \mathbf{a}, \boldsymbol{\sigma}$ & $* t$ & $t / t / \varnothing$ & & & & t & & & \\
\hline$* \mathrm{t}^{\mathrm{h}}$ & $* r$ & $\mathbf{j} / \mathbf{j} / \mathbf{j}$ & $\mathbf{j}$ & $\mathbf{t}^{\mathrm{h}}$ & $\mathbf{t}^{\mathrm{h}}$ & $\mathbf{s} \sim \int$ & $* T$ & $\mathrm{t}$ & $t$ \\
\hline${ }^{*} \mathbf{k} /{ }_{-} \mathbf{i}, \mathbf{i}$ & \multirow{4}{*}{$* \mathbf{k}$} & $\boldsymbol{\sigma} / \mathrm{s} / \mathrm{k}$ & $t$ & $\mathbf{s}$ & $\mathbf{s}$ & \multirow{2}{*}{$k>?>\varnothing$} & $* \mathrm{~S}$ & \multirow{4}{*}{$\mathbf{k}$} & \multirow{4}{*}{$\mathrm{k}$} \\
\hline${ }^{*} \mathbf{k} / \ldots{ }^{*} \mathbf{a}, \boldsymbol{v}$ & & $\boldsymbol{\varnothing} / \mathbf{k} / \mathbf{k}$ & $\mathbf{k}$ & $\mathbf{k}$ & $\mathbf{k}$ & & $* \mathbf{k}$ & & \\
\hline${ }^{*} \mathbf{k}^{\mathrm{h}} /{ }^{*} \mathbf{i}, \mathbf{i}$ & & $\boldsymbol{\sigma} / \mathbf{s} / \mathbf{k}$ & t & $k^{h}$ & $\mathbf{k}^{\mathrm{h}}$ & $\mathbf{k} / \mathbf{i}$ & $* \mathrm{~S}$ & & \\
\hline${ }^{*} \mathbf{k}^{\mathrm{h}} /{ }^{*} \mathbf{a}, \boldsymbol{\sigma}$ & & $\boldsymbol{\emptyset} / \mathbf{k} / \mathbf{k}$ & $\mathbf{k}$ & $\mathbf{k}^{\mathrm{h}}$ & $\mathbf{k}^{\mathrm{h}}$ & h & $* \mathbf{k}$ & & \\
\hline$* I$ & $* \mathbf{j}$ & $\mathbf{j} / \mathbf{j} / \mathbf{j}$ & $\mathbf{j}$ & 1 & 1 & $1 / \mathbf{r}$ & $* 1$ & $\mathrm{t}$ & $\mathbf{r}$ \\
\hline$* \mathbf{r}$ & $* \mathbf{r}$ & $1 / 1 / r$ & $\mathbf{r}$ & $1 / r / r$ & $1 / r / r$ & $1 / r$ & $*_{\mathbf{r}}$ & $\mathbf{r}$ & $\mathbf{r}$ \\
\hline
\end{tabular}

${ }^{7}$ Para todas essas línguas, o leitor poderá consultar a Enciclopédia das línguas Arawak e as referências bibliográficas nela incluídas. 
LIAMES 19

\begin{tabular}{|c|c|c|c|c|c|c|c|c|c|}
\hline$*$ ts & $*_{c}$ (h) & $\mathbf{s} / \mathrm{l} / \mathrm{t}$ & h & h & 1 & $\mathbf{s}$ & $*$ ts & $\int$ & $\mathbf{s}$ \\
\hline$*_{s}$ & $*$ ts & Ø / Ø / Ø & h & $?$ & $?$ & $?$ & $* \varnothing$ & I & ts \\
\hline${ }^{*} c ̧(* h)$ & ${ }^{*}$ ç (h) & $\varnothing / \varnothing / \varnothing$ & $\mathbf{h}$ & $\mathbf{h}$ & h & $\mathbf{h} \sim \boldsymbol{\emptyset}$ & $* \mathbf{h}$ & $?$ & $\mathbf{h}$ \\
\hline${ }^{*} \mathbf{j}$ & $* \mathbf{j}$ & $\mathbf{j} / \mathbf{j} / \mathbf{j}$ & $\mathbf{j}$ & $\mathbf{j}$ & $\mathbf{j}$ & $\mathbf{j}$ & $* \mathbf{j}$ & $(t) \int$ & $\mathbf{j}$ \\
\hline$*_{\mathbf{i}}$ & $*_{i}$ & $\mathbf{i} / \mathbf{i} / \mathbf{i}$ & $\mathbf{i}$ & $\dot{\mathbf{t}}$ & $\dot{\mathbf{i}}$ & $\dot{\mathbf{i}}$ & $*_{\mathbf{i}}$ & $\dot{\mathbf{i}}$ & i \\
\hline
\end{tabular}

Como se vê, as correspondências são muito confusas, e, como em muitas línguas arawak ou em muitas outras línguas do mundo (como as línguas neolatinas), as fricativas e as africadas levantam problemas irritantes e extremamente complicados. No entanto, tudo fica mais claro quando se compara as línguas do subgrupo Bolívia (mojeño, baure, pauna, tereno) com as línguas do subgrupo Purus (piro, iñapari, apurinã, kararí) e do subgrupo Kampa. Na realidade, o proto-Bolívia, o proto-Purus e o pré-Kampa deviam ter o mesmo sistema fonológico: mesmas protoconsoantes e mesmas protovogais, à exceção de *i্i, que fusionou com *i em proto-Bolívia e em pré-kampa, mas não em proto-Purus:

*BOLÍVIA

\begin{tabular}{|c|c|c|c|c|}
\hline${ }^{*} \mathbf{p}$ & $* t$ & & ${ }^{*} \mathbf{k}$ & \\
\hline & *ts & $* \mathrm{t} \int$ & & \\
\hline & (s) & ${ }^{*} \mathrm{c}$ & & ${ }^{*} \mathbf{h}$ \\
\hline${ }^{*} \mathrm{~m}$ & ${ }^{*} \mathbf{n}$ & & & \\
\hline & $* \mathbf{r}$ & & & \\
\hline${ }^{*} \mathbf{W}$ & & $* \mathbf{j}$ & & \\
\hline
\end{tabular}

\begin{tabular}{|l|l|l|}
\hline$*_{\mathbf{i}}$ & & \multirow{2}{*}{${ }^{*} \boldsymbol{}$} \\
\cline { 1 - 1 }$*_{\mathrm{e}}$ & & \\
\hline & $*_{\mathrm{a}}$ & \\
\hline
\end{tabular}

*PURUS

\begin{tabular}{|c|c|c|c|c|}
\hline$* \mathbf{p}$ & $* \mathbf{t}$ & & $*_{\mathbf{k}}$ & \\
\hline & $* \mathbf{t s}$ & $(\mathbf{t})$ & & \\
\hline & & $*^{\mathbf{c}}$ & & $* \mathbf{h}$ \\
\hline$*_{\mathbf{m}}$ & $*_{\mathbf{n}}$ & & & \\
\hline & $*_{\mathbf{r}}$ & & & \\
\hline$*_{\mathbf{w}}$ & & $*_{\mathbf{j}}$ & & \\
\hline
\end{tabular}

\begin{tabular}{|c|c|c|}
\hline$*_{\mathbf{i}}$ & $*_{\mathbf{i}}$ & $*_{\boldsymbol{U}}$ \\
\cline { 1 - 1 }$*_{\mathrm{e}}$ & & \\
\hline & $*_{\mathbf{a}}$ & \\
\hline
\end{tabular}

*PRÉ-KAMPA

\begin{tabular}{|c|c|c|c|c|}
\hline${ }^{\mathbf{p}}$ & $* \mathbf{t}$ & & ${ }^{*} \mathbf{k}$ & \\
\hline & $* \mathbf{t s}$ & $\mathbf{( t \mathbf { j } )}$ & & \\
\hline & & ${ }^{*} \mathbf{c}$ & & $* \mathbf{h}$ \\
\hline$*_{\mathbf{m}}$ & ${ }^{*} \mathbf{n}$ & & & \\
\hline & ${ }^{*} \mathbf{r}$ & & & \\
\hline$*_{\mathbf{w}}$ & & $\mathbf{( j )}$ & & \\
\hline
\end{tabular}

\begin{tabular}{|l|l|l|}
\hline$*_{\mathbf{i}}$ & & \multirow{2}{*}{$*_{\boldsymbol{U}}$} \\
\cline { 1 - 1 }$*_{\mathrm{e}}$ & & \\
\hline & $*_{\mathrm{a}}$ & \\
\hline
\end{tabular}

com os reflexos seguintes:

\begin{tabular}{|c|c|c|c|c|c|c|c|c|c|}
\hline * BOLÍVIA > & MOJEÑO & BAURE & PAUNA & TERENO & PIRO & IÑAPARI & APURINÃ & $<*$ PURUS & *PRÉ-KAMPA \\
\hline *p & p & $\mathbf{p}$ & $\mathbf{p}$ & $\mathbf{p}$ & $\mathbf{p}$ & $\mathbf{p}$ & $\mathbf{p}$ & *p & ${ }^{*} \mathbf{p}>\mathbf{p} / \mathbf{w} / \mathbf{b}$ \\
\hline$* \mathbf{r}$ & $\mathbf{r},(?)$ & $\mathbf{r},(?)$ & $\mathbf{r},(?)$ & $\mathbf{r},(?)$ & $\mathbf{r}$ & $\mathbf{r}$ & $\mathbf{r}$ & ${ }^{*} \mathbf{r}$ & $* \mathbf{r}$ \\
\hline$* t$ & $\mathbf{t}$ & $\mathbf{t}$ & $\mathbf{t}$ & $\mathbf{t}$ & $t, t] \mathbf{i}$ & $t, t] \mathbf{i}$ & $\mathbf{t}$ & $* t$ & $* t>t / t s i$ \\
\hline $\begin{array}{l}{ }^{*} \mathbf{k} /_{-}{ }^{*} \mathbf{a} / \mathbf{u} \\
{ }^{*} \mathbf{k} /{ }_{-}{ }^{*} \mathbf{i} / \mathbf{e}\end{array}$ & $\begin{array}{l}\mathbf{k} \\
\mathbf{s}\end{array}$ & $\begin{array}{l}\mathbf{k} \\
\mathbf{s}\end{array}$ & $\begin{array}{l}\mathbf{k} \\
\mathrm{k}, \mathrm{s}\end{array}$ & $\begin{array}{l}\mathbf{k} \\
\mathbf{k}\end{array}$ & $\begin{array}{l}\mathbf{k} \\
\mathbf{x}\end{array}$ & $\begin{array}{l}? \\
\text { h }\end{array}$ & $\begin{array}{l}\mathbf{k} \\
\mathbf{k}\end{array}$ & $* \mathbf{k}$ & $* \mathbf{k}>\mathbf{k} / \mathbf{g} / \mathbf{j}$ \\
\hline$*$ ts & (t)s & $\mathbf{t}$ & $\mathrm{s}, \mathrm{t}$ & $s, t$ & ts $(t \mathrm{t} \mathbf{i})$ & $\mathbf{t}$ & ts $(\mathbf{t} \mathbf{j} \mathbf{i})$ & $*$ ts & $* t s>t s / t^{h}$ \\
\hline$* t \int$ & ts & $t(f)$ & ts & $(\mathrm{t}) \int$ & ts & ts & t & $* \mathrm{t} \int(?)$ & $* t \int(?)$ \\
\hline *s (???) & ts & $t(f)$ & $\mathbf{s}$ & $\mathbf{s}$ & -- & -- & -- & -- & -- \\
\hline *ç & h & h & h & $c ̧>h$ & $\mathrm{~s}(\mathbf{f i})$ & h & $\mathbf{s}(\mathbf{f i})$ & *ç & ${ }^{*} \boldsymbol{c}>\mathbf{s} / \mathbf{I} \mathbf{i} / \mathbf{h}$ \\
\hline$* \varnothing$ & $\varnothing$ & $\varnothing$ & $\varnothing$ & $\varnothing$ & $\mathbf{h}, \mathbf{x}$ & h & $\varnothing$ & ${ }^{*} \mathbf{h}$ & $* \mathbf{h}>\mathbf{h} / \boldsymbol{\emptyset}$ \\
\hline$* \mathbf{j}$ & $\mathbf{j}$ & $\mathbf{j}$ & $\mathbf{j}$ & $\mathbf{j}$ & $\mathbf{j}$ & $\mathbf{j}$ & $\mathbf{j}$ & $* \mathbf{j}$ & $* \mathbf{j}>\varnothing$ \\
\hline$*_{\mathbf{w}}$ & $\mathbf{w}$ & $\mathbf{w}$ & $\mathbf{w}$ & $\mathbf{w}$ & $w$ & $w$ & w & $*_{w}$ & $*_{\mathbf{w}}>\boldsymbol{\emptyset}$ \\
\hline$* \mathbf{i}$ & $\mathbf{i}$ & $\mathbf{i}$ & i & i & $\mathbf{i}$ & $\mathbf{i}$ & $\dot{\mathbf{i}}$ & $* \dot{i}$ & $* \mathbf{i}$ \\
\hline
\end{tabular}


- Exemplos de fusão dos dois protofonemas arawak $* \mathbf{t}^{\mathrm{h}} \mathrm{e} * \mathbf{r}$ :

“nariz”: Mojeño -siri, Baure -siri-ki, Tereno kiri „;; Piro -xri, Iñapari -hiri, Apurinã -kiri \#; Pré-Kampa *-kiri (< arawak *-kiri)

“animal”: Mojeño -pera, Baure -perø, Pauna -peø, Tereno -pêjo ;;; Piro -pra, Apurinã -pira ;; Pré-Kampa *-pira (< arawak *-pira)

"lua": Mojeño kahe, Baure kahere, Pauna kwhe, Tereno koçee ;;; Piro ksirti, Iñapari Pairi, Apurinã kasirit ;; Pré-Kampa *kaçiri (< arawak *kahith ${ }^{h}$ )

“beber”: Mojeño -era, Baure -ero, Pauna -ea, Tereno ero ;;; Piro -ira, Iñapari - $\tilde{t a}$, Apurinã -ĩa ;;; Pré-Kampa *-ir $\left(<\right.$ arawak $\left.*_{-}(d) \dot{t} t^{h} a\right)$

- Exemplos do protofonema *t:

"noite": Mojeño jati, Baure jatoi, Pauna joti, Tereno joti ;;; Iñapari jati

“muçum (peixe)": Mojeño itire, Baure (i)ti(re), Pauna itie, Tereno tie „;; Piro xitfri, Iñapari hetiri, Apurinã itfiri ;;; Pré-Kampa *tsiri

“dor”: Mojeño -kati, Baure -koti, Pauna -koti, Tereno koti- ;; Piro katfi-, Iñapari Pati-, Apurinã katfi ;; Pré-Kampa *katsi

"formiga": Mojeño matarø, Baure matari, Pauna motøi ;;; Piro matfahro, Apurinã mãjarv

- Exemplos do protofonema *ts:

"urina": Mojeño -sene, Baure -tene, Tereno sêne- ;; Piro -tsin-xa, Iñapari -tinit, Apurinã -tsina-ka ;; Pré-Kampa *-tsini

“azedo": Mojeño katsi, Tereno kotiwe- ;; Piro katføli, Iñapari Pati-øri, Apurinã katfi ;;; Pré-Kampa *katsio

“arco": Mojeño itsiparakv, Baure tipø- ;; Iñapari tfapori, Apurinã tapotfi

- Exemplos do protofonema *ç:

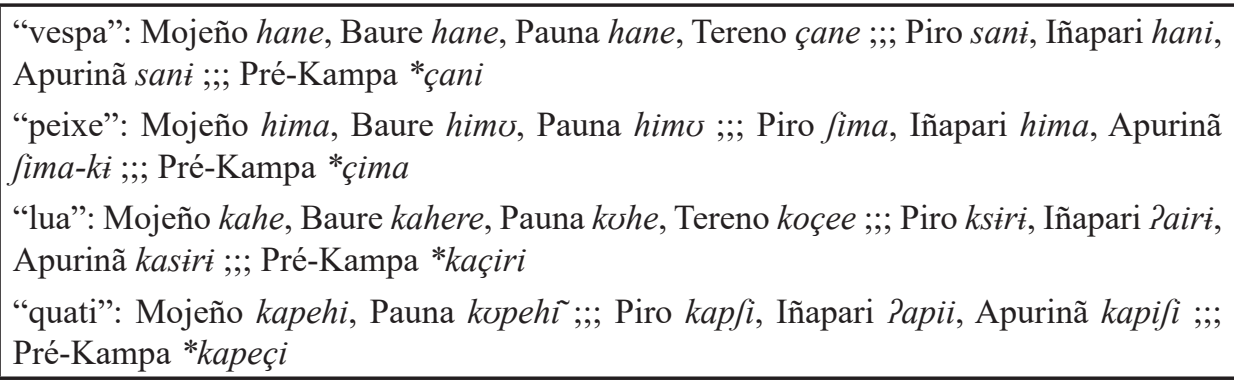


- Exemplos do protofonema *h do subgrupo Purus que desapareceu no subgrupo Bolívia (Ø):

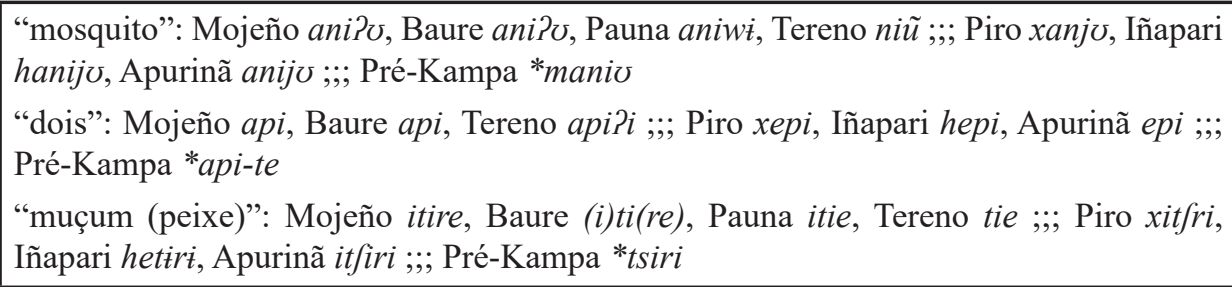

- Exemplos de fusão dos dois protofonemas arawak *j e *l:

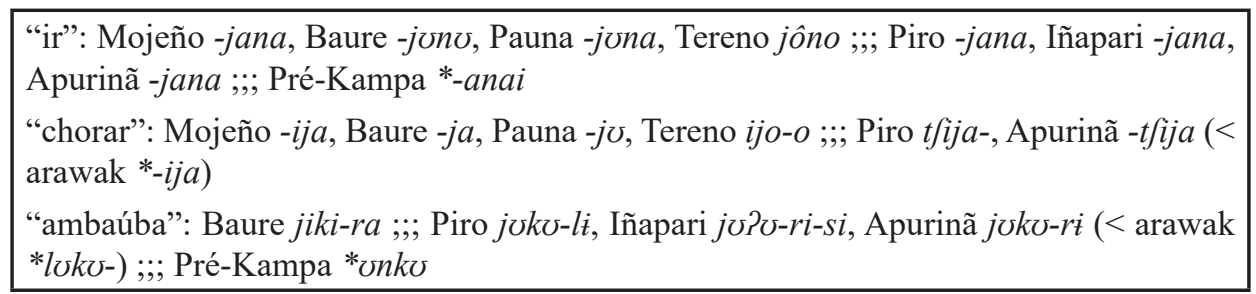

Além disso, as semelhanças lexicais e gramaticais do subgrupo Bolívia são maiores com o subgrupo Purus (piro-iñapari-apurinã) e também com as línguas kampa. Entre os subgrupos Bolívia e Purus, o leitor poderá consultar a Enciclopédia das Línguas Arawak e encontrará, no léxico básico de 100 conceitos, uma percentagem de $65 \%$ de cognatos, mais especialmente entre o baure e o iñapari. As percentagens são menores com o chamicuro e o amuesha (45\%), e as semelhanças lexicais e gramaticais caem drasticamente com o pareci (35-40\%). As distâncias lexicais entre os três subgrupos Bolívia, Purus e Kampa podem ser representadas pelo diagrama abaixo:

$$
\begin{aligned}
& \text { - Kampa / Purus: 53-58 \% } \\
& \text { - Bolívia / Purus: 60-62 \% } \\
& \text { - Kampa / Bolívia: 50\% }
\end{aligned}
$$

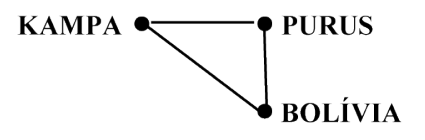

Tantas semelhanças fonológicas (fusão dos protofonemas arawak $* \mathbf{t}^{\mathbf{h}} \mathrm{e} * \mathbf{r}$, protofonemas Bolívia-Purus que denominamos *t, *ts e *ç e que apresentam reflexos coerentes e regulares), gramaticais e lexicais sugerem que os subgrupos Bolívia, Purus e Kampa formariam, dentro da família arawak, um supergrupo mais coeso que com todos os outros subgrupos arawak. 


\section{O supergrupo BPK(A)}

A comprovação da existência do supergrupo $P B K(A)$ (Bolívia-Purus-Kampa, com a possível inclusão do amuesha nele), deve necessariamente passar pelas etapas seguintes, que devem ser executadas dentro de um quadro de correspondências fônicas rigoroso e exigem muito trabalho:

- O amuesha deve ser minuciosamente comparado com as línguas kampa para distinguir o que é cognato do que foi adotado.

- O subgrupo Bolívia precisa de mais informações lexicais sobre a língua baure. $\mathrm{O}$ dicionário baure que os jesuítas elaboraram no século XVIII e que supostamente desapareceu deve ser urgentemente recuperado. Um bom dicionário de baure moderno é também necessário.

- Como a Enciclopédia das Línguas Arawak indica, a dialetologia do subgrupo Purus é totalmente deficiente. Os estudos linguísticos sobre esse subgrupo não alcançam a qualidade encontrada com os outros subgrupos em jogo. Em particular, faltam-nos um bom dicionário apurinã, uma boa gramática piro e mais dados sobre o iñapari.

- De onde viriam esses povos? Os estudos arqueológicos revelam uma cerâmica de tradições saladoide e barrancoide, do baixo rio Madeira até acima de Porto Velho (entre 700 a.C. e 700 d.C.), o que poderia sugerir que certos povos arawak teriam subido o Madeira há mais de 2.000 anos (Zuse 2016).

\section{A gênese caótica do subgrupo Bolívia}

Pelo que nossa pesquisa bibliográfica revelou, Rivet (Meillet e Cohen 1924: 646650) foi o primeiro a falar de um subgrupo boliviano (Groupe Bolivien) dentro da família arawak, incluindo nele o mojeño, o baure, o pauna, mas não o tereno. Loukotka (1935) retoma o subgrupo boliviano de Rivet e o completa com a inclusão do tereno, mas esquecendo-se do pauna, que não se encontra na sua classificação, e incluindo o sarave, um codialeto do pareci, uma língua que ironicamente aparece em outro subgrupo. Fazendo a média entre Rivet e Loukotka, parece que o subgrupo Bolívia já andava em terreno firme. Com Mason (1950: 213), as coisas voltam para trás: o mojeño, o baure e o pauna aparecem juntos em um subgrupo Bolívia, mas o tereno é novamente separado para formar, com seus parentes guaná, layaná e chané, um misterioso subgrupo Paraná.

Noble (1965: 10) confirma o subgrupo Bolívia que ele chama de "Meridional" e que ele divide em "Bolívia" (mojeño, baure, pauna) e em "Paraná" (tereno). Tudo isso é uma volta ao normal, mas por que a misteriosa denominação de subgrupo Paraná para o tereno? Enfim, o estudo de Payne (1991: 489) fortelece a existência do subgrupo Bolívia com as mesmas línguas (tereno, mojeño, baure), mas novamente com o nome de "BolíviaParaná”. 


\section{O subgrupo Bolívia-Paraná: mais uma bola de neve!}

De onde vem essa denominação de subgrupo Paraná para o tereno, o guaná, o layaná e o chané? Por que o "subgrupo Bolívia" de Rivet e de Loukotka chegou a chamar-se "subgrupo Bolívia-Paraná”? Vimos que os chané (tereno) viveram na Bolívia até o fim do século XVIII, data na qual atravessaram o rio Paraguai e instalaram-se nas suas imediações. Seria então um erro geográfico? Alguns teriam confundido o rio Paraguai com o rio Paraná? Na realidade, não se trata de erro geográfico algum, e devemos remontar ao começo do século XX para entender a partir de que equívoco surgiu a denominação "Paraná". Desde 1903-1905, Schmidt sabe muito bem que os grupos guaná ou chané atravessaram o Chaco para chegar ao rio Paraguai no fim do século XVIII, onde ficaram na região do rio Miranda, afluente do rio Paraguai. O próprio Schmidt acrescenta que o grupo guaná-chané é "um subgrupo do ramo mojo-baure da família nu-arawak", e isso bem antes de Rivet e Loukotka (Perea y Alonso 1937). No entanto, a denominação "Paraná" já aparece, pelos menos com Schmidt, em 1926 (Noble 1965: 3). Então, de onde vem o erro? Por que "Bolívia-Paraná" e não "Bolívia-Paraguai" ou mais simplesmente "Bolívia"? É que, nos baixos rios Uruguai e Paraná (Rio da Prata, perto de Buenos Aires), havia também certos grupos indígenas conhecidos como Chaná e Chané, provavelmente da família charrua, mas que vários estudiosos tentaram em vão conectar à família arawak no começo do século XX (Perea y Alonso 1937). E é dessa tentativa insensata, que confunde os chané-charrua do Paraná com os chané-arawak da Bolívia, que nasceu a denominação equivocada de "Bolívia-Paraná". Da mesma forma, muitos confundiram os guaná-chané (arawak) com os Guaná do Chaco, da família lengua ou maskoy (Perea y Alonso 1937).

Se a classificação das línguas americanas fosse encarada como uma coisa séria, teria que aplicar os mesmos princípios de nomenclatura usados na biologia, com o princípio de prioridade: deixar o nome científico do primeiro a descrever uma espécie, um gênero, uma família ou uma ordem, a não ser que o nome esteja taxonomicamente insano ou que ele esteja formado a partir de um latim adulterado.

Obedecendo a esse princípio de prioridade, seguiremos aqui a denominação de "subgrupo Bolívia" sugerido por Rivet e Loukotka, mesmo se Rivet contentou-se em inserir nele o pauna, o que Orbigny nem tinha visto, e mesmo se Loukotka contentou-se em inserir nele o tereno, o que Schmidt tinha visto 30 anos antes dele. A denominação "subgrupo Bolívia” tem a vantagem de ser biunívoca: todas as línguas deste subgrupo estavam na atual Bolívia (bacia dos rios Mamoré e Guaporé) desde a fundação de Santa Cruz no século XVI; e, em sentido inverso, não há nenhuma língua arawak, na Bolívia, que não pertença a este subgrupo. É verdade que, em 1720-1730, havia sarave(ka) e um certo número de pareci instalados nas missões jesuítas da Chiquitania, mas isso se deve ao fato que os pareci e os saraveka, que são originários do alto rio Paraguai (Brasil), fugiam diante do avanço dos bandeirantes luso-brasileiros que, em 1720, fundaram Cuiabá e precipitaram-se furiosamente atrás do ouro nos territórios pareci-sarave. Na Bolívia, não há (ou não havia) outras línguas arawak que o chané (tereno), o baure, o pauna e o mojeño. Sobre o magíana e a farça apolista, vejam as seções 9. e 10. 
- Depois de Payne, Campbell (1997: 181) junta o subgrupo Purus (piro, apurinã) ao subgrupo Bolívia-Paraná de Payne, chamando o conjunto de "Ramo Meridional Periférico". A palavra "Meridional" não nos parece totalmente correta, já que outro subgrupo arawak, que inclui o pareci, vive em regiões muito mais meridionais que os apurinã. Em uma classificação improcedente, Aikhenvald (1999b: 67) chama o subgrupo Bolívia de "Subgrupo Meridional", inserindo nele, além do mojeño, do tereno e do baure, o apolista (sic!) e o salumã (enawene-nawe), que é um codialeto do pareci, enquanto o subgrupo pareci-xingu forma um subgrupo separado: assim, o salumã e o pareci, que são tão parecidos entre si, acabam em subgrupos diferentes, e aqui surge um apolista misterioso que seria parente do mojeño. Danielsen (2011: 517) cria um grupo-lixeira "Meridional", dentro do qual ela atira o mojeño, o baure, o pauna (com o paikone!) e o tereno, assim como o pareci e as línguas arawak do Xingu. Todas essas "novas" classificações são apresentadas como meras compilações, sem argumentação ou sem procedimento taxonômico que possa permitir alguma crítica da parte do leitor.

Em resumo: depois da descoberta por Schmidt, Rivet e Loukotka, no começo do século XX, de um subgrupo Bolívia que incluiria o mojeño, o pauna, o baure e o tereno, e depois de uma boa argumentação linguística no que se refere à unidade deste subgrupo (Payne 1991), tudo acaba como se nada tivesse sido dito ou estudado.

-Acabamos de ver que o "parto" do subgrupo Bolívia foi extremamente doloroso. Veremos agora as sucessivas tentativas efetuadas para reconstruir os protofonemas desse subgrupo e como tudo isso levaria, com o tempo, a uma verdadeira fúria de equívocos. Matteson (1972: 186-192) é a primeira a reconstruir o que ela denomina de subgrupo shani (tereno, kinikinau, baure). Infelizmente, a autora não tem dados mojeño e pauna, ou esqueceu-se dessas línguas. Certas "reconstruções" são óbvios empréstimos kadiwéu (como wateke "canoa"), e os dados são às vezes tão precários que a diferença feita entre o tereno e o kinikinau é equivocada, como o seguinte "jogo de cognato": siike [kinikinau] / fume [tereno] "flecha". Na realidade, não se trata de jogo de cognatos, mas de duas formas tanto em tereno quanto em kinikinau: fike é a flecha já preparada (arma), enquanto fume designa a planta ribeirinha que serve na elaboração das flechas.

No estudo de Payne (1991), não há propriamente uma reconstrução do proto-Bolívia. No entanto, certas observações são feitas ao longo do trabalho, e a fase final das derivas vocálicas $(* \mathbf{a}>\mathbf{0})$ é evidenciada.

- Jolkesky (2016) tenta reconstruir o que ele denomina de subgrupo Mamoré-Guaporé (mojeño, pauna, baure). Infelizmente, o autor esqueceu-se do tereno e, de fato, nem sequer chega a mencionar essa língua, o que não deixa de ser estranho para um trabalho elaborado no começo do século XXI. Esse tipo de falha não é decisivo para quem deseja estabelecer a hierarquia de um subgrupo: o acréscimo de uma língua pode ser realizado posteriormente com uma simples operação de enxerto nos ramos adequados da árvore proposta, e a que ele propõe para seu Mamoré-Guaporé é a mesma que aquela que evidenciamos em 6.2. para o nosso subgrupo Bolívia, com a ausência, é claro, do tereno. No entanto, tal omissão é literalmente fatal para quem deseja reconstruir um subgrupo: sem o tereno, muito conservador nos processos de palatalização, muitos termos reconstruídos por Jolkesky estão errados. 
Além disso, o autor não enxerga nenhuma deriva vocálica, mesmo aquelas que são óbvias, como *a $>\boldsymbol{\sigma} / \mathbf{o}$. Sem suspeitar em que terreno vocálico pisa, ele adota uma metodologia inadequada para línguas que apresentam mudanças em cadeia. Por exemplo, a partir de jogos de cognatos mojeño do tipo ([I] ignaciano, [T] trinitario): -tsana- [I] / -tsano [T] "perna", saware [I] / saware [T] "tabaco", -a?e [I] / -o?e [T] "dente", ele obtém dois jogos de correspondências e dois protofonemas *a /a a/ e *o /a o/ para o proto-ignacianotrinitario. Mas por que parar por aí? Acrescentando mais um dialeto, por exemplo o loretano [L], obteríamos outra série de jogos de cognatos mojeño do tipo:

$$
\begin{aligned}
& \text {-tsana- }[\mathrm{I}] \text { / -tsano }[\mathrm{T}] \text { / -tsano }[\mathrm{L}] \text { "perna" } \\
& \text {-mira }[\mathrm{I}] \text { / -miro }[\mathrm{T}] \text { / -miro }[\mathrm{L}] \text { "rosto" } \\
& \text { esena }[\mathrm{I}] \text { / Pseno }[\mathrm{T}] \text { / esena }[\mathrm{L}] \text { "mulher" }
\end{aligned}
$$

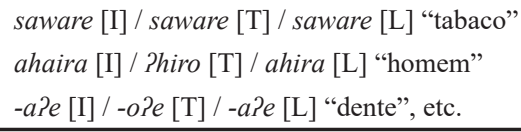

o que nos levaria a três protofonemas mojeño: * $\mathbf{a}_{\mathbf{0}} / \mathbf{a} \mathbf{a} \mathbf{a} /, \boldsymbol{a}_{\mathbf{1}} / \mathbf{a} \mathbf{0} \mathbf{a} /,{ }^{*} \mathbf{a}_{\mathbf{2}} / \mathbf{a} \mathbf{0} \mathbf{0} / . \mathrm{E}$, acrescentando mais dialetos, o número de supostas protovogais do mojeño aumentaria de forma exponencial. Com tal metodologia, em vez de 4-5 vogais, o que se espera das línguas arawak e das línguas consideradas, que têm somente quatro ou cinco vogais nos seus sistemas fonológicos, o autor reconstrói 7 vogais para o proto-Bolívia e, como acabamos de ver, teria ainda mais protovogais se tivesse considerado todos os dialetos (loretano, javeriano, etc.): uma boa dúzia! Se Adão e Eva falassem o protoarawak, quantas dezenas de vogais teriam de utilizar para se comunicarem no Jardim do Éden? Embora errado, o trabalho de Jolkesky nos ensina que a linguística comparativa, com suas aparências objetivas e científicas, não deve servir de álibi que se usaria de forma simplista, e com a melhor consciência do mundo, em línguas que passaram por derivas vocálicas ou consonânticas.

Por ter ignorado o tereno e as derivas vocálicas $\left({ }^{*} \mathbf{a}>\boldsymbol{\sigma} / \mathbf{0},{ }^{*} \boldsymbol{\mho}>\mathbf{i} / \mathbf{i}\right)$, dos 129 jogos de cognatos propostos pelo autor, somente 13 (10\%) estão certos ou, melhor dizendo, poderiam estar certos, pois ninguém tem certeza alguma em línguas que não deixaram vestígios escritos de suas fases anteriores. Note que esses 13 "jogos certos" o são simplesmente porque tudo é igual nas formas, como: * $i$ "fruta": Mojeño $-? i$, Baure - $i$, Pauna -?i.

- O estudo de Carvalho (2016) sobre a nomenclatura dos grupos tereno mostra claramente que muitos etnônimos (tereno, chané, guaná, kinikinau, etc.) sugerem línguas diferentes ou uma grande variedade dialetal que, na realidade, não existe. Na página 45, o autor nota perspicazmente que a maior contribuição no vocabulário que Aguirre (1898) elaborou no fim do século XVIII é a revelação de uma mudança diacrônica, especificamente *a $>\mathbf{0}$, que teria ocorrido entre os séculos XVIII e XX (tereno atual), e que está de acordo com as observações de Payne para todo o subgrupo Bolívia: é a fase final de nossa deriva vocálica (cf. 1.3.).

No entanto, em outro estudo, essa mudança diacrônica *a $>\mathbf{0}$, que foi observada entre o guaná de Aguirre e o tereno moderno, é descartada no caso do mojeño (Carvalho e Rose 2018), apesar de ser observada entre o mojeño de Marbán (1699) e o trinitario moderno da mesma forma e com muito mais frequência que com o guaná de Aguirre. Na página 18, os autores alegam que somente "algumas" formas de Marbán mostrariam a variação a/o, que 


\section{RAMIREZ \& FRANCCA - LÍNGUAS ARAWAK DA BOLÍVIA}

elas seriam "excepcionais" e que essas "complicações" poderiam ser o fruto de mistura "inadvertida" com o pré-ignaciano. Tudo isso é mal contado e tem todas as aparências de alegações ad hoc para se livrar de um problema. Em 1.3., demos 30 cognatos recolhidos no vocabulário básico, onde a vogal a de Marbán corresponde à vogal o do trinitario atual, o que significa que os pares diacrônicos a/o são extremamente mais comuns em Marbán que em Aguirre. Portanto, essa variação a/o está longe de ser "excepcional” e, quando se considera o léxico mojeño inteiro, ela então torna-se extremamente comum. Além disso, como poderíamos alegar uma mistura com o pré-ignaciano? Marbán estudou a língua dos moremono durante anos nas margens do rio Mamoré, acima da foz do rio Sécure-Isiboro, bem longe dos pampas ocidentais, em lugares onde a possibilidade de misturar os dialetos em $\mathbf{O}$ com os dialetos em A seria pelo menos bizarra. É pena que Carvalho tomou direções opostas para solucionar o mesmo problema: por que interpretou a variação diacrônica a/o do tereno como *a > $\mathbf{0}$, e a mesma variação em mojeño como *0 $>\mathbf{a}$ ? Por que Payne estaria certo em 2016 e errado em 2018? E essa "inadvertência" custa caro: das 191 protoformas propostas para o protomojeño, 105 apresentam uma vogal *o em lugar de *a, e assim estão erradas: por exemplo, *-upono "fígado", *-opera "osso", *himo "peixe", *samo "anta", *kohe "lua", *-niko "comer", *-ero "beber", *-sipo "lavar", *-samo "ouvir", em que todos as vogais $\underline{\boldsymbol{o}}$ em negrito correspondem à vogal $\underline{\boldsymbol{a}} \mathrm{em}$ todas as outras subfamílias arawak: -upana "fígado", -ape "osso", hima "peixe", kema "anta", -kipa "lavar", etc.

Os autores afirmam também que *jn pode ser reconstruído para o protomojeño. Aqui há um erro de lógica grave: o fato que $\mathbf{n}$ seja um fonema em ignaciano, em trinitario e em Marbán (i.e. com oposição e pares mínimos n/y) não significa necessariamente que ele estava presente em protomojeño. Em baniwa-koripako, por exemplo, o fonema n nasceu da cisão fonológica de $* \mathbf{n}$ contíguo a $* \mathbf{i} / \mathbf{e}$ (com ou sem perda da vogal condicionante) tanto nos dialetos centrais como nos dialetos setentrionais, e também em tariano, mas não nos dialetos meridionais. Por exemplo, compare: -íinha [d. central] / -íinha [d. meridional] “comer", -naa [d. central] / -naa [d. meridional] "bater", (i)napi [d. central] / ínapi [d. meridional] "osso", -kénøa [d. central] / -kénøa [d. meridional] "começar", etc. Voltando ao mojeño, o fato de que Marbán tenha observado uma certa diversidade dialetal em mojeño antes da chegada dos jesuítas no fim do século XVII, como já dissemos em 2.1., convida-nos a não excluir a potencial existência de dialetos que, como os dialetos centrais do baniwa-koripako, não tinham o fonema $\mathbf{n}$, mas que, infelizmente, no caso do mojeño, desapareceram sem deixar vestígios. Em outras palavras, o conjunto [Ignaciano + Trinitario + Marbán] não é suficiente para fazer aparecer o protomojeño. Além disso, os autores esquecem-se de dizer que há uma certa variação entre $\mathbf{n} e \mathbf{n}$ nos próprios dialetos que eles estudam, como, por

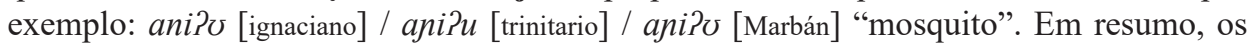
autores do artigo podem estar certos ou não, e o mesmo vale para Jolkesky: nesse ponto, o protomojeño não pode ser tão categoricamente alcançado.

- Reiteramos e insistimos: a aplicação de um método comparativo simplista ("para cada jogo de reflexos há um protofonema") custa caro no caso de derivas vocálicas que ainda não se estabilizaram. Além disso, o fato de que não se vê nenhum condicionamento fônico não implica que este não existe e não deve servir de álibi para utilizar esse método com uma suposta aparência de rigor científico. Esse tipo de deriva vocálica $(\mathbf{a}>\mathbf{0})$ sem condicionamento fônico (acento, consoantes adjacentes, etc.) é comum nas línguas do 


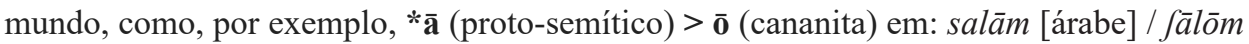
[hebraico] "paz", lisān [árabe] / lāfōn [hebraico] "língua", lā [árabe] / lō [hebraico] "não", etc.

E foi justamente esse método exageradamente simplista que Jolkesky (2016) e, seguindo seus passos, Carvalho e Rose (2018) aplicaram. A partir de jogos de cognatos mojeño, os últimos autores obtiveram cinco jogos de correspondências vocálicas e cinco supostas "protovogais" ([I] ignaciano, [T] trinitario): *i /i [I] i [T]/, *e /e [I] e [T]/, *a /a [I] $\mathbf{a}[\mathrm{T}] /, \boldsymbol{o}_{\mathbf{o}} / \mathbf{a}[\mathrm{I}] \mathbf{0}[\mathrm{T}] /,{ }^{*} \mathbf{u} / \mathbf{u}[\mathrm{I}] \mathbf{u}[\mathrm{T}] /$. No entanto, o jogo *o $_{1} / \mathbf{u}[\mathrm{I}] \mathbf{o}[\mathrm{T}] /$ foi totalmente esquecido. Alguns exemplos desse jogo:

\begin{tabular}{|c|}
\hline $\begin{array}{l}\text { amúu-ja [I] / (a)mó-jo [T] "bebê" } \\
\text { púpe }[\mathrm{I}] \text { / pópe }[\mathrm{T}] \text { "preguiça (animal)" } \\
\text { patúre }[\mathrm{I}] \text { / patóre }[\mathrm{T}] \text { "macaco" }\end{array}$ \\
\hline
\end{tabular}

onde temos a correspondência u (I) / o (T), e não a correspondência esperada: u (I) / u (T). Nesses exemplos, não há nenhuma harmonia vocálica que permitiria se livrar do problema, já que temos também: pakúre (I) / p(a)kúre (T) "canoa”, kájure (I) / kájure (T) "ave", tfúje (I) / tfúje (T) "raposa", etc.

Agora, os autores estão com seis protovogais mojeño $\left(* \mathbf{i},{ }^{*} \mathbf{e},{ }^{*} \mathbf{a},{ }^{*} \mathbf{0},{ }^{*} \mathbf{o}_{1},{ }^{*} \mathbf{u}\right)$, um número que, até para eles, é extremamente embaraçoso. Como já vimos em 2.2., esse último jogo u / o não apresenta nenhum problema. Uma vez que se aceita que, mesmo em ignaciano, a deriva *a $>\boldsymbol{\sigma}$ ocorreu levemente, quatro protovogais (*i /i [I] $\mathbf{i}[\mathrm{T}] /,{ }^{*} \mathbf{e} / \mathbf{e}[\mathrm{I}] \mathbf{e}$ $\left.[\mathrm{T}] /, \boldsymbol{*}^{\mathbf{a}} / \mathbf{a}>\boldsymbol{\boldsymbol { \sigma } [ \mathrm { I } ]} \mathbf{a}>\mathbf{0}[\mathrm{T}] /,{ }^{*} \boldsymbol{\mho} / \boldsymbol{\mho}[\mathrm{I}] \mathbf{u}[\mathrm{T}] /\right)$ são o bastante para o protomojeño.

- Quando nosso trabalho já estava no prelo, foi-nos indicado um artigo recentemente publicado de que não tínhamos conhecimento. Nesse artigo, Carvalho (2018a) parece admitir que as cinco protovogais do seu suposto protomojeño (*a, $\left.{ }^{*} \mathbf{e},{ }^{*} \mathbf{i} .{ }^{*} \mathbf{o}(>\mathbf{a}[\mathrm{I}]),{ }^{*} \mathbf{u}\right)$ são exatamente iguais às do proto-Bolívia. No entanto, ele deixa de lado o baure, por ser ele "extremamente inovador", i.e. extremamente desconcertante. Mesmo assim, ele nota quatro formas baure antigas e modernas, entre as quais o leitor nota t faka-ne (baure antigo) / tfoko-ne (baure moderno) "orelha", o que sugere que uma simples deriva *a $>\boldsymbol{\sigma}$ poderia resolver quase tudo em baure. Sem essa deriva, como explicar cognatos como ([Tr]

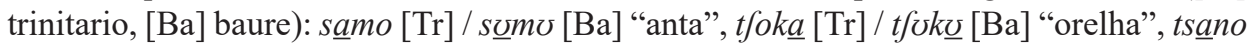

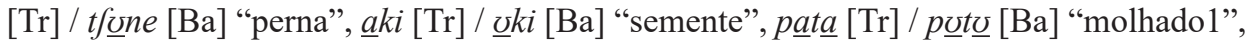

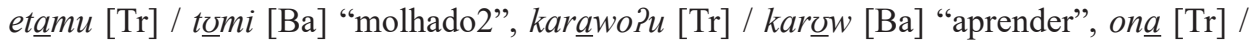

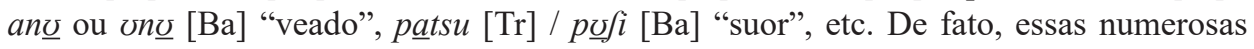
correspondências mostram que há duas correspondências importantes entre o trinitario e o baure: uma que o autor esperava e que corresponde a seu *o /o [Tr] $\boldsymbol{\sigma}[\mathrm{Ba}] /$, e outra frequentíssima, mas muito mais embaraçosa para ele: * $\mathbf{a}_{\mathbf{1}} / \mathbf{a}[\mathrm{Tr}] \boldsymbol{\sigma}[\mathrm{Ba}] /$.

Com isso, o proto-Bolívia teria pelo menos sete protovogais, com a inclusão de ${ }^{*} \mathbf{o}_{1}$ comentado acima: 


\section{RAMIREZ \& FRANCCA - LÍNGUAS ARAWAK DA BOLÍVIA}

\begin{tabular}{|c|c|c|c|c|}
\hline & $\underline{I} / \mathrm{T}$ (mojeño) & Baure & Pauna & Tereno \\
\hline$* \mathbf{i}$ & $\mathbf{i} / \mathbf{i}$ & $\mathbf{i}$ & $\mathbf{i}$ & $\mathbf{i}$ \\
\hline$* \mathrm{e}$ & e / e & e & e & e \\
\hline$* a$ & $\mathbf{a} / \mathbf{a}$ & $\mathbf{a}$ & $\mathbf{a}$ & a \\
\hline$*_{0}$ & $\mathbf{a} / \mathbf{o}$ & $\boldsymbol{\sigma}$ & $\boldsymbol{U}$ & $\mathbf{0}$ \\
\hline$* \mathbf{u}$ & $\boldsymbol{v} / \mathbf{u}$ & $\mathbf{i}$ & $\dot{\mathbf{i}}$ & $\mathbf{u}$ \\
\hline$* a_{1}$ & $\mathbf{a} / \mathbf{a}$ & U & $\mathbf{a}$ & a \\
\hline$*_{1}$ & $\sigma / 0$ & U & U & $\mathbf{0}$ \\
\hline
\end{tabular}

Assim, a omissão do baure nos jogos de cognatos torna-se catastrófica: como Jolkesky desconsiderou o tereno, muito conservador nos seus processos de palatalização, Carvalho deixou de lado o baure, língua em que a deriva vocálica $\mathbf{a}>\boldsymbol{\sigma}$ é literalmente "frenética". Tendo perdido sua única vogal posterior $\left({ }^{*} \boldsymbol{\sigma}>\mathbf{i}\right)$, entende-se muito bem por que a mudança *a $>\boldsymbol{\sigma}$ é muito mais produtiva em baure que nas outras línguas.

Em 1.3., vimos que os empréstimos de palavras castelhanas e a comparação entre as línguas antigas e modernas não deixam margem à mínima dúvida sobre o caráter recente da deriva vocálica $\mathbf{a}>\mathbf{o} / \boldsymbol{v}$. Por que se recusar a considerar seriamente esses fatos importantes? Como as sete protovogais de Jolkesky são radicalmente diferentes das sete protovogais de Carvalho, ninguém sabe mais ao certo quantas vogais havia em protoBolívia!

Note enfim que, mesmo em tereno [Te] e em pauna [Pa], as correspondências propostas pelo autor entram frequentemente em colapso, justamente por causa da mesma deriva vocálica a > o/v. Por exemplo: kuja $[\mathrm{Tr}] /$ kijo $[\mathrm{Pa}]$ / kâja $[\mathrm{Te}]$ "cérebro", takuro $[\mathrm{Tr}] /$

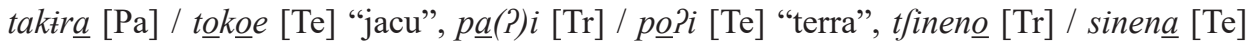
"nora", kosa-ra [Tr] / kasa-ti [Te] "frio", kâ?e-re [Tr] / kô?ê-e [Te] "batata-doce", etc.

\section{O magíana de Ribera}

Entre 1786 e 1792, Lázaro de Ribera (Palau e Sáiz 1989: 170) menciona os magíana na missão de Reyes de Moxos (no rio Beni) e fornece oito palavras de sua língua:

\begin{tabular}{|c|c|}
\hline chimaré "bom" [?] & nuи?amí "o irmão" [cf. mojeño awi "irmão", ou -amri "neto"] \\
\hline mononeparé "mau" [?] & piyochó “um” [cf. mojeño (a)pi- "dois", e não "um”!] \\
\hline nuи?á “o pai" [cf. mojeño $n u$ - "1sg" \& -ia "pai"] & tonocovó “dois" [cf. mojeño (e)to- "um", e não "dois”!] \\
\hline nuиPéno "a mãe" [cf. mojeño nu- "1sg" \& -eno "mãe"] & mopoicovó "três" [cf. mojeño mopo- "três"] \\
\hline
\end{tabular}

Com tão magro material, não se pode concluir nada: talvez o magíana de Ribera seja um dialeto mojeño, talvez seja uma língua pertencendo a outra família linguística que Ribera não conseguiu descobrir, talvez Ribera tivesse caído no mesmo tipo de equívoco que pode ter ocorrido com o paikone de Orbigny. Eis o que Hervás y Panduro (1800: 249) escreve sobre o assunto: 
A língua majiena ou maxiena era falada por uma tribo que estava no ano de 1767 no povoado de San Francisco de Borja, chamado dos Ticomeris [i.e. povoado conhecido como São Francisco dos Ticomeris]. Desconhece-se o caráter da língua majiena, que nem os mojos nem outras nações que há em seus povoados entendem.

No povoado já mencionado de San Borja, que acima chamei de retrato de Babel [por ter nele muitas línguas diferentes], havia o que sobrou da missão de San Pablo, que foi destruída, assim como tribos de várias nações achadas ou recolhidas por acidentes incomuns. Havia no dito povoado tribos majienas, ticomeris [que falavam um dialeto mojeño], pacabaris, cabinis e tibois.

Métraux (1948a: 409) pretende que há uma contradição em Hervás y Panduro quando este afirma que os Ticomeri falavam um dialeto mojeño depois de declarar que a língua majiena desses Ticomeri era uma língua isolada falada em San Francisco de Borja. Na realidade, não há nenhuma contradição e, mais uma vez, Métraux mostra que não soube ler. Hervás y Panduro não se contradiz porque deixa bem claro que ele distingue os ticomeri, que, para ele, eram um grupo mojeño, dos majiena, que falavam uma língua que ninguém entendia. Enquanto Hervás y Panduro escreve que o povoado de San Francisco de Borja era então chamado "São Francisco dos Ticomeris", Métraux entende que a língua majiena era chamada "Ticomeri"!

\section{0. $\mathrm{O}$ apolista}

Nesta seção, estudaremos o que é geralmente chamado de "apolista". Veremos que duas línguas aparecem com este nome. No começo do século xx, Nordenskiöld recolheu uma lista de palavras com os últimos falantes "apolista" ou "lapachu". Em 1979, Montaño Aragón teria juntado 45 palavras de uma língua com o mesmo nome, mas bem diferente da precedente. Enquanto o apolista de Nordenskiöld parece uma mistura de muitos idiomas, o apolista de Aragón é lamentavelmente uma falsificação.

10.1. O apolista de Nordenskiöld. Como já indicamos, Nordenskiöld recolheu um pequeno vocabulário "apolista" ou "lapachu" no começo do século XX (Créqui-Montfort e Rivet 1913). Esse idioma estava em processo de extinção, e o próprio autor não exclui alguns erros dentro de seu vocabulário. Sobre as missões franciscanas de Apolobamba, o leitor poderá ler a introdução histórica de Créqui-Montfort e Rivet (1913: 512-516), com a bibliografia indicada pelos autores. A missão de Apolo foi fundada no século XVII com índios leko, aguachile e pamaino. Nota-se que ninguém falava de "índios apolista" naquela época e, de fato, esses "apolista" ou "lapachu" somente aparecem no começo do século Xx. A língua deles era falada na região de Apolo e, ao leste, na direção do rio Tuichi, um afluente do rio Beni. É justamente nessa região que vivem ou viviam os aguachile. Conforme os moseten dos yungas do rio Beni que entrevistamos, os aguachile não dão mais sinal de vida desde os últimos 50 anos.

O que podemos retirar do vocabulário heteróclito de Nordenskiöld? No meio de mais de 150 palavras, muitas delas são quéchua ou de origem extremamente variada. Retomamos abaixo o vocabulário elaborado por Nordenskiöld com possíveis indicações sobre afiliações e/ou adoções: 
- ja-tuni orelha/cabeça [arawak: pareci, baré, etc.], tuni-tapa cabelo, ni-tuni olho [arawak: pareci], huania pé, tesi perna, petjo peito [castellano], huakamé couro, kara casca [quéchua], pesko / piku pênis [yamiaka], intári / mankuro vagina, huanjuska (?) esqueleto [quéchua: wañusqa "morto"], asasjapna diarréia, amuata homem, pinimi mãe, suiiua filho, inta-siua filha, murumaxta rapaz, pasnia moça [quéchua], huakimi irmão [quéchua], ninua(mi) / ninami irmã, kuraxni sobrinho, patuani avô, paini avó, sapuîmi cunhado, patini índio, tfifnitania (?) inimigo [quéchua: t/ihnis “odiado"], mujmo(o) árvore, muó ramo, mujmaa-kuni na floresta, iti sol [quéchua], uri estrela, t tani água / rio [pano?], pampa planície [quéchua], huijo roça, atari [takana, ashaninca] / piua / ui casa [quéchua], húinipi nuvem [pano kuini], l'ejni noite, apan-si um dia, mara ano [quéchua], tarisama-ku sombra, ajta(-ku) doente, haiñuru / niosuk / niosut f novo, to(i)uajna ama-ku velho (coisas), ára-ko seco, sumá(h) bom, bonito, limpo [quéchua], t fet]niko mau, matasuru sujo, ila baixo, sajariá longe, junó perto, pet pouco, jutiá-ku molhado, sapapa branco [mojeño hapu]. t tupepi preto, feio, tfimura vermelho, patfaja verde [pano], t taju maduro [quéchua], jumunha amarelo, saurenka pronto, mañin-amaku morrer, mante amakupla (?) matar, sumajni amakupla amar uma mulher, ila vou embora, l'apinila vamos embora!, inima adeus!, masnajti traz! [quéchua: maña "pedir"], apaj dou [amuesha, kampa, mojeño], apaj-na / apaj-ña me dá! [quéchua: apa "levar, trazer"], tejnja[pini] / taina[pini] comprar, tejnla-pla / tainla-pla vender, hiiti acender (fogo), huaiti apagar (fogo), tatfej / tatfai dançar, jate / jato / ajti pegar, tarajapi tecer, samajni apila estás apaixonado?, hajn(u)ama / hajn ter / há, tiampala intari fornicar, huima-amaneika quanto vale?, ila / nila $e u$, ñi-ampa $m e u$, pila $t u$, pi-ampa teu, maneinka / maniinka não, hari sim [quéchua] + palavras quéchua para os números "3", “4”, "5", “6”, “7”, “9”, "10" e "100".

- ukumari urso [quéchua], ára onça, útfi cão [arawak ???], jari-tuna macaco, atalpa galinha [quéchua], tukurui galo [quéchua, takana].

- tJaju abacaxi [takana, iñapari], siuva algodão, plantani banana [castellano], papas batata [quéchua], goma caucho [castellano], sasáse coca [takana], patu-nave cuia / abóbora, ta(j) milho [leko, tsimane], poj cigarro.

- naraj flecha [takana], tumaj bolsa de algodão [takana, pano], huilisa colher [quéchua], hat]a machado [castellano], t futfu malária [quéchua, mojo, etc.], maturi / matari pote [takana].

No meio dessas palavras que parecem vir de todas as direções, há aproximadamente 20 palavras básicas que se parecem arawak, o que inclui alguns afixos pessoais. As semelhanças são maiores com o mojeño, o kampa e o amuesha. Há também 6-7 palavras que designam animais ou plantas e que poderiam ser arawak ou simples empréstimos. O leitor não deve esquecer-se de que línguas vizinhas, como o tsimane-moseten e o yuracaré, estão repletas de palavras mojeño (cf. seção 11). Eis os vocábulos que seriam de procedência arawak: 
- ja-tuni cabeça [mojeño, kampa, amuesha], ni-apa nariz [baniva de Maroa], niatáu boca [wapixana -dakv, bahuana -dav], ñani língua [arawak: amuesha], ási dente [arawak], (h)uipasjo mão [mojeño: wu-pe], asanu pescoço [arawak: kampa], taar-pana folha [arawak: kampa], tuparé raiz [kampa -pari, mojeño: $t$-apare], jui(i)si madeira / tronco [mojeño: jvkv-çi] , intári mulher [arawak], ási lua / mês [pano osi, baniva de Maroa: asita], mapaj pedra [arawak: kampa, tereno, amuesha], juó fogo [mojeño jokv], t fenio / t tinio caminho [arawak: mojeño, etc.], ni- [Sujeito] / -na [Objeto] eu [arawak], pitu [arawak], apa-ni um [arawak], japi-ni dois [arawak].

- l'ama anta [mojeño: sama], sari (paasi) pato [mojeño, iñapari, piro: opahi], amujsi capim [mojeño: muihi], ili batata-doce [arawak, pano: keere], átfi pimenta [arawak], tfiuvi sal [mojeño, kampa, piro: (i)tfeve], matari pote [mojeño, pareci: matehisi].

A partir dessas semelhanças e de muitas outras erroneamente interpretadas, CréquiMontfort e Rivet (1913: 520) pensam ter "demonstrado que o apolista é um dialeto arawak". Tudo isso é possível, mas bem improvável: o vocabulário recolhido é tão heterogêneo que dá a impressão de que os falantes utilizavam uma palavra quéchua, outra pano, outra kampa, etc. De qualquer forma, a afiliação arawak deste apolista está longe de ser "demonstrada".

10.2. O apolista de Montaño Aragón. De 1972 a 1979, Montaño Aragón (1987: 175-185) viajou a Apolo a fim de realizar suas campanhas políticas. O leitor não deve esquecer-se de que, naquela época, os povos dos yungas de Apolo e de Atén procuravam suas raízes através de línguas ou costumes que não fossem o castelhano nem o quéchua. E foi nesse cenário sociopolítico inflamado que Montaño Aragón descobriu de 160 a 200 falantes de um idioma que poderia ser o "apolista" ou o "aguachile", mas "que se recusavam a falá-lo por vergonha" (sic!). No entanto, o autor conseguiu 45 palavras dessa língua com a ajuda de Arturo Saravia, uma pessoa idosa de 83 anos que também teria falado a rik'a (leko). Reproduzimos abaixo as 45 palavras "apolista" recolhidas por Montaño Aragón (página 181), e comparamos cada uma delas com o baniva de Maroa, uma língua arawak falada nas cabeceiras do rio Negro, na fronteira entre a Venezuela, a Colômbia e o Brasil: 
RAMIREZ \& FRANÇA - LÍNGUAS ARAWAK DA BOLÍVIA

\begin{tabular}{|c|c|c|c|}
\hline APOLISTA & BANIVA de MAROA & APOLISTA & BANIVA de MAROA \\
\hline panishi & panisi "casa" & maropa & molopa "canoa" \\
\hline iruyani & iroami "grande" & atapi & aatapi "árvore" \\
\hline achiki & asi-hi "mandioca" & eru & elv "batata-doce" \\
\hline ipa & ipa "pedra" & nawipi & nv-wepi-pi "minha flecha" \\
\hline wachi & waşi "onça" & ema & eema "anta" \\
\hline towiri & dowili "caimão" & mapa & mapa "abelha" \\
\hline chuwita & tsuida "piolho" & amushiti & amosi "sol" \\
\hline ashi & asita "lua" & enui & enซ "céu" \\
\hline awini & awi-ni-ni "frio" & irini & sele-li "preto" \\
\hline liki & ali-hi "branco" & inami & enami "homem" \\
\hline niyipi & nejawa / nejepe "mulher" & miki & -mi-hi “esposo" \\
\hline nisorami & $n \mho-s \delta l(\mho) a m i$ "minha mãe" & niamari & niamari "pessoa" \\
\hline niromi & $n v-l v(a) m i$ "meu pai" & nimbaku & $n \mho-i b v-h v$ "(minha) cabeça" \\
\hline nichipami & nv-tsipana "(meu) cabelo" & nipisi & -api, -apisi "mão" \\
\hline niyape & -(i)japa "nariz" & nituni & nv-tani $[-$ pala] "(minha) orelha" \\
\hline chimapi & simapi “osso" & piya & pija "tu" \\
\hline ipila & epalv "ele" & ayipila & ajopalo "ela" \\
\hline anipila & anipalv "eles" & wa'aha & waja-ha "nós" \\
\hline nipija & nijaha "vós" & iyaru & peja-rv "um" \\
\hline inapa & enaba "dois" & & \\
\hline erikoni & kiriko- [baré] "três" & nuni & nuni [baré] "eu” \\
\hline
\end{tabular}

Nota-se imediatamente que, das 45 palavras que Montaño Aragón pretende ter recolhido nas imediações de Apolo e de Atén, 39 são baniva de Maroa e 2 são baré do rio Negro, com algumas mudanças ou erros fônicos insignificantes. Somente 4 palavras não são parecidas nem com o baniva de Maroa nem com o baré. São: chami "água" (em Nordenskiöld: tfani, na língua yuracaré: samma), yuho "fogo" (em Nordenskiöld: juo), nuri "estrela" (em Nordenskiöld: uri), machinki "milho" (em kampa: finki).

Tal coincidência deste novo apolista de Montaño Aragón com o baniva de Maroa era, para nós, ao mesmo tempo extraordinária e altamente suspeita. A fim de verificar a existência do "apolista de Montaño Aragón", fomos a Apolo em 2007 e vasculhamos suas imediações com a ajuda de um comerciante aimara que lá vivia. Assim que chegamos em Apolo, constatamos que o povo de lá era bilíngue em castelhano e em quéchua cusquenho e que ninguém falava outra língua. Arturo Saravia já estava morto, mas seus parentes nos asseguraram que ele não falava leko nem qualquer outro idioma misterioso. Enfim, não achamos nada que não seja quéchua nos povoados das imediações. Em particular, a palavra que Montaño Aragón registrou para designar a canoa era objeto de risada para todos: como alguém podia deslocar-se em canoa na vasta região montanhosa de Apolo, ao sul ou ao leste do rio Tuichi, sem ser despedaçado ou triturado pela correnteza e pelos rochedos?

Depois daquele fracasso, voltamos a La Paz e fomos procurar Montaño Aragón, apelidado de El Capilla pelo Museu de Arqueologia, por ter afirmado há anos que tinha descoberto um templo pré-incaico, mas que era na realidade, como todos sabiam, uma 
capela espanhola do século XVII. O autor nos recebeu muito bem. Ele estava então absorvido e muito entusiasmado pela última descoberta que acabava de fazer: conforme sua pesquisa, o quéchua era uma língua da Mesopotâmia antiga (mas, no dia seguinte, afirmou-nos que não era mais mesopotâmico, mas sim mongólico), e tentava nos convencer que o povo inca tinha embarcado em um certo porto do Japão rumo às Américas. Enfim, perguntamos por que o apolista dele era igual ao baniva da Venezuela. Respondeu com toda honestidade que, de suas viagens à Venezuela, tinha trazido alguns vocabulários de lá e, provavelmente, confundido ou transferido esses vocabulários para sua "pesquisa" em Apolo!

A obra de Montaño Aragón é muito interessante no que se refere à história dos povos nativos da Bolívia, mas não é recomendada para os linguistas. Por exemplo, no segundo volume da mesma obra, o autor alega ter descoberto uma nova família linguística, a família chunene, sem mesmo ver que o vocabulário que ele apresenta é simplesmente esse-ejja (família takana).

O mais intrigante da história é que essa falsificação parece ter passado despercebida nos meios linguísticos. Depois de 1991, Payne (2005) analisou o "apolista de Montaño Aragón" e concluiu que se tratava de uma "língua arawak setentrional" aparentada com o yavitero da Venezuela. Note que Payne não tinha dados do baniva de Maroa, o que, com certeza, teria ajudado a desvendar o engano. Depois dessa grotesca descoberta, que equivale a dizer que o baniva de Maroa é aparentado com o yavitero, o que é óbvio para todos, quase todos os compiladores atuais fazem desse apolista-fantasma "uma língua arawak setentrional" falada perto de La Paz: tudo isso é inconcebível!

\section{Os contatos entre o mojeño e as outras línguas indígenas}

Algumas poucas palavras encontram-se em mojeño, em pareci e em outras línguas indígenas das regiões limítrofes:

1) A palavra para "tamanduá-bandeira" é atikore em mojeño, atikie em pauna, tikoa em tereno e atikori em pareci. Não sabemos ao certo a origem desta palavra. Observe que ela também se encontra em outras línguas:

- em certas língua arawak do norte: arikuri (mandawaka do Canal Cassiquiare), haikuli (guinau do Orinoco) e talvez ate (baniwa-koripako);

- em nambiquara, onde é tikali (provável adoção do pareci);

- e nas línguas tupi de Rondônia: afukur (puruborá), hásio (tupari), mifakor (suruí), wasakuli (aruá, cinta-larga), etfikut (arara).

2) Uma palavra aparentemente comum para "amendoim" encontra-se na subfamília Bolívia (mojeño korike-re, baure kiriki-ri, pauna kiike, tereno kurîke), em pareci (koliki) (mas não nas línguas arawak do Xingu ou em qualquer outra língua arawak), e também em takana e em caviñeno (kanitse). Não sabemos ao certo a direção dos empréstimos.

3) Outras poucas semelhanças achane-pareci, como itfini "onça" em achane e em pareci, ou kori (achane) / okore (pareci) "flecha" (cf. uku nas línguas arawak do Xingu), parecem de origem arawak. 
RAMIREZ \& FRANÇA - LÍNGUAS ARAWAK DA BOLÍVIA

- As semelhanças entre o mojeño, o tsimane-moseten (perto de San Borja) e o yuracaré (yungas de Cochabamba e de Santa cruz) são numerosas. Alguns exemplos onde o leitor notará que certas entradas ("pessoa", "água", "sal”, "jabuti”, "jutaí") sugerem um contato antigo, que teria ocorrido antes da deriva vocálica $*_{\mathbf{i}}>\mathbf{i}>\mathbf{e}$ e da palatalização $* \mathbf{k}>\mathbf{s} / \mathbf{i}$ :

\begin{tabular}{|c|c|c|c|}
\hline & $\begin{array}{c}\text { MOJEÑO } \\
\text { Ignaciano / Trinitario }\end{array}$ & MOSETEN & YURACARÉ \\
\hline orelha & kina / kijno & t fhr̃n & --- \\
\hline pessoa & tfane & --- & tfaniu \\
\hline água & one / une & õhni? & --- \\
\hline cinzas & tsima-pa & t fim & --- \\
\hline banco & $\mathrm{t}$ forma / t fumo & --- & t fummu \\
\hline canoa & pakore / pkure & --- & pohore \\
\hline cerca & naro / noru & na?ri & --- \\
\hline remo & naurape / noope & --- & norpe \\
\hline sal & it fewe / t fewe & --- & tike \\
\hline mucura & t furuisi & --- & t fijeut $\int \mathrm{e}$ \\
\hline tatu-canastra & (j)ape / jopesi & Jahpe & --- \\
\hline capivara & otfo & otjo? & jutijuti \\
\hline paca & japa / jopo & --- & jopore \\
\hline preá, porquinho-da-índia & mojokv / mujuku & mojohko & mujuhu \\
\hline ariranha (lontra) & owowori (baure) & owe?werih & --- \\
\hline cão & tam $\mho k v$ / tamuku & --- & t $\int a h m u$ \\
\hline zogue-zogue (macaco) & wa?u / wo?u & wõhõ? & --- \\
\hline macaco-caiarara & ojo-re (baure) & õjõh & --- \\
\hline pato & opahi / opohi & ĩpih & upifi \\
\hline anhuma & t $\int \mathrm{aPa} / \mathrm{t} \int \mathrm{Pa}$ & tfaha & Jahale \\
\hline urutau & wehoho/wehuhu & ehoho? & wəhoho \\
\hline gaivota & sarue / sororo?i & --- & sərrəwo \\
\hline jabiru & kasipi / ksipi & --- & sipili \\
\hline cujubim & howi / huwi & tjowih & Suije \\
\hline anu & woriku-siri / woriku-sri & oris & uji \\
\hline coruja & jusa / jusa & --- & jufa \\
\hline urubu-rei & sina?i / seno?i & --- & $\operatorname{sinni}$ \\
\hline carcará & waja / wajo & --- & waija \\
\hline joão-de-barro & atsikero / Ptsiçeru & t fihkõ? & tjikoko \\
\hline andorinha & Bir (baure) & bĩr & --- \\
\hline papagaio & waro / woru & awaro? & --- \\
\hline ema (nandu) & sipa-re & hipare & --- \\
\hline jacaré & kahiore / kçiore & kofifore & --- \\
\hline
\end{tabular}


LIAMES 19

\begin{tabular}{|c|c|c|c|}
\hline jabuti & $\operatorname{sip} v / \operatorname{sipu}(<*$ kipv $)$ & kihbo & --- \\
\hline surubim & jana / jona & sona?-re? & janore \\
\hline tambuatá & wat $\int e-r e$ & watse & --- \\
\hline acari-bodó & sapatu & --- & sobodje \\
\hline tucunaré & samapi / smopi & samapĩ & --- \\
\hline piranha & oroma / Prumo & irimo? & --- \\
\hline arraia & ihina / hinomo & isini? & isuna \\
\hline macaúba (palmeira) & kajara / kjara & katsãrẽ? & --- \\
\hline samaúma & wahenara & eohfinah & --- \\
\hline mamão & apapahi / pophi & pofi & --- \\
\hline jutaí (árvore) & paki / paçi & behki? & --- \\
\hline almendrillo (leguminosa) & $\mathrm{t}$ Jima / t fimo & --- & t fimore \\
\hline batata-doce & kaere & ka?ìh & fetfe \\
\hline cuia & erepa / Prepo & erepah & --- \\
\hline assacu (ochoó) & kanawa / know & konohfito? & --- \\
\hline jenipapo & jana / jono & --- & jənnə \\
\hline tarumá & mitu / mitu & mito & --- \\
\hline
\end{tabular}

Há também algumas semelhanças com o leko, como -jap [leko] / japa [mojeño] "paca" e kimsl-wo [leko] / simaro (< proto-Bolívia *kimarø) [mojeño] “porco", e também com o takana (como idzaka [takana] / t faka [mojeño] "orelha”). A palavra para "porco" em leko parece mostrar um contato antigo entre o leko e o mojeño, antes da palatalização *k $>\mathbf{s}$ /_i.

\section{Os cognatos do subgrupo Bolívia: uma lista provisória}

A lista de cognatos abaixo é provisória e as reconstruções propostas são meras sugestões de trabalho. O leitor encontrará a lista completa na Enciclopédia das Línguas Arawak. Note as abreviaturas seguintes:

(JC) Japurá-Colômbia ; (Pi) piro, (In) iñapari, (Ap) apurinã (<*Purus) ; (Ka) kampa 
RAMIREZ \& FRANÇA - LÍNGUAS ARAWAK DA BOLÍVIA

\begin{tabular}{|c|c|c|c|c|c|c|}
\hline Português & * Bolívia & Ignaciano & \begin{tabular}{|l}
\multicolumn{1}{c}{ Trinitario } \\
$\left({ }^{*}\right)$ Marbán $(1701)$ \\
(L) Loretano \\
(J) Javeriano
\end{tabular} & \begin{tabular}{|l|}
\multicolumn{1}{|c|}{ Baure } \\
$\left({ }^{*}\right)$ Magio $(\sim 1740),(\mathbf{o})$ \\
Orbigny $(1832),(\mathbf{m u})$ \\
muchojeono (1832), \\
(Pai) paikone (1832), (J) \\
Joaquiniano \\
\end{tabular} & Pauna & \begin{tabular}{l}
\multicolumn{1}{c}{ Tereno } \\
$\left({ }^{*}\right)$ Aguirre $(1793)$ \\
(K) kinikinau \\
{$[$ F] Fonseca $(1875)$}
\end{tabular} \\
\hline 1. cabeça ${ }^{1}$ & 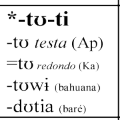 & $\begin{array}{l}-\mathrm{t} \int \mathrm{o}-\mathrm{ti}, \\
\text { bochecha }\end{array}$ & $-\mathrm{t}$ futi & -to-kié cérebro & $\begin{array}{l}\text {-t } \tilde{y} \text {-ti, } \\
\text { testa }\end{array}$ & $\begin{array}{l}\text { tû-ti, apúku topo } \\
\text { da cabeça, hhôwo } \\
\text { bochecha }\end{array}$ \\
\hline 2. cabeça ${ }^{2}$ & *-paki & -pv?i redondo & & $\begin{array}{l}\text {-pv?e } /{ }^{*} \text {-pa?e } / \\
{ }^{*} \text { po?e, -pe } / / \text {-piki } / \\
\text {-poki (Pai) }\end{array}$ & & $\begin{array}{l}\text { pû?i / po?e } \\
\text { redondo }\end{array}$ \\
\hline 3. testa & $*^{*}$-(i)nako & -na?o & -no?u / *-na?u & & & inúku /*inaku \\
\hline 8. pelo, pena & $\begin{array}{l}\text { *-ise / -isi } \\
\text {--iitfoi (JC) } \\
\text {-si CL (Ka) }\end{array}$ & -se pena & -se pena & 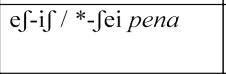 & & ifé-?o \\
\hline 12. ouvido & $\begin{array}{l}\text { *-kai-na- } \\
\text { ko } \\
\text { "-Sai-nako } \\
(\mathrm{JC}) \text {-ke-nako } \\
(\mathrm{Ap}) \\
\end{array}$ & -kina & -çino /*-kina & $\begin{array}{ll}\text {-senv-ki, } & \text {-seju-ki } \\
\text { (Pai) } & \end{array}$ & & keno / ke.éna [F] \\
\hline 13. olho & $\begin{array}{l}{ }^{*} \text {-(w)oki } \\
\text {-oki (Ap) } \\
\text {-oki (Ka) }\end{array}$ & -óki(Pa) & $\begin{array}{l}\text {-uç-Pa / -uçi?a } \\
(\mathbf{L}) / * \text {-uki }\end{array}$ & $\begin{array}{ll}\begin{array}{l}\text {-(i)ki-se, } \\
\text { (Pai) }\end{array} & \text {-wiki-s } \\
\end{array}$ & -ke-wíke & uke \\
\hline 23. coxa & $*_{-p a ? i}$ & $\begin{array}{lr}\text {-pewa, } & \text {-pai-ke } \\
\text { perna, } & \text {-pa?e } \\
\text { coxa } & \\
\end{array}$ & -pa?e coxa & $\begin{array}{l}\text {-poji / -pvij / *poji, } \\
\text {-pe-s perna }\end{array}$ & & \\
\hline 28. mão & $\begin{array}{l}\text { *-wako } \\
\text {-wako } \\
\text {-waku (Ap,Ka) } \\
\end{array}$ & -wa?u & $\begin{array}{|lll|}-\mathrm{w}(\mathrm{o}) \mathrm{u} & / & *_{-} \\
\text {wo(P)u } & & \\
\end{array}$ & -waki palma & -wúi & wo?u / wa(?)u [F] \\
\hline 29. braço & ${ }^{*}$-pawa & $\begin{array}{l}\text {-páwa-ki } \\
\text { braço/asa }\end{array}$ & -powo-ki (J) & -powo-ki & $\mathrm{po}(\mathrm{w}) \mathrm{v}$ asa & pôwo / pawa \\
\hline 31. ombro & $\begin{array}{l}{ }^{*} \text {-çi?u } \\
{ }^{*} \text {-tse (JC) } \\
\text {-tsekv (Ka) }\end{array}$ & -hi?v & -hi?u & eu, e-tsié galho & & \\
\hline 32. costas & $\begin{array}{l}\text { *tJepa } \\
\text { *-tepe-pa (JC) } \\
\text { omoplata, -ti- } \\
(\mathrm{Pi}),- \text {-sema-pa } \\
\text { (Ka) } \\
\end{array}$ & -t $\int$ epa & $-t \int e p o$ & $\begin{array}{l}\text {-t } \int \mathrm{ipi} / \text {-t } \int \text { opi (o), - } \\
\text { nopi (Pai) }\end{array}$ & & Jupu- \\
\hline 36. fezes & $\begin{array}{l}*_{*}^{*} \text {-itika } \\
*_{\text {-i?iSa (JC) }} \\
\text {-tika (Ap,Ka) } \\
\end{array}$ & -itfika-hi & -itfiko-hi & - fiko, -ti-se tripa & -tike-hi & isiko \\
\hline 41. urinar & $*^{*}$-ta & & & -tapa / topo /*-to & & tapú?o- / tô-wo \\
\hline 45. peito & $*$ tfaka & & & -tfakv-ki & & fâ?a \\
\hline 46. seio & $\begin{array}{l}* \text { *-tene } \\
*-2 \text { iini (JC) } \\
\text {-tini (Ap) } \\
\text {-tene (Ka) } \\
\end{array}$ & -t fene & $-t$ fene & $\begin{array}{l}- \text {-fona / -t fena / - } \\
\text { fene (J) }\end{array}$ & $-\mathrm{t} \int \mathrm{ene}$ & fene \\
\hline 53. carne & $\begin{array}{l}{ }^{*} \mathbf{C} \text {-içi } \\
*_{- \text {-i?i- (JC) }} \\
\text {-çiti (Purus) } \\
-\int i-n i(\text { Ka) }\end{array}$ & -etfe & -etfe & [n]-ef(e), e-n-if-on & -etfe-hĩ & ijé-u, hhîhhi \\
\hline 56. flor & $\begin{array}{l}{ }^{*} \text {-çiwu } \\
\text { *-irwi (JC) } \\
\text {-hiwi (Ap) }\end{array}$ & $\begin{array}{l}\text {-epu / -hipo / - } \\
\text { hiwo }\end{array}$ & $\begin{array}{l}\text {-Pu / *-hi?u / *- } \\
\text { epu / -hipu }\end{array}$ & & $\begin{array}{l}\text { (h)ipí-si / } \\
\text { hiwi }\end{array}$ & hîu \\
\hline 57. folha & $\begin{array}{l}{ }^{*} \text {-pa(ne) } \\
{ }^{*} \text {-pana (JC) } \\
\text {-pana (Ka) }\end{array}$ & -pa-ka & -po-ko & -pone / e-pono-i? & (etfi)-pone & \\
\hline $\begin{array}{l}59 . \quad \text { ferrão, } \\
\text { espinho }\end{array}$ & $\begin{array}{l}\text { *joi- } \\
*-\operatorname{lvi}(\text { JC) }\end{array}$ & ta-jora & ta-jura & & & i-juifa \\
\hline $\begin{array}{l}\text { 65. filho, } \\
\text { pequeno }\end{array}$ & $\begin{array}{l}*-\mathbf{t}(\mathbf{a}) \mathbf{i}-\quad / \\
{ }^{*} \mathbf{- t} \mathbf{e} \mathbf{e} \\
- \text { si dim. (In) }\end{array}$ & 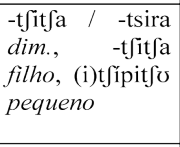 & $\begin{array}{l}\text {-t fitfa / -çira } \\
\text { dim., -t } \int \text { itfa filho, } \\
\mathrm{t} \int \mathrm{ipt} \int \mathrm{u} / * \text { atfipit } \int \mathrm{u} \\
\text { pequeno }\end{array}$ & 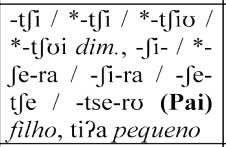 & $\begin{array}{l}\mathrm{t} \int \mathrm{i}-\mathrm{t} \int \mathrm{et} \int \mathrm{a} o v o, \\
\text {-t } \text { Sepi-ti } \\
\text { pequeno }\end{array}$ & $\begin{array}{l}\text { Je-?éfa filho/ovo, } \\
\text { Je-?a filho }\end{array}$ \\
\hline $\begin{array}{l}66 . \quad \text { novo } \\
\text { (pessoa) }\end{array}$ & $\begin{array}{l}\text { *ama } \\
\text { ama }(\mathrm{Pi}, \mathrm{Ap})\end{array}$ & $\begin{array}{l}\text { ama-pero } \\
\text { menino(a), } \\
\text { amo-ja bebe }\end{array}$ & $\begin{array}{l}\text { Pmó-peru } \\
\text { *amo-peru } \\
\text { menino, Pmo-jo / } \\
\text { *amo-ja bebê } \\
\end{array}$ & $\begin{array}{|lr|}\text { mon-t } \int \mathrm{i} & / \\
(\mathrm{J}) / \text { man- } \mathrm{t} \int \mathrm{i} \\
\text { omono } & \text { (Pai) } \\
\text { menino } & \\
\end{array}$ & & *ame-ne bebê \\
\hline 69. cauda & 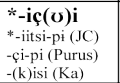 & (t)a-ihi-ki & $\begin{array}{l}\text { (t)a-ih?-çi / (ta)- } \\
\text { ehi-ki }(J, L)\end{array}$ & -eho-s / -ihu-se & t $\int i-k e-i s i$ & ihi \\
\hline 71. gordura & $\begin{array}{l}\dot{*}_{\text {*-vçi }} \\
*_{\text {-iitsi (JC) }}\end{array}$ & -ohe & (t-)uhe / -uhe-wo & eskiap & & 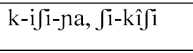 \\
\hline
\end{tabular}


LIAMES 19

\begin{tabular}{|c|c|c|c|c|c|c|}
\hline Português & * Bolívia & Ignaciano & \begin{tabular}{l}
\multicolumn{1}{c}{ Trinitario } \\
(*) Marbán (1701) \\
(L) Loretano \\
(J) Javeriano
\end{tabular} & \begin{tabular}{|l|}
\multicolumn{2}{|c|}{ Baure } \\
(*) Magio $(\sim 1740),(\mathbf{o})$ \\
Orbigny $(1832),(\mathbf{m u})$ \\
muchojeono (1832), \\
(Pai) paikone (1832), (J) \\
Joaquiniano \\
\end{tabular} & Pauna & \begin{tabular}{|l|}
\multicolumn{1}{|c|}{ Tereno } \\
(*) Aguirre $(1793)$ \\
(K) kinikinau \\
[F] Fonseca $(1875)$
\end{tabular} \\
\hline & 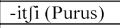 & & & & & \\
\hline 74. mulher & \begin{tabular}{|l|} 
*etsena \\
*iina (JC) \\
tsina-ne (Ka)
\end{tabular} & esena & $\begin{array}{l}\text { Pséno / esena (L) } \\
\text { / * eseno }\end{array}$ & \begin{tabular}{|l|} 
etona / eteno / \\
*eteno / etena (o, \\
mu), -a-iteno / \\
esenv (Pai)
\end{tabular} & \begin{tabular}{|l|}
$\begin{array}{l}\text { sev-nówe } \\
\text { eséno }\end{array}$
\end{tabular} & $\begin{array}{l}\text { seno / se.éna }[\mathrm{F}] / \\
\text { *saéna, têno } \\
\text { moça }\end{array}$ \\
\hline 76. marido & \begin{tabular}{|l|}
$*$-ima \\
*-imi- (JC) \\
-(h)ime (Ka) \\
\end{tabular} & -ima & -ima & & -ima & îma \\
\hline 78. avô & $\begin{array}{l}\text { *atjo } \\
\text {-atuki (Ap) } \\
\text {-t]a-ri (Ka) }\end{array}$ & atfo & otf?-ko / *atfu & $\begin{array}{l}-a \int v-k a /-a / i-k(o) / \\
-a \int i-k v(\mathbf{m u})\end{array}$ & $v t \int i-k v$ & ofu / otu! \\
\hline 80. tio & \begin{tabular}{|l|} 
"-eko-ka \\
*-aku-(IC) \\
-iku-ki (Pi,Ap) \\
-ko-ki (Ka) \\
\end{tabular} & -e-kuka & -(e)kuko & $\begin{array}{l}\text {-kik /*-kika / -kiku } \\
\text { (mu) }\end{array}$ & $-k i k v$ & eúko / ekú-seno \\
\hline 86. genro & $\dot{*}$-t]jina & $-\mathrm{t}$ /ina & $-\mathrm{t}$ /ina & - - Siná & & sina \\
\hline 98. pessoa & $\begin{array}{l}\text { *atfane } \\
\text { *atfani } \\
\text { *atjani-(JC) } \\
\text { asiani- (Ka) }\end{array}$ & atfane & $\begin{array}{l}\text { ?tfáne / atfane } \\
\text { (L) / *atfane }\end{array}$ & $\begin{array}{l}\text { tfene-ti / t tane-ti / } \\
\text { tfin-ti, ot fane (Pai) }\end{array}$ & otfane & fane \\
\hline 100. sol, dia & \begin{tabular}{|l} 
*ketfe \\
*Sariri (JC) \\
katfi (Ap) \\
katsi (Ka) \\
\end{tabular} & satfe & sát $\int e$ & sese, isese (Pai) & 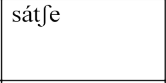 & kat $\int \mathrm{e}$ \\
\hline 101. céu, alto & \begin{tabular}{|l} 
*aano I \\
*wano \\
*eeno (JC) \\
teno (Purus) \\
heno- (Ka) \\
\end{tabular} & anú-ma & anu-mo & $\begin{array}{l}\text { ani / ane (mu), ani } \\
\text { (Pai) }\end{array}$ & $\begin{array}{l}\text { ani-mo / ani- } \\
\text { mu }\end{array}$ & $\begin{array}{l}\text { wanú-ke } \\
\text { *wanu-ke?e }\end{array}$ \\
\hline $\begin{array}{l}116 . \text { fogo, } \\
\text { pau }\end{array}$ & $\begin{array}{l}\text { *juku } \\
\text { *-luku- (IC) }\end{array}$ & joku & júku / uk- & $\begin{array}{l}\text { jaki / joki, t taki } \\
\text { (Pai) }\end{array}$ & jíki & joku / juku / uku \\
\hline 121. cinzas & $\begin{array}{l}\text { *pa?o } \\
\text { *pa?ari (JC) } \\
\text { pahi }(\mathrm{Pi})\end{array}$ & & & po?i-p(o) / pa?i-po & & po(P)ú \\
\hline 122. carvão & $\begin{array}{l}\text { "emani-ki } \\
\text { *-Simeni (IIC) } \\
\text {-me-ro (Pi) }\end{array}$ & emani-ki & emoni-ki & moni-si & -moni & moni-ke \\
\hline 125. casa & $\begin{array}{l}\text { "-pena } \\
\text { *-pana }(\mathrm{JC}) \\
\text {-pana }(\mathrm{Pi}) \\
\text {-panko }(\mathrm{Ka}) \\
\end{array}$ & -pena & -peno / -pena (L) & -penv & & -peno \\
\hline 136. fumaça & \begin{tabular}{|l|} 
*kiçare \\
*iitsa (JC) \\
katsiari (Ka) \\
\end{tabular} & kihare & çhore / *kihore & kitfare [Fonseca] & (k)ehr̃-e-pa & $\begin{array}{l}\text { kurího-e } \\
\text { ikurihea }\end{array}$ \\
\hline 138. caminho & \begin{tabular}{|l|} 
*atfe-ne \\
*hatini $(\mathrm{Pi})$ \\
\end{tabular} & 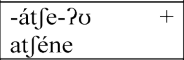 & Pt $\int e-n e$ & $\begin{array}{l}\text { fano-ki / fono-ki + } \\
\text {-ose-ne / *-otse-ne }\end{array}$ & $-\mathrm{t} \int$ ene-ki & 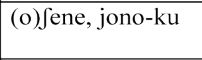 \\
\hline 140. noite & \begin{tabular}{|l|} 
*jati \\
*lai-pi (JC) \\
jati (In)
\end{tabular} & jati & jóti / *jati & $\begin{array}{l}\text { jotoe-r / jatio / } \\
* \text { jatoi / jete (o) } / \\
\text { jote }(\mathbf{m u})\end{array}$ & jóti & joti \\
\hline 145. arco & \begin{tabular}{|l|}
$*$ itsipa-ra \\
$*$ t/fipara $(J C)$ \\
t/fapu-ri $(\Lambda p)$ \\
\end{tabular} & itsiparako & tspóoku & tipo-pok & & \\
\hline 159. sal & $\begin{array}{l}\text { *itfewe } \\
\text { *iiwi (JC), }_{\text {tiwi (Pi) }} \\
\text { tiwi } \\
\text { tiwi (ka) } \\
\end{array}$ & itfewe & t féwe $/ *$ itfewe & $\begin{array}{l}\text { (v)t } \int \delta \beta \mathrm{e} ? / \mathrm{t} \rho \mathrm{e} \beta \mathrm{e}, \\
\text { isia (Pai) }\end{array}$ & & \\
\hline 176. comprido & *peru & & & pero- & & pe?u \\
\hline 188. vermelho & $\begin{array}{l}\text { "-keru } \\
\text { *kiiTa }(\mathrm{JC}) \\
\text { serv }(\mathrm{Pi}) \\
\text { kira }(\mathrm{Ka}) \\
\end{array}$ & & & mo-serv & & \\
\hline 192. azedo & $\begin{array}{l}* \text { kat(s)i } \\
\text { katsio (Purus) } \\
\text { katfo (Pi, Ka) } \\
\end{array}$ & katsi & $\begin{array}{l}\text {-kotsi / -katsi (L) } \\
\text { /*-katsi }\end{array}$ & & & koti-we-ti \\
\hline 195. doer & $\begin{array}{l}\text { "-kati } \\
\text { ka?iwi (JC) } \\
\text { katsi (Ap.Ka) } \\
\end{array}$ & -ka-ti & ko-ti-, *-ka-ti & $\begin{array}{l}\text {-kv-ti[- } \beta \mathrm{e}] /{ }^{*}-\mathrm{ka}- \\
\mathrm{ti}-\beta \mathrm{e}\end{array}$ & -koti & koti-we-ti \\
\hline $\begin{array}{l}200 . \text { velho } \\
\text { (usado) }\end{array}$ & \begin{tabular}{|l} 
"-itfa(i) \\
"tsari (JC) \\
\end{tabular} & itfa-si & ?tfo-si / *etfa-si & $\begin{array}{l}\mathrm{t} \int \mathrm{in} /{ }^{*} \mathrm{e}-\mathrm{t} \text { (Jaina, e- } \\
\mathrm{t} \int \mathrm{v} / \mathrm{e}-\mathrm{t} \int \mathrm{ia} \text { (Pai) } \\
\end{array}$ & $-\mathrm{t} \int 0-w o i$ & (*jeka-ti, kufo-ti) \\
\hline 202. bêbado & \begin{tabular}{|l|} 
*-kawa?a \\
*kama- $(J C)$ \\
\end{tabular} & -kawa?a & -kowo?o & kawia-ri & kowio & (kohíhi) \\
\hline 203. comer & \begin{tabular}{|l|} 
"-ni-ka \\
-iinSa (JC) \\
-nika (Purus) \\
\end{tabular} & -ni-ka & \begin{tabular}{|lll}
-ni-ko $/$ ni-kja \\
(L)
\end{tabular} & -ni-ku & $\begin{array}{l}\text {-ní-ka / -ni- } \\
\text { ko }\end{array}$ & ni-ko \\
\hline
\end{tabular}


RAMIREZ \& FRANCCA - LÍNGUAS ARAWAK DA BOLÍVIA

\begin{tabular}{|c|c|c|c|c|c|c|}
\hline Português & * Bolívia & Ignaciano & \begin{tabular}{l}
\multicolumn{1}{c}{ Trinitario } \\
$(*)$ Marbán $(1701)$ \\
(L) Loretano \\
(J) Javeriano
\end{tabular} & $\begin{array}{l}\text { Baure } \\
\left({ }^{*}\right) \text { Magio }(\sim 1740),(\mathbf{o}) \\
\text { Orbigny }(1832),(\mathbf{m u}) \\
\text { muchojeono (1832), } \\
\text { (Pai) paikone (1832), (J) } \\
\text { Joaquiniano } \\
\end{array}$ & Pauna & \begin{tabular}{l}
\multicolumn{1}{c}{ Tereno } \\
(*) Aguirre $(1793)$ \\
(K) kinikinau \\
{$[\mathrm{F}]$ Fonseca $(1875)$}
\end{tabular} \\
\hline & -nika (Ka) & & & & & \\
\hline 209. ouvir & $\begin{array}{l}\text { "-kema } \\
\text {-Sema (JC) } \\
-\operatorname{kema}(\mathrm{Ap}, \mathrm{Ka})\end{array}$ & -sama & -samo / -sama & -sum(o) / -samo & -sámo & kamo \\
\hline 210. saber & $\begin{array}{l}\text { *etfa } \\
\text {-ita (Pi,Ap) }\end{array}$ & -etfa & -etfa / -etfo & $-(\mathrm{e}) \mathrm{t} \int \mathrm{v}$ & -itfú-pa & efo- \\
\hline 212. dormir & $\begin{array}{l}\text { "-ima-ka } \\
\text {-imaa (JC) } \\
\text {-imaka (Purus) } \\
\text {-mak (Ka) }\end{array}$ & -íma-ka & -imo-ko / -ím-ka & -imo-ko / *-ima-ka & -ímo-ka & imó-ko \\
\hline 213. sonho & 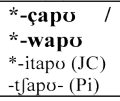 & -wapv / -tfap & -wopu / -tfopu & -hapi & & hhopú-fo \\
\hline 216. bater & 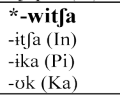 & & & -wet $\int(\delta) / *$-witfa & & -isú-ko \\
\hline 217. ir & $\begin{array}{l}\text { *jana } \\
\text {-jana }(\mathrm{Pi}, \mathrm{Ap}) \\
\text {-anai }(\mathrm{Ka})\end{array}$ & -jana & -jono / -jana & $\begin{array}{l}\text {-juno / *-jana, - } \\
\text { t funo (Pai) }\end{array}$ & -jona & jôno \\
\hline 223. chegar & $*_{-}^{*}$ (i)sima & & & -(i) Jima & & sîmo \\
\hline 233. lavar & $\begin{array}{l}\text { *-kipa } \\
\text { *-Sipa (JC) } \\
\text {-kipa (Ap) } \\
\text {-kip (Ka) }\end{array}$ & -sipa- & $\begin{array}{l}\text {-sip-hui / -sip-ri / } \\
\text { *-sipo- }\end{array}$ & -sipa & -kipo & kipo-?i / kipe- \\
\hline 242. voar & $\begin{array}{l}\text { *-ara } \\
\text { *-aaTa (JC) } \\
\text {-ara (Pi) } \\
- \text {-ar (Ka) } \\
\end{array}$ & -ara & -oro / -ara (L) & -aro /*-ara & & ôo- / -aa \\
\hline 249. de pé & $\begin{array}{l}\text { *-(i)t fema } \\
\text { *-?eema } \\
(\mathrm{JC}) \\
\text {-tima (Ap) }\end{array}$ & & & $\begin{array}{l}\text {-ifemv / -ifomo, - } \\
\text { itsumv (Pai) }\end{array}$ & $-\mathrm{t}$ fema & \\
\hline 258. cavar & $\begin{array}{l}\text { "-ke(ho)ka } \\
{ }^{*} \text {-Sika (JC) } \\
\text {-kito (Purus) } \\
\text {-kika / - } \\
\text { hoka (Ka) } \\
\end{array}$ & -seka & -seko & *-sehokiu & -seku & kehoko \\
\hline 263. correr & $\begin{array}{l}\text { *eha-ka } \\
{ }^{*} \text {-Se?ko (JC) } \\
\text {-asika (Pi) } \\
\text {-isika (Ka) } \\
\end{array}$ & & & & & $\begin{array}{l}\text { ehakowo } \\
\text { ahakowo }\end{array}$ \\
\hline 264. cortar & $\begin{array}{l}\text { *-(a)itfo-ka }^{*} \\
\text { *-wijua (JC) }\end{array}$ & \begin{tabular}{|l|}
-e-tfo-ka / -e- \\
tfati
\end{tabular} & $\begin{array}{l}\text {-e-tf-ka / -e-t fi-ka } \\
\text { (L) /*-t feti-ko }\end{array}$ & $\begin{array}{l}\text {-afu-k / *-afi / *- } \\
\text { efi-ku }\end{array}$ & & ifu?o-ko \\
\hline 268. curar & $\begin{array}{l}{ }^{*} \text {-ipu(i)-tfa } \\
\text {-pini (Ap,Ka) }\end{array}$ & $-i p v-t \int a$ & 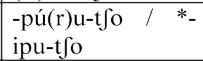 & & & ipi-fa \\
\hline 298. rir & $\begin{array}{l}\text { *-eka- } \\
\text { *-i?ika (JC) } \\
\text {-i?otja (In) } \\
\text {-ika- (Ka) }\end{array}$ & -ekáwa & -ekowo & $\begin{array}{l}\text {-ko-ka / -ka-ka / *- } \\
\text { eko, -hahak }\end{array}$ & $-k v$ & ekowo, ekasa \\
\hline 305. eu & 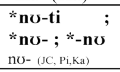 & nóti ; no- ; -no & núti ; nu- ; -nu & nti / *niti ; ni- ; -ni & núti ; ni- ; -nu & ûnti ; N- ; -nu \\
\hline 310. vós & $\begin{array}{l}*(\mathrm{j}) \mathrm{i}-\mathrm{ti} \\
*(\mathrm{j}) \mathrm{i}-;{ }^{*} ; \\
* \mathrm{i}-(\mathrm{JC}) \\
\mathrm{xi}-(\mathrm{Pi}) \\
\end{array}$ & éti ; e- ; -Pe & éti ; e- ; -Pe & $\begin{array}{l}\text { jiti / *jeti ; ji- / *je- } \\
;- \text { ji / *-e }\end{array}$ & eti ; e- ; -e & îti ; i- \\
\hline 334. tema & ${ }^{*}-\mathbf{k a}$ & $-\mathrm{ka}$ & -ko & $-k v$ & $-k o$ & -ko \\
\hline 337. positivo & $\begin{array}{l}* \text { ka- } \\
\text { ka- } \quad(\mathrm{JC}, \mathrm{Pi}, \mathrm{Ap}, \\
\mathrm{Ka})\end{array}$ & ka- & ko- / *ka- & $\mathrm{ko-} / * \mathrm{ka}-$ & ko- & ko- / ka- \\
\hline 344. reflexivo & 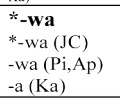 & -wa & -wo & -po /*-wo & -wo & -wo / -pu \\
\hline 360. dois & $\begin{array}{l}\text { *api- } \\
\text { hepi (Pi) } \\
\text { api- (Ka) }\end{array}$ & ápi- & ápi- & (m)api- & & pi?a, api?i-fo \\
\hline 369. capivara & ${ }^{*} v t \int u$ & ot $\int u$ & út $\int u$ & $\sigma \sqrt{1}$ & $\mathrm{it} / \mathrm{i}$ & \\
\hline 370. paca & $\begin{array}{l}\text { *japa } \\
\text { *laapa (JC) }\end{array}$ & japa & jópo & & jópo & \\
\hline 371. cutia & $\begin{array}{l}\text { *pe2i-ri } \\
\text { *piSit } \int \mathrm{i}(\mathrm{JC}) \\
\text { pekiri (Purus) }\end{array}$ & pe?i & pé?i & peri / piri $(\mathbf{o}, \mathbf{m u})$ & péi & \\
\hline
\end{tabular}


LIAMES 19

\begin{tabular}{|c|c|c|c|c|c|c|}
\hline Português & * Bolívia & Ignaciano & \begin{tabular}{l}
\multicolumn{1}{c}{ Trinitario } \\
(*) Marbán (1701) \\
(L) Loretano \\
(J) Javeriano
\end{tabular} & \begin{tabular}{|l|}
\multicolumn{2}{|c|}{ Baure } \\
(*) Magio $(\sim 1740),(\mathbf{o})$ \\
Orbigny $(1832),(\mathbf{m u})$ \\
muchojeono $(1832)$, \\
(Pai) paikone $(1832),(\mathbf{J})$ \\
Joaquiniano \\
\end{tabular} & Pauna & \begin{tabular}{|l}
\multicolumn{1}{c}{ Tereno } \\
(*) Aguirre $(1793)$ \\
(K) kinikinau \\
[F] Fonseca $(1875)$
\end{tabular} \\
\hline 377. anta & \begin{tabular}{|l|} 
*kema \\
*Sema (JC) \\
kema (Purus) \\
kemarri (Kai)
\end{tabular} & sama & sámo & somv, somv (Pai) & sámu & kámo \\
\hline 378. porco & *kimaro & simáro & smóo / s(i)móru & simuri & & kimõũ \\
\hline 385. quati & \begin{tabular}{|l} 
*kapeçi \\
*kapitsi (JC) \\
kapifi (Purus) \\
kapesi (Ka)
\end{tabular} & kapéhi & kpéhi & & kopéhĩ & \\
\hline 388. onça & $\begin{array}{l}\text { *itfini } \\
*_{t} \text { t jino (JC) }\end{array}$ & itfini & Pt fíni & (i)tfini & isíni & síni \\
\hline 392. raposa & *tfoje & t foje & tfúje & fije?, t fi?e (Pai) & & jowi-ré lobo \\
\hline $\begin{array}{l}\text { 397. caiarara } \\
\text { (macaco) }\end{array}$ & *ijo & ija & íjo & $\begin{array}{l}\text { (o)jore / ijore, itfo- } \\
\text { re (Pai) }\end{array}$ & íjo & \\
\hline 398. morcego & \begin{tabular}{|l|} 
*wite-re \\
*piitsi-ri (JC) \\
pihiri (Ka) \\
\end{tabular} & wite & wíte & $\beta$ ite-re & wite & wite-te \\
\hline 427. papagaio & $\begin{array}{l}\text { *waro } \\
\text { *waaTo (IC) } \\
\text { wawaTo (Purus) } \\
\text { eroti (Ka) } \\
\end{array}$ & waro & wóru & Boro & & \\
\hline $\begin{array}{ll}436 . & \text { beija- } \\
\text { flor } & \\
\end{array}$ & "pitse & pitse & pítse & pita/pite & $\begin{array}{l}\text { píse, } \\
\text { sepitikirí(rì) }\end{array}$ & 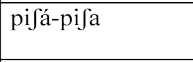 \\
\hline 445. jacaré & \begin{tabular}{|l|l|} 
*kaçiore \\
*kajuSiri (JC) \\
kafi(j)okirit \\
(Purus)
\end{tabular} & kahiơre & $\begin{array}{l}\text { ç(h)iúre } \\
\text { *kahiure }\end{array}$ & $\begin{array}{l}\text { kahiri / *kahire, } \\
\text { kwhira (Pai) }\end{array}$ & kohĩ(w)ie & \\
\hline 446. quelônio & $\begin{array}{l}\text { *kipu-re } \\
\text { *Sipu-ri (JC) } \\
\text { sipi-ri (Ap) } \\
\text { sempiri } \\
\text { (Ka) }\end{array}$ & sipv & sípu & $\begin{array}{l}\text { supi-ri / sipu-re, } \\
\text { sipi-ra (Pai) }\end{array}$ & kípi & \\
\hline 447. sapo & $\begin{array}{l}\text { *kipa-ru } \\
\text { *Siipa-Tu } \\
\text { (JC) }\end{array}$ & & & sipú-ri & & \\
\hline 448. peixe & $\begin{array}{l}\text { *çima } \\
\text { çima (Purus) } \\
\text { sima (Ka) }\end{array}$ & híma & hímo / hima (L) & himo / hima (o) & hímo & \\
\hline 458. piranha & $\begin{array}{l}\text { *oroma } \\
\text { *omai (JC) } \\
\text { homa (Purus) } \\
\text { homa (Ka) }\end{array}$ & oroma & Prúmo / *urumo & (o)rima / orimo & ímo & uruma / arumo \\
\hline $\begin{array}{l}\text { 460. muçum } \\
\text { (eel) }\end{array}$ & $\begin{array}{l}\text { *iti-re } \\
\text { *iit } \text { it } f \text { (JC) } \\
\text { hitsirí (Jurus) } \\
\text { tsiri (Ka) } \\
\end{array}$ & itire & tíre-pi / *itire & (i)ti(re), vtira (Pai) & itíe & tie \\
\hline $\begin{array}{l}\text { 463. formiga- } \\
\text { de-fogo }\end{array}$ & \begin{tabular}{|l} 
*katfi-ro / \\
*ket]i-ri \\
*keetfi (JC) \\
katsi- (Purus) \\
katsi- (Ka) \\
\end{tabular} & katji-ro & 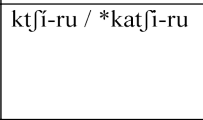 & kofi-ri / ke $\int i-r i(o)$ & $\begin{array}{l}\text { kosí-i / kusi- } \\
\text { u }\end{array}$ & kosi-u \\
\hline 465. vespa & \begin{tabular}{|l} 
"ça(?)ne \\
*haini (JC) \\
çani (Ap) \\
sani (Ka)
\end{tabular} & hane & háne & $\begin{array}{l}\text { hane / ha?ane / } \\
\text { dane (mu) }\end{array}$ & háne & $\begin{array}{l}\text { hháne, howo- } \\
\text { Powo }\end{array}$ \\
\hline 466. abelha & \begin{tabular}{|l|} 
* mapa \\
* maapa \\
$(\mathrm{JC})$ \\
mapa (Purus)
\end{tabular} & mapa & mópo & & & mapa / mopo mel \\
\hline 468. larva & \begin{tabular}{|l} 
*kane \\
*-iSeni (JC) \\
-kini \\
(Purus) \\
-keni (Ka) \\
\end{tabular} & kane & kane & kane & kane & kane \\
\hline 469. mosquito & $\begin{array}{l}* \text { *ani?(w)o } \\
\text { *ainiijo (JC) } \\
\text { hanijo (Pi) }\end{array}$ & aní?o & ?jní?u / aji?u & \begin{tabular}{|l|} 
(a)ni? / ani?o-re \\
(mu), oni (Pai)
\end{tabular} & aníwi & niũ \\
\hline 474. grilo & $\begin{array}{l}\text { *witfi } \\
\text { *pirito (JC) } \\
\text { pitfi (Pi) } \\
\text { pitiro (Ka) }\end{array}$ & witfi & witfi & witfi & wisi & wísi \\
\hline 476. pulga & $\begin{array}{l}\text { *kaito-re } \\
\text { *iitsito (JC) } \\
\text { kotopa (Ap) }\end{array}$ & sito-re & stú-re & $\begin{array}{l}\text { ito-ri (Pai) [cf. chiquito } \\
\text { ituri-s] }\end{array}$ & kiti-e / keti-e & \\
\hline $\begin{array}{l}485 . \quad \text { cipó, } \\
\text { liana }\end{array}$ & $\begin{array}{l}\text { "çepi-pi I } \\
\text { "çopi- }\end{array}$ & épire / -pi & épre / -pi & & hopí-pi & hhepí-pi \\
\hline
\end{tabular}


RAMIREZ \& FRANCCA - LÍNGUAS ARAWAK DA BOLÍVIA

\begin{tabular}{|c|c|c|c|c|c|c|}
\hline Português & * Bolívia & Ignaciano & $\begin{array}{l}\text { Trinitario } \\
\left({ }^{*}\right) \text { Marbán }(1701) \\
\text { (L) Loretano } \\
\text { (J) Javeriano }\end{array}$ & \begin{tabular}{|l|}
\multicolumn{1}{|c|}{ Baure } \\
(*) Magio $(\sim 1740),(\mathbf{o})$ \\
Orbigny $(1832),(\mathbf{m u})$ \\
muchojeono (1832), \\
(Pai) paikone (1832), (J) \\
Joaquiniano \\
\end{tabular} & Pauna & \begin{tabular}{l}
\multicolumn{1}{c}{ Tereno } \\
$\left({ }^{*}\right)$ Aguirre $(1793)$ \\
(K) kinikinau \\
[F] Fonseca (1875)
\end{tabular} \\
\hline & $\begin{array}{l}\text { *haipe-pi (JC) } \\
\text { fipi- (A) } \\
\text { sipi- (Ka) }\end{array}$ & & & & & \\
\hline $\begin{array}{l}\text { 497. batata- } \\
\text { doce }\end{array}$ & $\begin{array}{l}\text { *ka?e-re } \\
\text { *kari-ri (JC) } \\
\text { kuri-ti (Ka) }\end{array}$ & kae-re & káe-re / *koe-re & se-re(?) & koé-pi(a) & ko?ê-e \\
\hline 516. ambaúba & $\begin{array}{l}\text { *joko-ra } \\
\text { *looko- (JC) } \\
\text { joko-ri } \\
\text { (Purus) } \\
\text { onku-ri } \\
\text { (Ka) }\end{array}$ & & & \begin{tabular}{|l|} 
jikira-s \\
\end{tabular} & & \\
\hline $\begin{array}{l}\text { 518. amen- } \\
\text { doim (peanut) }\end{array}$ & "koriki & korike-re & $\begin{array}{l}\text { kríç-re / kriçie-re } \\
\text { (L) / *kurikie-re }\end{array}$ & \begin{tabular}{|l} 
kiriki-ri \\
\end{tabular} & kíike & kurîke \\
\hline 519. jenipapo & \begin{tabular}{|l|l|} 
*jana \\
*laana (JC) \\
ana (Ka) \\
\end{tabular} & jana & jóno & jana / jono & jóno & \\
\hline 521. pimenta & $\begin{array}{l}\text { *atfi-ti } \\
\text { *a?atsi (JC) } \\
\text { tsiti- (Ka) }\end{array}$ & itfeti & 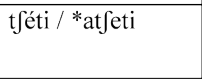 & $\begin{array}{l}\text { (i)jiti / ijeti / jati } \\
\text { (J), eheti (pai) }\end{array}$ & vtféti & têti + étetea \\
\hline
\end{tabular}

\section{Referências}

Adam. Lucien; Leclerc, Charles (1880). Arte de la lengua de los Indios Baures de la Provincia de los Moxos conforme al manuscrito original del P. Antonio Magio (1749). Bibliothèque Linguistique Américaine, vol, 7. Paris: Editores Maisonneuve \& $\mathrm{C}^{\text {ia }}$.

Aguirre, Juan Francisco (1898). Etnografía del Chaco (1793). Boletín del Instituto Geográfico Argentino 19: 464-510.

Aikhenvald, Alexandra Y. (1999). The Arawak language family. In R.M.W. Dixon \& Alexandra Y. Aikhenvald (eds.). The Amazonian languages, pp. 65-106, Cambridge: Cambridge University Press.

Altamirano, Diego Francisco (1979). Historia de la Misión de los Mojos ( 1712). La Paz: Instituto Boliviano de Cultura.

Baptista, Priscilla M.; Wallin, Ruth (1968). Baure vowel elision. Linguistics 38: 5-11.

Barnadas, Josep M.; Plaza, Manuel (2005). Mojos: seis relaciones jesuíticas (1670-1763). Cochabamba: Historia Boliviana.

Becerra Casanovas, Rogers (1980). De ayer e de hoy. Diccionario del idioma moxeño a través del tiempo. Estudio comparativo sobre su evolución. La Paz: Proinsa Empresa Editora.

Boggiani, Guido (1895). Vocabolario dell'idioma Guaná. Memorie de la Classe di Scienze Morali, Storiche e Filologische 3: 59-80.

Butler, Nancy E. (1978). Modo, extensão temporal, tempo verbal e relevância contrastiva na língua terêna. Ensaios Linguísticos 1. Brasília: Summer Institute of Linguistics.

Butler, Nancy E. (2003). The multiple functions of the definite article in Terena. Summer Institute of Linguistics (Ms.16 páginas). 
Campbell, Lyle (1997). American Indian Languages. The Historical Linguistics of Native America. Oxford: Oxford University Press.

Carvalho, Fernando O. de (2016). Terena, Chané, Guaná and Kinikinau are one and the same language: Setting the record straight on southern arawak diversity. LIAMES-Linguas Indigenas Americanas 16(1): 39-57. doi: https://doi.org/10.20396/liames.v16i1.8646165

Carvalho, Fernando O. de (2018a). The historical phonology of Paunaka (Arawakan). Boletim do Museu Paraense Emilio Goeldi, Ciências Humanas 13(2): 405-428.

Carvalho, Fernando O. de (2018b). Arawakan-Guaicuruan language contact in the South America Chaco. International Journal of American Linguistics 84(2): 243-263.

Carvalho, Fernando O. de; Rose, Françoise (2018). Comparative reconstruction of proto-mojeño and the phonological diversification of mojeño dialects. LIAMES-Linguas Indigenas Americanas 18(1): 7-48. doi: https://doi.org/10.20396/liames.v1i1.8648804

Castelnau, Francis de (1851). Expédition dans les parties centrales de l'Amérique du Sud. Paris: Chez P. Bertrand.

Chávez Suárez, José (1986). Historia de Moxos. La Paz: Editorial Don Bosco.

Combès, Isabelle (2010). Diccionario étnico. Santa Cruz la Vieja y su entorno en el siglo XVI. Cochabamba: Instituto de Misionología.

Créqui-Montfort, Georges de; Rivet, Paul (1913). La langue Lapaču ou Apolista. Zeitschrift für Ethnologie 45: $512-531$.

Danielsen, Swintha (2007). Baure: an Arawak language of Bolivia. Indigenous Languages of Latin America (ILLA), vol. 6. Leiden: Publicações do CNWS.

Danielsen, Swintha (2011). The personal paradigms in Baure and other Southern Arawakan languages. International Journal of American Linguistics 77(4): 495-520.

Eguiluz, Diego de (1696). Relación de la Misión Apostólica de los Mojos en esta Provincia del Perú que remite a N.M.R.P Thyrso Conzález, año de 1696. Lima.

Ekdahl, Elizabeth Muriel; Butler, Nancy E. (1969). Terêna dictionary. Arquivo Linguístico 095. Brasilia: Summer Institute of Linguistics.

Ekdahl, Elizabeth Muriel; Butler, Nancy E. (1979). Aprenda Terêna (volume 1). Brasília: Summer Institute of Linguistics.

Fonseca, João Severiano (1986). Viagem ao redor do Brasil (1875-1878). 2 volumes. Rio de Janeiro: Biblioteca do Exército Editora.

Gill, Wayne (1957). Trinitario grammar. San Lorenzo de Mojos: Misión Nuevas Tribus.

Gill, Wayne (1993). Diccionario trinitario-castellano. San Lorenzo de Mojos: Misión Nuevas Tribus.

Hervás y Panduro, Lorenzo (1800). Catálogo de las lenguas de las naciones conocidas. Volume 1. Madrid. 
Jolkesky, Marcelo (2016). Uma reconstrução do proto-mamoré-guaporé (família arawák). LIAMES-Linguas Indigenas Americanas 16(1): 7-37. doi: https://doi.org/10.20396/liames.v16i1.8646164

Loukotka, Čestmir (1935). Clasificación de las lenguas sudamericanas. Praga: Tipografía Josef Bartl.

Loukotka, Čestmir (1949). Sur quelques langues inconnues de l’Amérique du Sud. Lingua Posnaniensis 1: 5382. Poznan.

Marbán, P. Pedro (1701). Arte de la lengua Moxa con su vocabulario y cathecismo. Lima: Imprenta Real de Joseph de Contreras.

Marbán, P. Pedro (1898). Relación de la provincia de la Virgen del Pilar de Mojos. Boletín de la Sociedad Geográfica de La Paz 1(1): 120-137. La Paz.

Martins, Cosme Romero (2009). Fonologia da língua terena (Dissertação de Mestrado). São Paulo: Universidade de São Paulo.

Mason, J. Alden (1950). The languages of South American Indians. In Julian Steward (ed.). Handbook of South American Indians, vol. 6, pp. 159-317. Washington: Bureau of American Ethnology.

Matienzo, Javier; Tomichá, Roberto; Combès, Isabelle; Page, Carlos (2011). Chiquitos en las anuas de la Compañia de Jesús (1691-1767). Cochabamba: Instituto de Misionología.

Matteson, Esther (1972). Proto Arawakan. In Esther Matteson; Alva Wheeler; Frances L. Jackson; Nathan E. Waltz \& Diana R. Christian (eds.). Comparative studies in Amerindian languages, pp. 160-242. The Hague: Mouton.

Meillet, Antoine; Cohen, Marcel (1924). Les langues du monde par un groupe de linguistes. Paris: Librairie Ancienne Édouard Champion.

Métraux, Alfred (1942). The native tribes of Eastern Bolivia and Western Matto Grosso. Bulletin 134. Washington: Smithsonian Institution, Bureau of American Ethnology.

Métraux, Alfred (1946). Ethnography of the Chaco. In Julian Steward (ed.). Handbook of South American Indians, vol.1, pp. 197-370. Washington: Bureau of American Ethnology.

Métraux, Alfred (1948a). Tribes of eastern Bolivia and the Madeira Headwaters. In Julian Steward (ed.). Handbook of South American Indians, vol. 3, pp. 381-454. Washington: Bureau of American Ethnology.

Métraux, Alfred (1948b). Tribes of the eastern slopes of the Bolivian Andes. In Julian Steward (ed.). Handbook of South American Indians, vol. 3, pp. 465-506. Washington: Bureau of American Ethnology.

Montaño Aragón, Mario (1987). Guía etnográfica lingüistica de Bolivia (Tribus de la Selva), volume 1. La Paz: Editorial Don Bosco.

Nascimento, Gardenia Barbosa Neubaner (2012). Aspectos gramaticais da língua Terena (Dissertação de Mestrado). Belo Horizonte: Universidade Federal de Minas Gerais (UFMG).

Natterer, Johann (s.d.). Wortlisten von Indianersprachen in Brasilien (1817-1835). Basileia: Basel University Library. (manuscrito)

Noble, G. Kingsley (1965). Proto-Arawakan and its descendants. Bloomington: Indiana University Press.

Nordenskiöld, Erland (2002). La vida de los indios. La Paz: АРCOB. 
Olza Zubiri, Jesús; Nuni de Chapi, Conchita; Tube, Juan (2004). Gramática moja ignaciana (morfosintaxis). Cochabamba: Universidad Católica Boliviana.

Orbigny, Alcide D’ (1831). Vocabulario de la lengua Paiconeca (manuscrito nos arquivos do Professor Paul Rivet, Paris).

Orbigny, Alcide D’ (1832). Pequeño vocabulario de la lengua Muchojeone (manuscrito nos arquivos do Professor Paul Rivet, Paris).

Orbigny, Alcide D’ (1944). El hombre americano. Buenos Aires: Editorial Futuro.

Orbigny, Alcide D’ (2002). Viaje a la América Meridional (1826-1833), 4 volumes. La Paz: Instituto Francés de Estudios Andinos, Plural editores.

Ott, Willis; Ott, Rebecca Burke de (1983). Diccionario ignaciano y castellano com apuntes gramaticales. Cochabamba: Instituto Lingüístico de Verano.

Palau, Mercedes; Sáiz, Blanca (1989). Moxos. Descripciones exactas e historia fiel de los indios, animales y plantas de la provincia de Moxos en el virreinato del Perú por Lázaro de Ribera, 1786-1794. Madrid: Ediciones El Viso.

Payne, David L. (1991). A classification of Maipuran (Arawakan) languages based on shared lexical retentions. In Desmond C. Derbyshire \& Geoffrey K. Pullum (eds.). Handbook of Amazonian Languages, vol. 3, pp. 355-499. Berlin: Mouton de Gruyter.

Payne, David L. (2005). Apolista (Lapachu) as a Maipuran Arawakan language. Revista Latinoamericana de Estudios Etnolingüísticos 10: 239-250.

Perea y Alonso, Sixto (1937). Apuntes para la prehistoria indígena del Río de la Plata y especialmente de la banda oriental de Uruguay, como introducción a la filología comparada de las lenguas y dialectos Arawak. Boletín de Filología 1: 217-245.

Ramirez, Henri (2010). Etnônimos e topônimos no Madeira (séculos XVI-XX): um sem-número de equívocos. Revista Brasileira de Linguística Antropológica 2(2): 179-224).

Ramirez, Henri (2019). Enciclopédia das linguas arawak - acrescida de seis novas línguas e dois bancos de dados. http://www.etnolinguistica.org/arawak. (disponível em breve)

Silva, Denise (2013). Estudo lexicográfico da língua terena (Tese de Doutorado). Araraquara: UNESP.

Souza, Ilda de (2008). Koenukuno'e Emo'u: a língua dos índios kinikinau (Tese de Doutorado). Campinas: UNICAMP.

Tormo, Leandro (1972). Situación y población de los Mojos em 1679. Revista Española de Antropología Americana 7(2): 151-159.

Zuse, Silvana (2016). Variabilidade cerâmica e diversidade cultural no Alto rio Madeira. In Cristiana Barreto, Helena Pinto Lima \& Carla Jaimes Betancourt (eds.). Cerâmicas arqueológicas na Amazônia, pp. 385401. Belém: MPEG, IPHAN.

Recebido: 23/3//2019

Versão revista: $27 / 7 / 2019$

Aceito: 19/8/2019.

LIAMES, Campinas, SP, v. 19, 1-71, e019012, 2019 